\author{
UNIVERSIDADE DE SÃO PAULO \\ ESCOLA POLITÉCNICA DA UNIVERSIDADE DE SÃO PAULO
}

CESAR ROBERTO DE SOUZA

Sistema de túnel de vento aplicado no monitoramento de pressão dinâmica

São Paulo

2020 
CESAR ROBERTO DE SOUZA

Sistema de túnel de vento aplicado no monitoramento de pressão dinâmica

Dissertação apresentada à Escola Politécnica da Universidade de São Paulo para obtenção do título de Mestre em Ciências.

São Paulo

2020 
CESAR ROBERTO DE SOUZA

\section{Sistema de túnel de vento aplicado no monitoramento de pressão dinâmica}

\section{Versão Corrigida}

(Versão original encontra-se na unidade que aloja o Programa de Pós-graduação)

Dissertação apresentada à Escola Politécnica da Universidade de São Paulo para obtenção do título de Mestre em Ciências.

Área de concentração: Microeletrônica

Orientador: Prof. Dr. Walter James Salcedo

São Paulo

2020 
Autorizo a reprodução e divulgação total ou parcial deste trabalho, por qualquer meio convencional ou eletrônico, para fins de estudo e pesquisa, desde que citada a fonte.

Este exemplar foi revisado e corrigido em relação à versão original, sob responsabilidade única do autor e com a anuência de seu orientador.

São Paulo, de de

Assinatura do autor:

Assinatura do orientador:

\section{Catalogação-na-publicação}

Souza, Cesar Roberto de

Sistema de túnel de vento aplicado no monitoramento de pressão dinâmica / C. R. Souza -- versão corr. -- São Paulo, 2020.

$131 \mathrm{p.}$

Dissertação (Mestrado) - Escola Politécnica da Universidade de São Paulo. Departamento de Engenharia de Sistemas Eletrônicos.

1.Túneis de vento 2.Instrumentação e medidas elétricas 3.Instrumentação de sistemas 4.Aerodinâmica (modelagem) 5.Constrole de Sistemas I.Universidade de São Paulo. Escola Politécnica. Departamento de Engenharia de Sistemas Eletrônicos II.t. 


\section{DEDICATÓRIA}

Dedico este trabalho ao meu pai Ademir de Souza (in memorian), minha mãe Maria José, minha avó Maria (in memorian), meu irmão Clayton, meu tio Toninho e à minha adorável esposa Fabiana. 


\section{AGRADECIMENTOS}

Agradeço primeiramente a Deus pela força que me concedeu no decorrer do presente trabalho.

À minha mãe Maria José pela paciência, pois, toda montagem do túnel foi feita em sua garagem e os testes altamente ruidosos foram efetuados durante as madrugadas, atrapalhando seu sono.

Ao meu irmão Clayton pelo incentivo e ajuda no fomento de equipamentos, além do auxilio financeiro ao longo do desenvolvimento o presente projeto.

À minha esposa Fabiana pela compreensão e paciência de tantas noites, domingos e feriados passados fora de casa, ao longo destes anos de trabalho.

Ao meu Orientador professor Walter pela dedicação e motivação para o desenvolvimento deste trabalho.

Ao meu grande amigo Mauro pela motivação, constante ajuda e parceria ao longo de todo o projeto.

Ao meu amigo Moacir pela ajuda nos cálculos e dimensionamento do túnel.

Aos meus queridos alunos Baldasso, Maurício e Guilherme Moisés pelos auxilios e motivação no decorrer deste trabalho

Aos meus amigos Tiago Pucca e Ivan Santos da Emerson que tanto ajudaram com a instrumentação de medição do Túnel de Vento.

À supervisora da biblioteca da Engenharia Elétrica, Ana Maria, pelo auxílio na formatação final do presente trabalho.

À minha amiga Fátima que tanto me motivou nos momentos finais do desenvolvimento.

À esta universidade e aos docentes que de alguma forma contribuíram para a finalização deste trabalho.

Aos amigos e todos que contribuíram de forma direta e indireta com o presente trabalho. 
"O dinheiro não representa tal valor como os homens colocaram em cima dele. Todo o meu dinheiro foi investido nas experiências com as quais eu fiz descobertas novas, permitindo a humanidade de ter uma vida um pouco mais fácil." 


\section{RESUMO}

SOUZA, C.R. Sistema de túnel de vento aplicado no monitoramento de pressão dinâmica. 2020. 131p. Dissertação (Mestrado) - Escola Politécnica da Universidade de São Paulo, 2020 .

O presente trabalho reporta os resultados do projeto e fabricação de um túnel de vento com instrumentação automatizada aplicado no monitoramento de pressão dinâmica em modelos aerodinâmicos. Com esta finalidade, primeiramente foi desenvolvido um túnel de vento equipado com instrumentos disponíveis no mercado e de precisão para caracterizar velocidade do fluxo de ar que por ele trafega. Posteriormente, foi instalado uma turbina para gerar um fluxo de ar contínuo no túnel, dessa forma, o sistema de medição instalado na seção de testes coleta as informações de velocidade. Os dados foram coletados por um sistema de aquisição baseados em um CLP (Controlador Lógico Programável), armazenados em um banco de dados $S Q L$ Server e apresentadas em um sistema de supervisão. As variações de pressão sobre o modelo aerodinâmico foram obtidas utilizando-se uma camada fina sensível depositada sobre a superfície do modelo aerodinâmico, técnica conhecida como Pressure Sensitive Paint (PSP). A camada sensível é um filme de PVC dopadas com moléculas de Octaetilporfirina de platina PtOEP, o sensoreamento da pressão dinâmica foi monitorado através da emissão fotoluminescente das moléculas de PtOEP coletadas com uma câmera com sensor CMOS obtendo-se assim imagens da distribuição da pressão dinâmica na superfície do modelo aerodinâmico. O sistema para a obtenção de imagens da pressão dinâmica foi constituído por uma fonte laser de $380 \mathrm{~nm}$, utilizada para excitar o filme sensível a pressão e uma câmera CMOS com um filtro ótico passa-faixa na mesma faixa de emissão fotoluminescente das moléculas de PtOEP bloqueando-se assim a luz de excitação na câmera CMOS.

Palavras-chaves: Octaetilporfirina de platina. Fotoluminescente. Pressure Sensitive Paint. Câmera CMOS. Túnel de Vento. 


\begin{abstract}
SOUZA, C.R. Sistema de túnel de vento aplicado no monitoramento de pressão dinâmica. 2020. 131p. Dissertação (Mestrado) - Escola Politécnica da Universidade de São Paulo, 2020 .

This paper reports the results of the design and manufacture of an automated instrumentation wind tunnel applied to dynamic pressure monitoring in aerodynamic models. To this end, a wind tunnel equipped with commercially available precision instruments was first developed to characterize airflow velocity through which it travels. Afterwards, a turbine was installed to generate a continuous air flow in the tunnel, so the measuring system installed in the test section collects the speed information. Data were collected by a PLC (Programmable Logic Controller) acquisition system, stored in a SQL Server database and presented in a supervision system. Pressure variations on the aerodynamic model were obtained using a sensitive thin layer deposited on the surface of the aerodynamic model, a technique known as Pressure Sensitive Paint (PSP). The sensitive layer is a PVC film doped with platinum Octaethylporphyrin PtOEP molecules, the dynamic pressure sensing was monitored by photoluminescent emission of the PtOEP molecules collected with a CMOS camera, thus images of the dynamic pressure distribution on the surface of the aerodynamic model. The system for dynamic pressure imaging consisted of a $380 \mathrm{~nm}$ laser source to excite the sensitive layer and the CMOS camera with an optical bandpass filter tuned to the photoluminescent emission range of the textit PtOEP molecules blocking the excitation light on CMOS camera.
\end{abstract}

Keywords: Platinum Octaethylporphyrin. Photoluminescent. Pressure Sensitive Paint. CMOS Camera. Wind Tunnel. 


\section{LISTA DE FIGURAS}

Figura 1 - Modelo padrão de supressão do oxigênio . . . . . . . . . . . . . . . . 22

Figura 2 - O diagrama de Jablonski demonstra os estados de excitação da molécula. 24

Figura 3 - Caracterização do PSP pela técnica de tempo de vida. . . . . . . . . . 25

Figura 4 - Diagrama esquemático do arranjo experimental utilizado para os ensaios de sensibilidade dos sensores poliméricos. . . . . . . . . . . . 26

Figura 5 - Túnel de vento de circuito fechado, o qual, o fluxo de ar recircula pelo

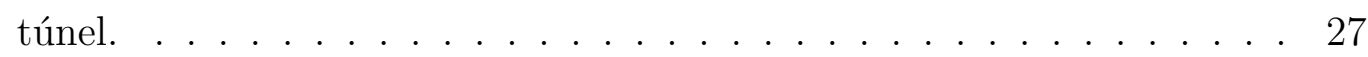

Figura 6 - Túnel de vento de circuito aberto. . . . . . . . . . . . . . . . . . . . 29

Figura 7 - Tipos de túnel (a) Design do Túnel Subsônico. (b) Design do Túnel Supersônico. . . . . . . . . . . . . . . . . 31

Figura 8 - Velocidade em diferentes áreas de seção transversal da tubulação. . . . 36

Figura 9 - Tubo de Pitot com ponta hemisférica. . . . . . . . . . . . . 38

Figura 10 - Pontos de medição de velocidade média com o tubo de Pitot . . . . . . 38

Figura 11 - Princípio de funcionamento do Annubar. . . . . . . . . . . . . . . 41

Figura 12 - Topologia da rede IO-Link. . . . . . . . . . . . . . . . . . . . . . 42

Figura 13 - Pinos de conexão IO-Link . . . . . . . . . . . . . . . . . . 43

Figura 14 - Diagrama de funcionamento do CLP. . . . . . . . . . . . . . . 43

Figura 15 - Relação Performance x Complexidade CLP SIEMENS. . . . . . . . . . 44

Figura 16 - Banco de dados em rede local. . . . . . . . . . . . . . . . . . . . 46

Figura 17 - Simulação do túnel com seção de teste de 300x300 mm. . . . . . . . . . 49

Figura 18 - Simulação do túnel com seção de teste de 200 mm. . . . . . . . . . . . 50

Figura 19 - Simulação do túnel com seção de teste de 150 mm. . . . . . . . . . . . 51

Figura 20 - Dimensões do túnel de vento desenvolvido em mm. . . . . . . . . . . 53

Figura 21 - Sistema de ventilação. . . . . . . . . . . . . . . . . 54

Figura 22 - Diagrama de blocos do controle em malha fechada. . . . . . . . . . . . 55

Figura 23 - Diagrama P\&ID da malha de controle do sistema. . . . . . . . . . . 56

Figura 24 - Annubar utilizado. a) Vista frontal; b) Vista traseira . . . . . . . . . 58

Figura 25 - Tubo de Pitot com ponta hemisférica. . . . . . . . . . . . . . 59

Figura 26 - Transmissor de pressão Rosemount 2051. . . . . . . . . . . . . . . . . . 60

Figura 27 - Controlador Lógico Programável - S7-1500 . . . . . . . . . . . . . . . 61 
Figura 28 - Inversor de frequência CFW09. . . . . . . . . . . . . . . . . 62

Figura 29 - Dispositivos IO-Link utilizados. . . . . . . . . . . . . . . . 63

Figura 30 - Sistema de supervisão. . . . . . . . . . . . . . . . . . . . . 64

Figura 31 - Topologia da rede. . . . . . . . . . . . . . . . . 66

Figura 32 - Encapsulamento do LED de $380 \mathrm{~nm}$. . . . . . . . . . . . . . . 70

Figura 33 - Câmera NIKON D5100. . . . . . . . . . . . . . . . 72

Figura 34 - Amostras desenvolvidas. . . . . . . . . . . . . . . 73

Figura 35 - Vista superior do projeto do aerofólio impresso com dimensões em mm. 75

Figura 36 - Vista lateral do projeto do aerofólio impresso com dimensões em mm. . 76

Figura 37 - Modelo em formato de aerofólio desenvolvido para testes. . . . . . . . . 76

Figura 38 - Modelo com deposição de PtOEP. . . . . . . . . . . . . . . 77

Figura 39 - Disposição da amostra. . . . . . . . . . . . . . . 78

Figura 40 - Disposição da câmera e LED emissor da excitação. . . . . . . . . . . . 79

Figura 41 - Montagem completa do Túnel de Vento. . . . . . . . . . . . . . . . . . 81

Figura 42 - Imagem com o túnel desligado e ligado a $107 \mathrm{~km} \mathrm{~h}^{-1}$ da Amostra 1. . . 86

Figura 43 - Imagens binarizadas da amostra 1. . . . . . . . . . . . . . . 88

Figura 44 - Imagens com o túnel desligado e ligado da amostra 2 . . . . . . . . . . 88

Figura 45 - Imagens binarizadas com limiar de $0,03 \ldots \ldots$. . . . . . . . . . . . 91

Figura 46 - Amostras em escala cinza no interior do túnel, com o sistema desligado, a $95 \mathrm{~km} \mathrm{~h}^{-1}$ e a $107 \mathrm{~km} \mathrm{~h}^{-1}$ da primeira sequência de testes. . . . . . . 93

Figura 47 - Imagem binarizada do modelo na primeira sequência de testes. . . . . . 96

Figura 48 - Amostras em escala cinza no interior do túnel, com o sistema desligado, a $95 \mathrm{~km} \mathrm{~h}^{-1}$ e a $107 \mathrm{~km} \mathrm{~h}^{-1}$ da segunda sequência de testes. . . . . . . . 98

Figura 49 - Imagem binarizada do modelo na segunda sequência de testes. . . . . . 100 Figura 50 - Amostras em escala cinza no interior do túnel, com o sistema desligado, a $95 \mathrm{~km} \mathrm{~h}^{-1}$ e a $107 \mathrm{~km} \mathrm{~h}^{-1}$ da terceira sequência de testes. . . . . . . . 102

Figura 51 - Imagem binarizada do modelo na terceira sequência de testes. . . . . . 104 


\section{LISTA DE GRÁFICOS}

Gráfico 1 - Tendência dos bancos de dados mais populares. . . . . . . . . . . . . 47

Gráfico 2 - Transmitância do filtro QB29 de $380 \mathrm{~nm}$. . . . . . . . . 71

Gráfico 3 - Transmitância do filtro de $640 \mathrm{~nm}$. . . . . . . . . . . . 73

Gráfico 4 - Velocidade do vento no interior do túnel em relação a rotação do motor. 83

Gráfico 5 - Verificação da limiar com diminuição na velocidade do vento no interior do túnel. . . . . . . . . . . . . . . . . . . 83

Gráfico 6 - Testes de velocidade no interior do túnel. . . . . . . . . . . . . 85

Gráfico 7 - Histograma gerado das imagens tiradas com o túnel desligado e ligado a $107 \mathrm{~km} \mathrm{~h}^{-1} \ldots \ldots \ldots \ldots \ldots$. . . . . . . . . . . . . 87

Gráfico 8 - Histograma gerado das imagens tiradas com o túnel desligado e ligado a $95 \mathrm{~km} \mathrm{~h}^{-1}, 100 \mathrm{~km} \mathrm{~h}^{-1} \mathrm{e} 107 \mathrm{~km} \mathrm{~h}^{-1}$. . . . . . . . . . . . . . 90

Gráfico 9 - Histograma gerado das imagens tiradas com o túnel desligado, ligado a $95 \mathrm{~km} \mathrm{~h}^{-1}$ e $107 \mathrm{~km} \mathrm{~h}^{-1}$ da primeira sequência de testes. . . . . . . . 95

Gráfico 10 - Histograma gerado das imagens tiradas com o túnel desligado, ligado a $95 \mathrm{~km} \mathrm{~h}^{-1}$ e $107 \mathrm{~km} \mathrm{~h}^{-1}$ da segunda sequência de testes. . . . . . . . 99

Gráfico 11 - Histograma gerado das imagens tiradas com o túnel desligado, ligado a $95 \mathrm{~km} \mathrm{~h}^{-1}$ e $107 \mathrm{~km} \mathrm{~h}^{-1}$ da terceira sequência de testes. . . . . . . . . 103 


\section{LISTA DE TABELAS}

Tabela 1 - Pontos de medição de velocidades em tubulações em função do raio. . . 39

Tabela 2 - Pontos de medição de velocidades na seção de teste. . . . . . . . . . . 68

Tabela 3 - Rotações aplicadas ao motor no intervalo de 1 minuto . . . . . . . . . 69

Tabela 4 - Velocidade média na seção de testes . . . . . . . . . . . . . 82 


\section{LISTA DE SIGLAS}

\begin{tabular}{|c|c|}
\hline CCD & Charge-coupled device \\
\hline CLP & Controlador Lógico Programável \\
\hline $\mathrm{CM}$ & Communication Module \\
\hline CMOS & Complementary Metal Oxide Semiconductor \\
\hline $\mathrm{CPU}$ & Central Processing Unit \\
\hline DB & Database \\
\hline FB & Function Block \\
\hline $\mathrm{FC}$ & Function \\
\hline GB & Gigabyte \\
\hline $\mathrm{IHM}$ & Interface Homem-Máquina \\
\hline ISA & International Society of Automation \\
\hline LED & Light Emitting Diode \\
\hline LME & Laboratório de Microeletrônica \\
\hline NoSQL & Not only Structured Query Language \\
\hline NPL & National Physical Laboratory \\
\hline ODBC & Open Database Connectivity \\
\hline P\&ID & Piping and Instrumentation Diagram \\
\hline PSP & Pressure Sensitive Paint \\
\hline PT100 & Platinum resistance temperature sensors \\
\hline PtOEP & Octaetilporfirina de Platina \\
\hline SQL & Structured Query Language \\
\hline $\mathrm{pm}$ & Rotações por minuto \\
\hline
\end{tabular}


RT

RTD

SCL

THF

TIA Portal

uPSP

UV
Runtime

Resistance Temperature Detector

Structured Control Language

Tetrahidrofurano

Totally Integrated Automation Portal

unsteady Pressure Sensitive Paint

Ultra-violeta 


\section{LISTA DE SÍMBOLOS}

\begin{tabular}{|c|c|}
\hline$\rho$ & Densidade \\
\hline$\Delta \mathrm{P}$ & Diferencial de pressão \\
\hline$\Delta \mathrm{T}$ & Diferencial de temperatura \\
\hline $\mathrm{Pa}$ & Pascal \\
\hline h & Altura referencial \\
\hline $\mathrm{A}_{1}$ & Área 1 \\
\hline $\mathrm{A}_{2}$ & Área 2 \\
\hline $\mathrm{V}_{1}$ & Velocidade do fluido de entrada do túnel \\
\hline $\mathrm{V}_{2}$ & Velocidade do fluido na saída do túnel de contração \\
\hline $\mathrm{V}_{3}$ & Velocidade do fluido na saída do túnel \\
\hline $\mathrm{P}_{1}$ & Pressão na $A_{1}$ da tubulação \\
\hline $\mathrm{P}_{2}$ & Pressão na $\mathrm{A}_{2}$ da tubulação \\
\hline $\mathrm{S}_{0}$ & Estado fundamental da molécula \\
\hline$S_{1}$ & Estado de excitação 1 da molécula \\
\hline $\mathrm{S}_{2}$ & Estado de excitação 2 da molécula \\
\hline${ }^{1} \mathrm{O}_{2}$ & Oxigênio singleto \\
\hline${ }^{3} \mathrm{O}_{2}$ & Oxigênio tripleto \\
\hline $\mathrm{O}_{2}$ & Oxigênio \\
\hline$V_{\text {Pitot }}$ & Média de velocidade do Tubo de Pitot \\
\hline$V_{\text {Annubar }}$ & Velocidade medida pelo Annubar \\
\hline $\mathrm{cv}$ & Cavalo-vapor \\
\hline mbar & Milibar \\
\hline
\end{tabular}




\begin{tabular}{|c|c|}
\hline $\mathrm{mm}$ & Milímetros \\
\hline $\mathrm{nm}$ & Nanômetros \\
\hline g & Aceleração da gravidade \\
\hline $\mathrm{ms}^{-2}$ & Metros por segundo ao quadrado \\
\hline $\mathrm{ms}^{-1}$ & Metros por segundo \\
\hline $\mathrm{km} \mathrm{h}^{-1}$ & Quilômetros por hora \\
\hline $\mathrm{kg} \mathrm{m}^{-3}$ & Quilogramas por metro cúbico \\
\hline $\mathrm{N}_{2}$ & Nitrogênio \\
\hline Ma & Número Mach \\
\hline $\mathrm{Q}$ & Vazão \\
\hline $\mathrm{K}$ & Fator de correção da vazão \\
\hline $\mathrm{L}+$ & Alimentação positiva \\
\hline L- & Alimentação negativa \\
\hline $\mathrm{C} / \mathrm{Q}$ & Informações de entrada/saída e pacotes de rede $I O$-Link \\
\hline$d$ & Distância do raio \\
\hline$r_{\text {tunel }}$ & Raio \\
\hline$n_{\mathrm{n}}$ & $\begin{array}{l}\text { Fator } n \text { de acordo com método de cálculo da velocidade média no } \\
\text { interior do túnel }\end{array}$ \\
\hline $\mathrm{ST}$ & Speed Transmitter \\
\hline $\mathrm{SE}$ & Speed Sensor \\
\hline $\mathrm{TT}$ & Temperature Transmitter \\
\hline $\mathrm{TE}$ & Tempeature Sensor \\
\hline $\mathrm{SZ}$ & Speed Actuator \\
\hline
\end{tabular}


Motor

UIR Multivariable Indicator and Register

UC Multivariable Controller 


\section{Sumário}

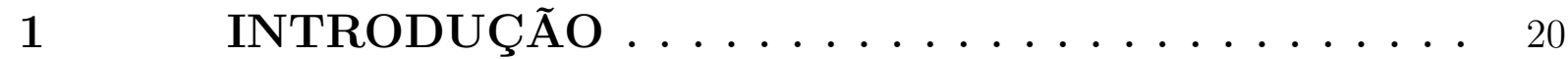

$1.1 \quad$ Caracterização dos esforços por PSP . . . . . . . . . . . 21

1.1.1 Técnica PSP obtida por Intensidade . . . . . . . . . . . . . . . . 23

1.1.2 Técnica PSP obtida por tempo de vida . . . . . . . . . . . 23

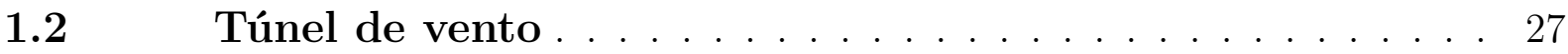

1.2.1 Túnel de vento em circuito fechado . . . . . . . . . . . . . 27

1.2.2 Túnel de vento em circuito aberto . . . . . . . . . . . . . . 28

1.2.3 Design do Túnel de Vento . . . . . . . . . . . . . . . . 30

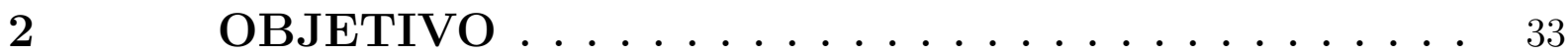

$2.1 \quad$ Objetivos específicos . . . . . . . . . . . . . 33

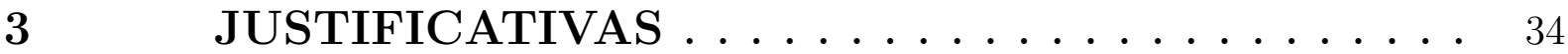

4 FUNDAMENTOS TEÓRICOS ........... 35

4.1 Medição de vazão . . . . . . . . . . . . . . 35

4.1.1 Equação da continuidade . . . . . . . . . . . . . . . . 35

4.1.2 Lei de Bernoulli . . . . . . . . . . . . . . . . . . 35

4.2 Tubo de Pitot . . . . . . . . . . . . . . . . 37

4.2.1 Velocidade média no interior da tubulação . . . . . . . . . . . . . 39

4.3 Tubo de Pitot de média . . . . . . . . . . . . . . . 40

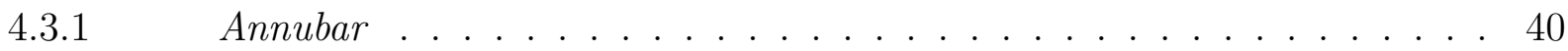

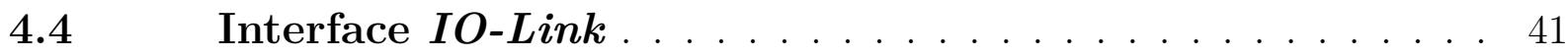

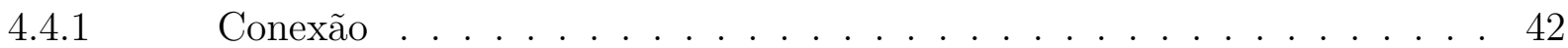

$4.5 \quad$ Controlador Lógico Programável . . . . . . . . . . . . . 43

4.6 Banco de dados . . . . . . . . . . . . . . . . . 45

4.6.1 Banco de dados Relacional . . . . . . . . . . . . . . . . . . . 45

4.6.2 Banco de dados não relacional . . . . . . . . . . . . . . . . . . 46

$4.6 .3 \quad$ Banco de dados existentes . . . . . . . . . . . . . . . 47

5 MATERIAIS E MÉTODOS ............ 48

$5.1 \quad$ Componentes do túnel de vento . . . . . . . . . . 48 
$5.1 .1 \quad$ Simulações . . . . . . . . . . . . . . . . . . . . 48

$5.1 .2 \quad$ Montagem do túnel . . . . . . . . . . . . . . . 51

5.1.2.1 Túnel de contração . . . . . . . . . . . . . . . 51

$5.1 .2 .2 \quad$ Seção de Teste . . . . . . . . . . . . . . . . . . . . 52

$5.1 .2 .3 \quad$ Montagem . . . . . . . . . . . . . . . . . 52

$5.1 .3 \quad$ Sistema de medição e controle . . . . . . . . . . . . 54

5.1.4 Instrumentação selecionada . . . . . . . . . . . . . . . 57

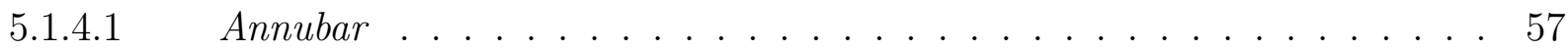

$5.1 .4 .2 \quad$ Tubo de Pitot . . . . . . . . . . . . . . . . 59

5.1.4.3 Transmissor de Pressão . . . . . . . . . . . . . . . . . . . . 59

5.1.4.4 Controlador Lógico Programável . . . . . . . . . . . . . . . . . . . . . . 60

5.1.4.5 Inversor de frequência . . . . . . . . . . . . 61

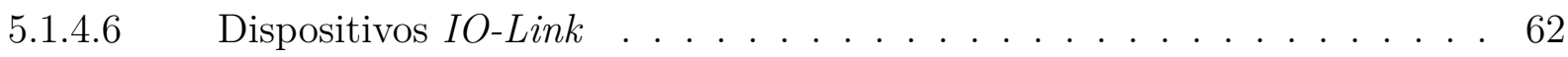

$5.2 \quad$ Sistema de supervisão . . . . . . . . . . . . . . . 64

$5.3 \quad$ Topologia da rede . . . . . . . . . . . . . 65

5.4 Coleta de dados . . . . . . . . . . . . . . . 66

5.4.1 Armazenamento de dados . . . . . . . . . . . . . . . 66

$5.4 .2 \quad$ Calibração do Annubar . . . . . . . . . . . . . . . 67

5.4 .3 Definição da rotação do motor . . . . . . . . . . . . . 68

5.5 Captação de imagens . . . . . . . . . . . . . 69

5.5.1 Excitação da molécula . . . . . . . . . . . . . . . . 70

5.5.2 Medição da resposta da molécula . . . . . . . . . . . . . 71

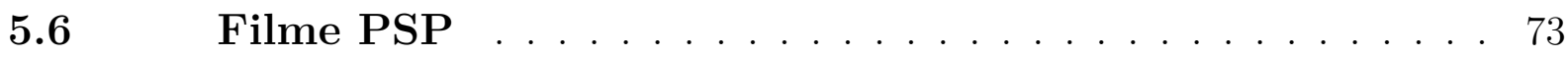

$5.6 .1 \quad$ Superfícies utilizadas . . . . . . . . . . . . . . 74

5.6.1.1 Deposição em lâminas de microscopia . . . . . . . . . . . . . . . 74

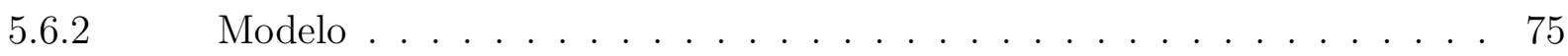

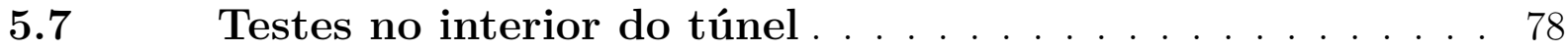

5.7.1 Análise das imagens . . . . . . . . . . . . . . . . . . . . 79

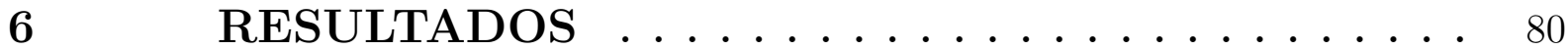

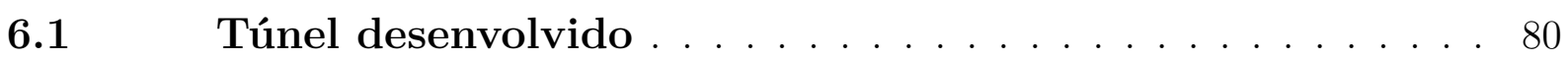

6.1.1 Montagem do Túnel . . . . . . . . . . . . . 80

6.1.2 Fator de correção do Annubar . . . . . . . . . . . . . . 81 
6.1.3 Dados coletados . . . . . . . . . . . . . . . 82

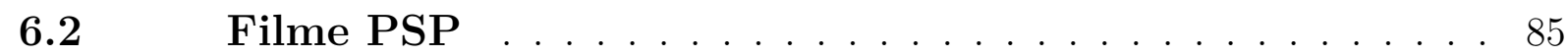

6.2.1 Testes com amostra depositada nas lâminas . . . . . . . . . . . . 85

6.2.2 Teste no modelo . . . . . . . . . . . . . . . . . . . . 91

6.2.3 Primeira sequência de testes . . . . . . . . . . . . 92

6.2.4 Segunda sequência de testes . . . . . . . . . . . 96

6.2.5 Terceira sequência de testes . . . . . . . . . . . . . . . 101

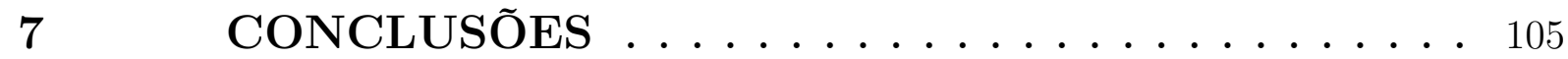

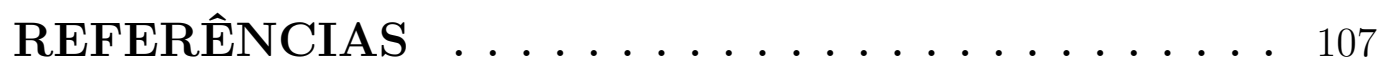

$\begin{array}{ll}\text { APENNDICES } & 111\end{array}$

Apêndice $\mathbf{A}$-Lógica de Controle . . . . . . . . . 112

Apêndice B-Script de integração no SQL Server . . 121

Apêndice C-Estrutura da tabela criada no SQL . . 123

Apêndice D-Algoritmo que gera histograma no MA-

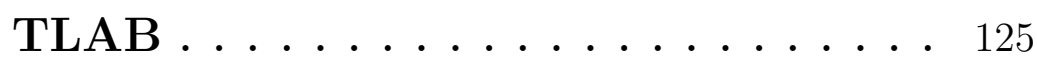

Apêndice E-Algoritmo de binarização de imagem no MATLAB . . . . . . . . . . . 127

ANEXOS

Anexo A-Especificações Técnicas da câmera NIKON D5100 .................... 130 


\section{INTRODUÇÃO}

Os estudos de Pressure Sensitive Paint (PSP) se iniciaram no final da década de 70 no Instituto Central de Aero-Hidrodinâmica, na União Soviética. Em 1981 Pervushin e Nevsky desenvolveram o primeiro revestimento sensível a pressão (KOSE, 2005). Desde então, diversos estudos voltados para determinar a pressão fazendo uso da técnica de PSP vem sendo conduzidos por centros de pesquisa localizadas nos Estados Unidos e Europa.

A aplicação de uma camada de tinta sensível a pressão pode auxiliar a determinar os esforços sofridos por um modelo fazendo uso de dispositivos para testes aerodinâmicos como, por exemplo, um túnel de vento (ENGLER; CHR, 2000).

As técnicas de medições tradicionais de pressão são feitas por meio de matrizes de sensores distribuídas pela superfície do modelo, porém, essa técnica leva a grandes esforços e muito tempo, que o torna um processo com altos custos. Além disso, como a distribuição dos sensores segue de forma discreta, possui baixa resolução espacial (JAHANMIRI, 2011).

A PSP é basicamente um dispositivo sensor que se baseia na concentração de oxigênio no interior dos filmes poliméricos e reflete a pressão parcial do oxigênio sobre o filme (MATOS, 2011), ou seja, é uma técnica especial e de aplicação adequada para sistemas óticos. Com isso, valores de pressão sobre a superfície de modelos podem ser determinados utilizando sistemas óticos e de processamento de imagem quando este for analisado em uma ferramenta de teste, no caso, um túnel de vento (CHR. et al., 2005).

A determinação da pressão em um modelo pode ser obtida por técnicas distintas de PSP, dentre elas, por intensidade e tempo de vida da molécula (KOSE, 2005).

Pelo método de intensidade, a intensidade luminescente no modelo depende da pressão a qual o corpo é submetido, ou seja, quanto maior a pressão a qual o corpo é submetido, maior a supressão de oxigênio, consequentemente menor a intensidade fotoluminescente sobre modelo (BRAGA, 2016).

A instrumentação utilizada para o método de intensidade envolve diodo emissor de luz (LED) de alta intensidade e alta estabilidade de iluminação, a fotoluminescência coletada por meio de uma câmera científica Charge-coupled device (CCD) ou Complementary Metal Oxide Semicondutor (CMOS) (GREGORY. et al., 2014) (YORITA et al., 2019). Infelizmente não é apenas a luminescência que a câmera capta, a temperatura do 
meio deve ser medida e levada em consideração para fins de compensação na medição (MERBARKI, 2000).

Pelo método de tempo de vida a pressão é determinada pelo tempo de vida da molécula excitada. Na qual, as moléculas permanecem em seu estado fundamental, quando a molécula é excitada por uma fonte de luz externa, ela deixa seu nível fundamental e vai para um nível superior, porém, não permanece em estado excitado por muito tempo e quando retorna ao seu estado fundamental emite um fóton, por um processo de radiação, o qual, é chamado de luminescência (GREGORY et al., 2008).

Para que essa caracterização possa ser efetuada é necessário a utilização de uma estrutura tubular, em que o fluxo de ar possa fluir de maneira que testes aerodinâmicos possam ser efetuados.

O Túnel de vento é uma estrutura tubular, onde, é gerado um fluxo de ar contínuo, normalmente por um grande ventilador, para que testes aerodinâmicos sejam efetuados (HALL, 2015f).

Além disso, tuneis de vento auxiliam os engenheiros e cientistas a efetuarem testes de performance e, dessa forma, eliminar possíveis erros de projeto (HALL, 2015f).

Os testes aerodinâmicos, por muitos anos, tem sido o método primário para verificação aerodinâmica de modelos. Essa verificação é extremamente importante para engenharia e desenvolvimento de aeronaves modernas, dinâmica de automóveis e construções. Dessa forma, o túnel de vento possibilita determinar os esforços aerodinâmicos sofridos por determinadas estruturas. Com isso, é possível trabalhar geometricamente nos objetos para reduzir a intensidade do fluxo de energia no seu entorno (MAGRYTA, 2013).

Porém, muitos destes testes são efetuados utilizando sensores distribuídos pelos objetos, conforme mencionado no início deste capítulo. Esse tipo de caracterização além de determinar os esforços pontuais nos objetos é altamente custoso, pois, pequenos sensores devem ser espalhados pela geometria do corpo para que se tenha eficacia na determinação dos esforços sofridos pela aerodinâmica do modelo.

\subsection{Caracterização dos esforços por PSP}

Na figura 1 é possível verificar como ocorre a supressão do oxigênio quando um corpo com uma fina camada de um filme sensível a pressão é submetido a variações de 
pressão. Quando um corpo é submetido a esforços aerodinâmicos um fóton proveniente de uma fonte luminosa irá excitar os elétrons de valência, o que fará com que eles permaneçam por um curto período de tempo em um estado excitado, quando retornam ao seu estado natural, ele emite uma fotoluminescência, porém, a intensidade pode ser maior ou menor, depende da pressão sofrida naquele ponto.

Dessa forma, com a excitação de uma fonte luminosa incidente sobre o filme de PSP ocorre a luminescência inversamente proporcional a pressão aplicada ao corpo. Quanto maior a pressão sobre o objeto maior a supressão de oxigênio resultando em uma menor intensidade luminescente e, quanto menor a supressão do oxigênio, maior a intensidade da luminescência (BRAGA, 2016) (GREGORY. et al., 2014) (KOSE, 2005).

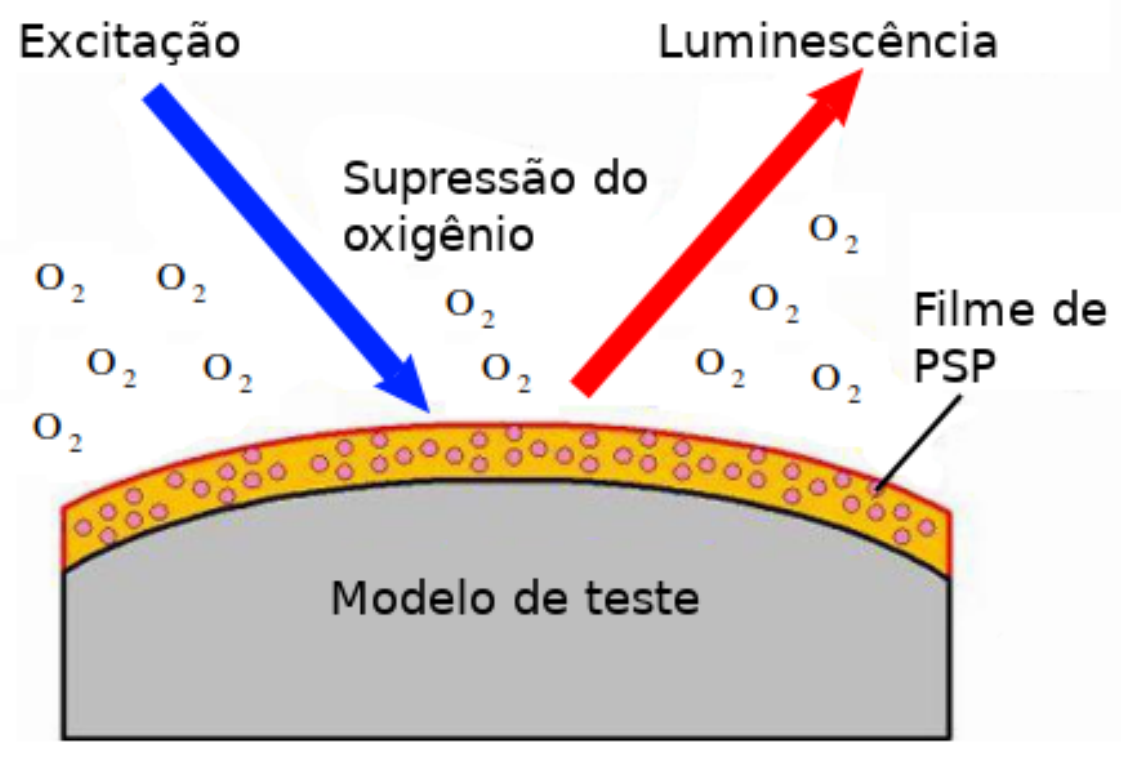

Figura 1 - Modelo padrão de supressão de oxigênio.

Fonte: Adaptação, tradução do autor dos itens de identificação da figura (JAHANMIRI, 2011)

Recentemente, novas abordagens vem sendo desenvolvidas para medir pressões aerodinâmicas induzidas por flutuações em modelos aerodinâmicos utilizando tinta sensível a pressão instável (uPSP). Essas tintas possuem respostas rápidas para medição de pressão instável em relação técnicas convencionais de PSP. Essa resposta é importante, pois, veículos aeroespaciais experimentam fortes cargas aerodinâmicas que são difíceis de medir (HOFFPAUIR, 2017).

Dentre as técnicas disponíveis para determinação da pressão em um modelo, fazendo uso do PSP, existem: intensidade e tempo de vida (KOSE, 2005). 


\subsubsection{Técnica PSP obtida por Intensidade}

Pelo método de intensidade, a intensidade luminescente no modelo é inversamente proporcional a pressão sob o mesmo, ou seja, quanto maior a intensidade luminescente menor a pressão em determinado ponto do modelo. Essa intensidade é captada por uma câmera científica CCD OU CMOS (GREGORY. et al., 2014) (MERBARKI, 2000) (YORITA et al., 2019).

Para utilizar o método de intensidade é necessário uma câmera científica, receptores óticos, dispositivos de excitação luminosa, dispositivos óticos de saída, sistema de aquisição de dados com um sistema externo de calibração (ENGLER; CHR, 2000). Para se obter bons resultados ENGLER e Chr (2000) utilizaram uma câmera de CCD de laboratório de 16 bits instalada em um túnel de vento disponível. Essa técnica também conhecida como Wind on e Wind off, na qual, uma imagem de referência é tomada com o túnel desligado e outra com o túnel ligado para analisar os esforços aerodinâmicos sofridos pelo corpo. Além disso, diversos tipos de fontes luminosas tem sido empregado em estudos de túnel de vento, porém, os tipos mais comuns utilizados são lasers pulsantes e ondas contínuas (KOSE, 2005).

A emissão captada pela câmera científica não dependerá somente da pressão de ar sofrida pelo objeto, a temperatura do ambiente deve ser levada em consideração para a determinação dos esforços aerodinâmicos sofridos pelo corpo (MERBARKI, 2000).

\subsubsection{Técnica PSP obtida por tempo de vida}

Pelo método de tempo de vida a pressão é determinada pelo tempo de vida da molécula excitada que pode ser descrita pelo diagrama de Jablonski na figura 2. 


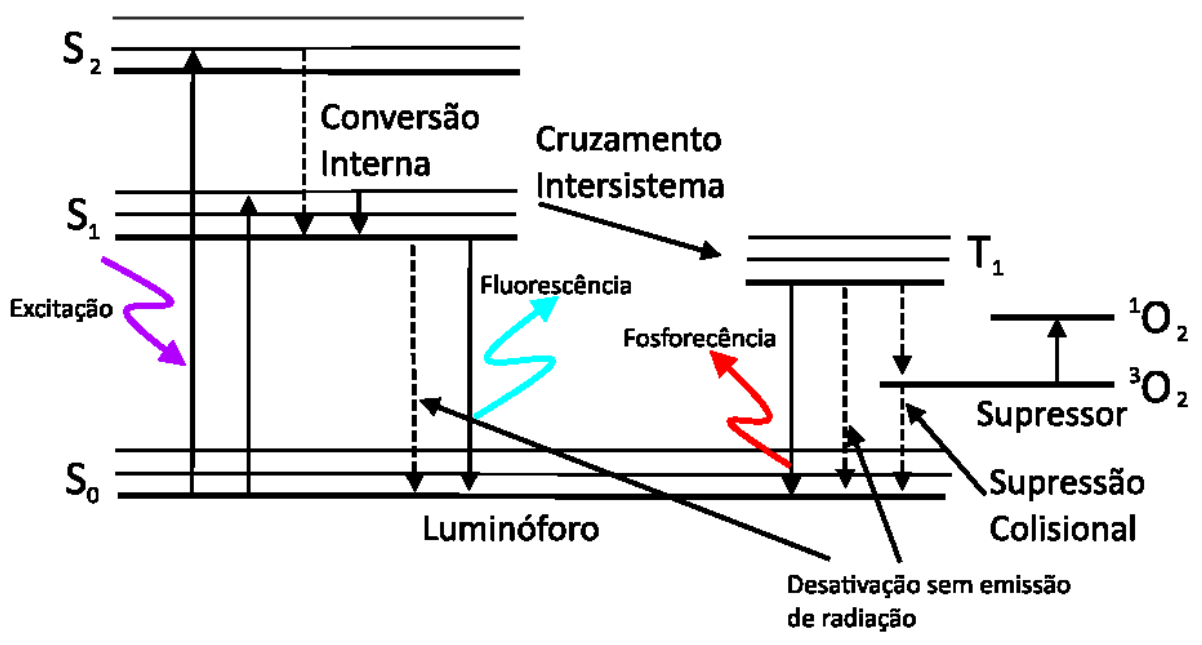

Figura 2 - O diagrama de Jablonski demonstra os estados de excitação da molécula.

Fonte: Adaptação, tradução do autor dos itens de identificação da figura (GREGORY et al., 2008)

Conforme pode ser analisado na figura 2 as moléculas permanecem em seu estado fundamental, porém, quando é excitada por uma fonte de luz, ela deixa seu estado fundamental e é elevada para um nível superior, contudo, não permanece em estado excitado por muito tempo e quando retorna a seu estado fundamental emite um fóton, por um processo de radiação, o qual, é chamado de luminescência (GREGORY et al., 2008).

Dessa forma, o método de intensidade do tempo de vida explora o tempo de decaimento da molécula que utiliza-se desse tempo para verificar a pressão sofrida pelo corpo. Com isso, o objeto deve ser excitado por um flash ou uma fonte de luz modulada. Como o tempo de vida é uma propriedade intrínseca do luminóforo utilizado no objeto. Neste caso, não há a necessidade de uma imagem de referência (KOSE, 2005), como visto na seção 1.1.1.

Existem duas possibilidades distintas para caracterização do PSP pelo método do tempo de vida: pulsed lifetime imaging e phase shift imaging (KOSE, 2005). Por isso, a câmera deve ser capaz de operar com um tempo de integração de pelo menos mil vezes mais rápido que câmeras CCD científicas convencionais, devido ao tempo de decaimento da ordem de $1 \mathrm{~s}$. A figura 3 apresenta um exemplo de funcionamento de como efetuar a medição por tempo de vida de duas imagens durante o tempo de decaimento da molécula. 


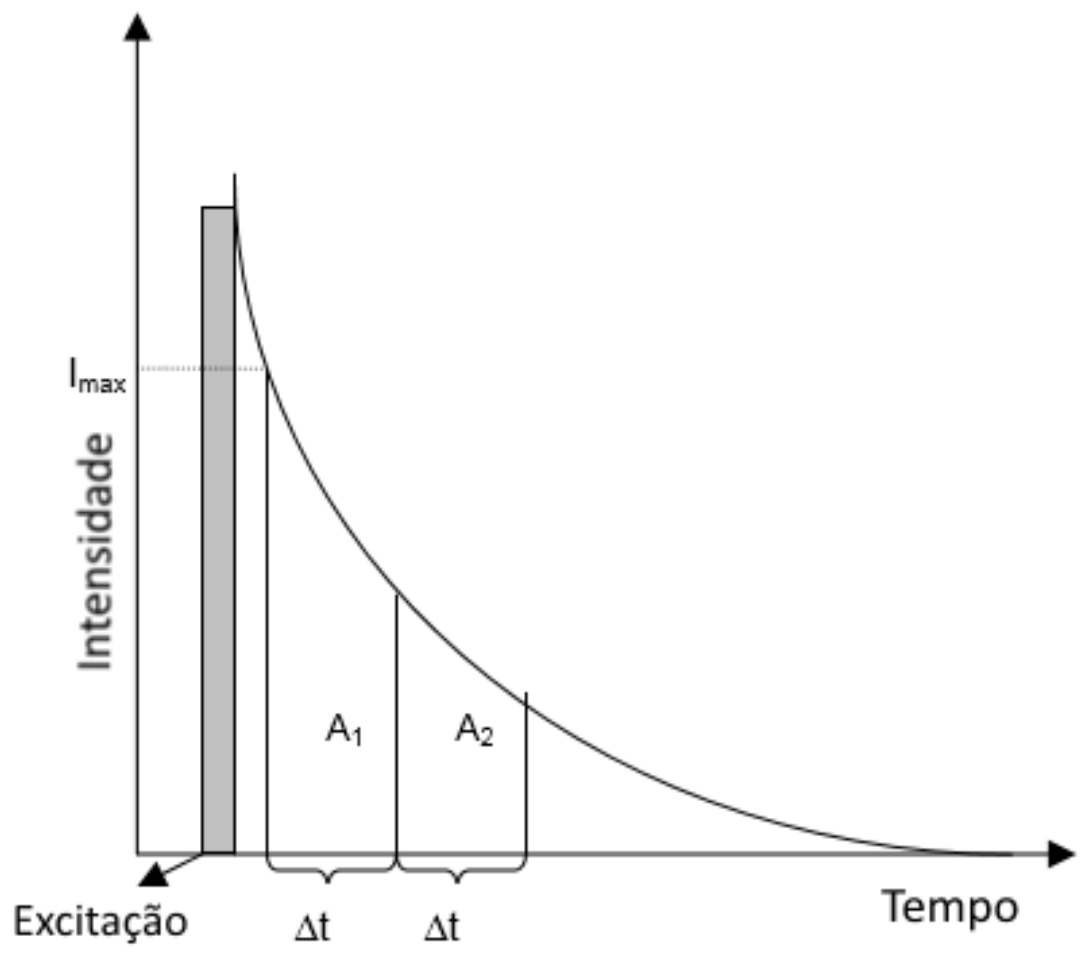

Figura 3 - Caracterização do PSP pela técnica de tempo de vida.

Fonte: Adaptação, tradução do autor dos itens de identificação da figura (KOSE, 2005)

No método de tempo de vida câmeras científicas são utilizadas, o intensificador age como um disparo ultra rápido para controlar o tempo de exposição do CCD ou CMOS. Dessa forma, após a excitação pelo flash duas imagens são coletadas em intervalos iguais e a razão das imagens adquiridas durante o processo podem ser relacionadas ao luminophore a determinada pressão e temperatura (KOSE, 2005) (YORITA et al., 2019).

Conforme citado anteriormente os testes aerodinâmicos em objetos normalmente é efetuado em um túnel de vento, pois, dessa forma, é possível controlar as variáveis a qual o corpo está sujeito. Como por exemplo, manter velocidades contantes (CHR. et al., 2005) e, dessa forma, permitir que cientistas e engenheiros analisem como o modelo responderá aos esforços sofridos (HITT, 2008).

Assim sendo, o modelo é alocado no túnel e o fluxo de ar que passa sobre ele faz com que sofra os mesmos esforços de um ambiente real. Não importa se o objeto é um modelo completo contendo todas as suas partes ou apenas partes do mesmo, desde que este esteja com os dispositivos necessários para se determinar os esforços sofridos por ele (HITT, 2008) que no caso seria o filme PSP. 
Porém, para efetuar o teste do filme, não é fundamental o uso de um túnel de vento. Em laboratório podem ser efetuados ensaios em uma câmara de ensaio conforme apresentado na figura 4.

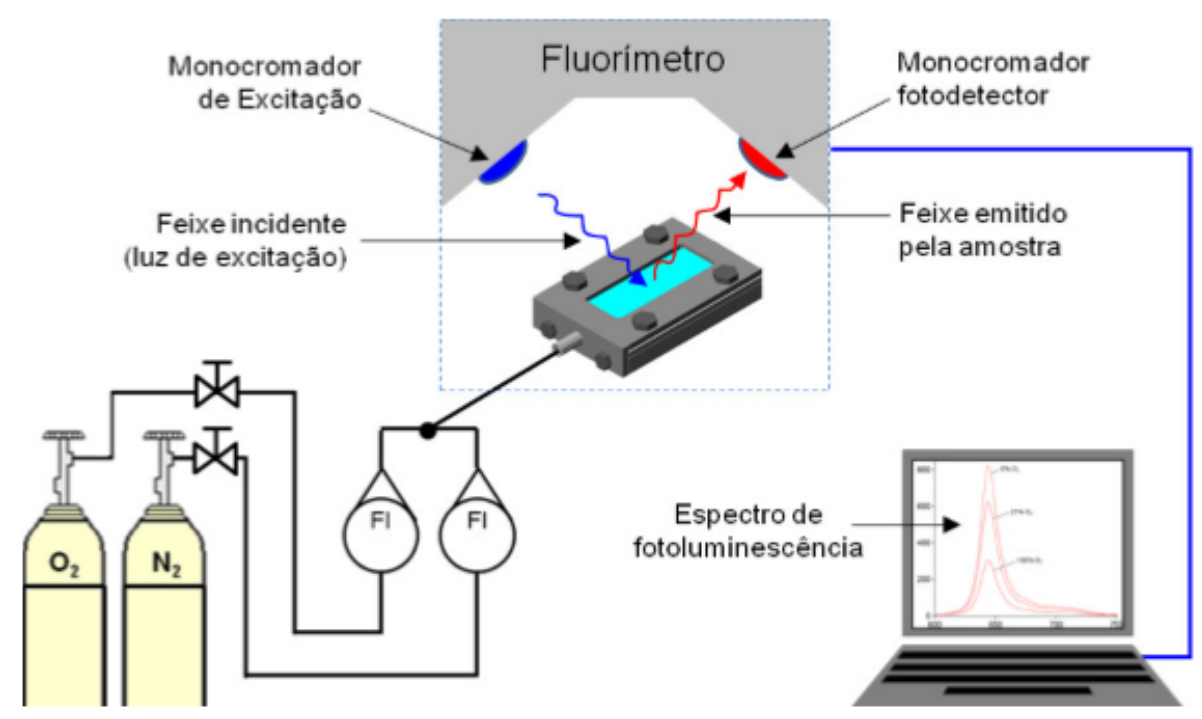

Figura 4 - Diagrama esquemático do arranjo experimental utilizado para os ensaios de sensibilidade dos sensores poliméricos.

Fonte: Adaptação (MATOS, 2011)

Segundo MATOS (2011) para obter o espectro de fotoluminescência dos sensores, foi utilizado um fluorímetro. Ainda no teste a temperatura da amostra foi controlada à cerca de $25^{\circ} \mathrm{C}$. Além disso, a concentração de oxigênio no gás de carga (nitrogênio) foi controlada com o uso de rotâmetros. Com essa câmara ele pode validar o sensor desenvolvido, pois, utilizou uma fonte excitadora de luz e um fotodetector para verificar a fotoluminescência, ou seja, controlando a pressão e oxigênio na câmara ele pode validar o filme sensível a pressão.

Este sensor foi desenvolvido na escola politécnica da USP em São Paulo e como não havia disponível um túnel de vento no laboratório LME da USP para caracterização aerodinâmica de objetos, todos os testes foram efetuados em uma câmara de teste em laboratório (MATOS, 2011).

No presente trabalho foi utilizada a molécula Octaetilporfirina de Platina (PtOEP) desenvolvida por Braga e Salcedo (2018). Essa molécula, segundo o autor é ativada por uma excitação luminosa na região de 380 nm, que corresponde a região de máxima absorção da molécula PtOEP. A região de máxima emissão fotoluminescente da molécula foi de 644 nm (BRAGA; SALCEDO, 2018). 


\subsection{Túnel de vento}

O túnel de vento é utilizado para que engenheiros possam estudar os esforços aerodinâmicos que determinados objetos estão sujeitos, sejam eles, aéreos ou terrestres.

Existem 2 tipos de túnel de vento, que podem ser construídos: Túnel de circuito aberto e Túnel de circuito fechado.

\subsubsection{Túnel de vento em circuito fechado}

É um túnel de grandes dimensões e custos elevados para ser construído, porém, possibilita um maior controle sobre o fluxo de ar que circula por ele. Dessa forma, produz os resultados de maneira mais precisa e eficiente quando os modelos são testados nesse tipo de túnel (SPAHN; STEELMAN, 2015) (BENSON, 2014). Na figura 5 é possível ver uma representação construtiva desse tipo de túnel de vento.

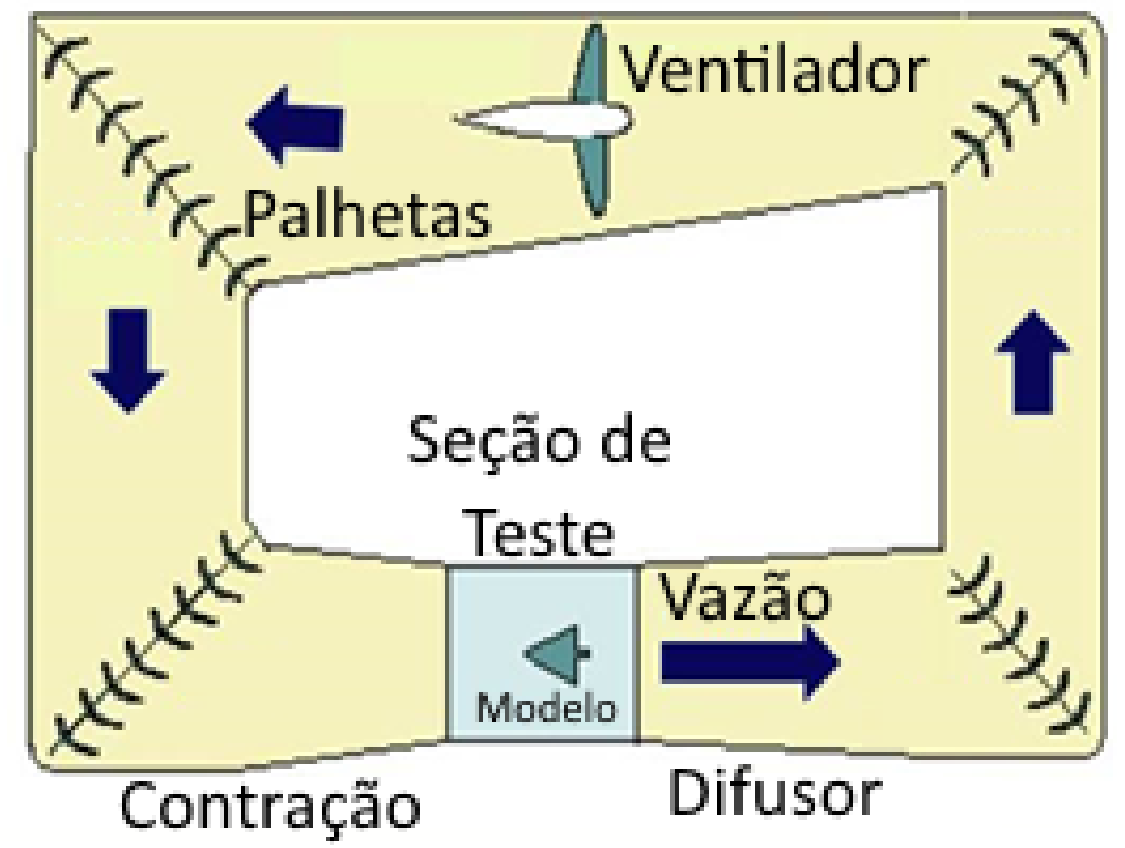

Figura 5 - Túnel de vento de circuito fechado, o qual, o fluxo de ar recircula pelo túnel.

Fonte: Adaptação, tradução do autor dos itens de identificação da figura (HALL, 2015a)

Conforme pode-se visualizar na figura 5 o ar fica circulando de maneira permanente pelo túnel. Esse tipo de túnel também é chamado de Prandtl tunnel ou Gottingen Tunnel, pois, foi desenvolvido primeiramente na Alemanha. Nesse túnel o ar é conduzido desde 
a seção de teste (local este onde o modelo é alocado) até o ventilador por uma série de palhetas. Na saída do ventilador o ar percorre até o túnel de contração, que aumenta a velocidade do ar, e de lá para a seção de teste. Ao passar pelo difusor a velocidade é diminuída (HALL, 2015a). Com esse tipo de estrutura o ar circula de maneira contínua pelo túnel, fazendo com o que o ventilador funcione apenas para compensar as perdas durante a recirculação de ar.

A função das palhetas é para manter a circulação do ar de maneira uniforme e evitar os choques com as paredes do túnel, gerando turbulência, portanto, mantém o fluxo laminar no interior do túnel.

Esse túnel pode operar a uma velocidade subsônica ou supersônica. Sendo que no caso de supersônica alguns cuidados a mais devem ser tomados devido a condensação na seção de teste devido à baixa pressão. Possui vantagens e desvantagens (HALL, 2015a):

- Vantagens:

- qualidade superior no controle da vazão de ar na seção de teste;

- baixos custos de operação, pois, o motor é ligado somente para compensar as perdas de carga;

- operação silenciosa se comparada ao túnel de circuito aberto.

- Desvantagens:

- alto custo de construção devido suas dimensões;

- design inferior para testes de propulsão e visualização da vazão de fumaça no túnel;

- deve empregar altos trocadores de calor devido as altas temperaturas que estes ficam submetidos.

\subsubsection{Túnel de vento em circuito aberto}

Este tipo de túnel é mais parecido com um tubo, pois, é aberto em ambas as extremidades (SPAHN; STEELMAN, 2015). Seu formato não permite que se tenha um controle completo da vazão de ar, pois, o ar circula pelo local onde este túnel estiver alocado.

Na figura 6 é possível verificar um diagrama de funcionamento do túnel em circuito aberto. 


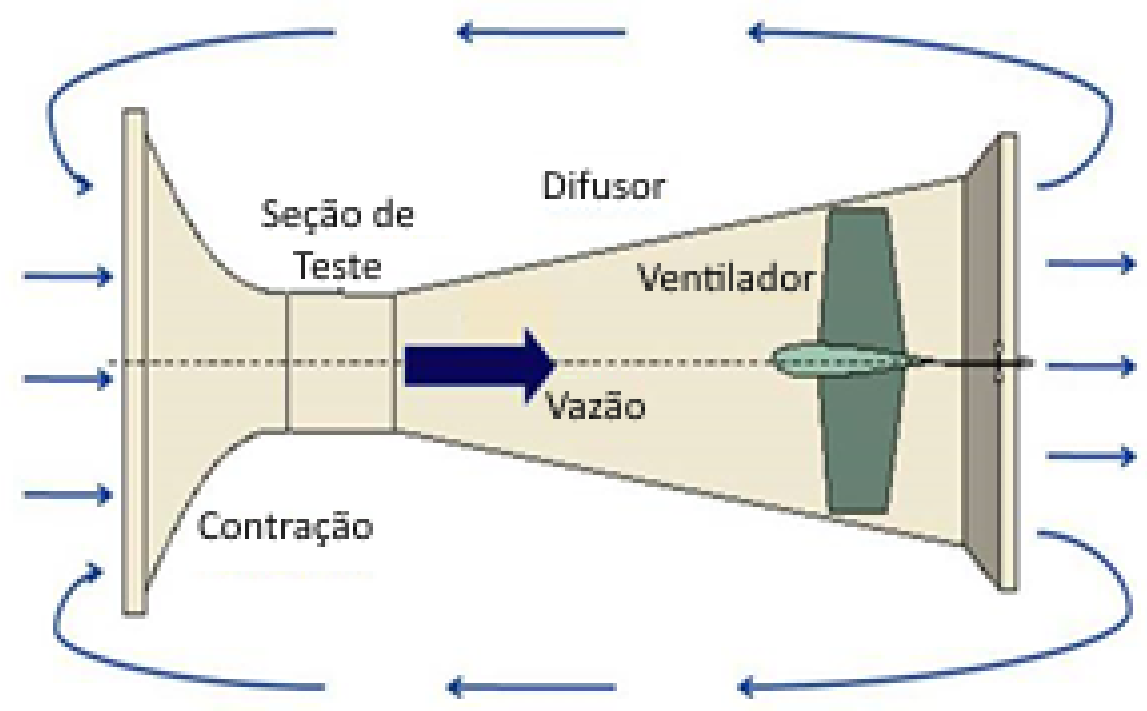

Figura 6 - Túnel de vento de circuito aberto.

Fonte: Adaptação, tradução do autor dos itens de identificação da figura (HALL, 2015c)

Esse tipo de túnel também é chamado de Eiffel Tunnel ou NPL tunnel pois, foi primeiramente utilizado em um laboratório inglês e desenvolvido por um engenheiro francês (HALL, 2015c).

Neste tipo de túnel o ar que passa pela seção de teste é sugado da sala em que o túnel está localizado. Na figura 6 é possível verificar o sentido da vazão de ar.

Alguns questionamentos que podem ser levantados nesse tipo de túnel é o motivo do ventilador estar na parte de trás do túnel e não na frente. Esse é atualmente o melhor local para se dispor o ventilador, pois, ele vai puxar o ar para dentro do túnel soprando-o para fora dele (HALL, 2015c). Puxar o ar do túnel é melhor do que soprar o ar para dentro do túnel, pois, minimiza a incidência de turbulência no interior da seção de testes (SPAHN; STEELMAN, 2015). Assim como o túnel de circuito fechado, também possui vantagens e desvantagens:

- Vantagens:

- baixo custo de construção;

- excelente design para testes de propulsão e visualização de fumaça.

- Desvantagens

- baixa qualidade da vazão de ar na seção de teste, devido a recirculação no local; 
- altos custos operacionais, pois, o motor deve ficar em operação, em quanto os testes forem necessários;

- alto ruído no ambiente.

\subsubsection{Design do Túnel de Vento}

Para que o túnel seja desenvolvido deve-se definir o range de velocidade que o modelo será submetido no túnel, pois, a velocidade na seção de teste do túnel é determinada pelo design do túnel (HALL, 2015d). Ou seja, a velocidade da seção de teste altera o design do túnel.

Dessa forma, para velocidades subsônicas a densidade do ar permanece aproximadamente constante e diminuindo a seção de cruzamento faz com que haja um aumento na velocidade do ar e uma diminuição da pressão na seção de teste. Da mesma forma, caso haja aumento na seção de cruzamento haverá diminuição na velocidade do túnel e aumento na pressão. Em um túnel subsônico a seção de teste é disposta logo após o tubo de contração e antes da montante do difusor (HALL, 2015d). A equação 1 demonstra essa situação (HALL, 2015e).

$$
\left(1-M a^{2}\right) \times \frac{d V}{V}=-\frac{d A}{A}
$$

Com isso, verificamos que com fluxo subsônico (número Mach $<1$ ), e com o aumento na área, aumentará o valor negativo na velocidade, ou seja, um decréscimo da velocidade; da mesma forma, se houver uma diminuição na área, haverá um acréscimo de velocidade.

A figura 7 apresenta a relação de aumento e diminuição da velocidade de acordo com o tipo de túnel de vento utilizado: subsônico e supersônico. 


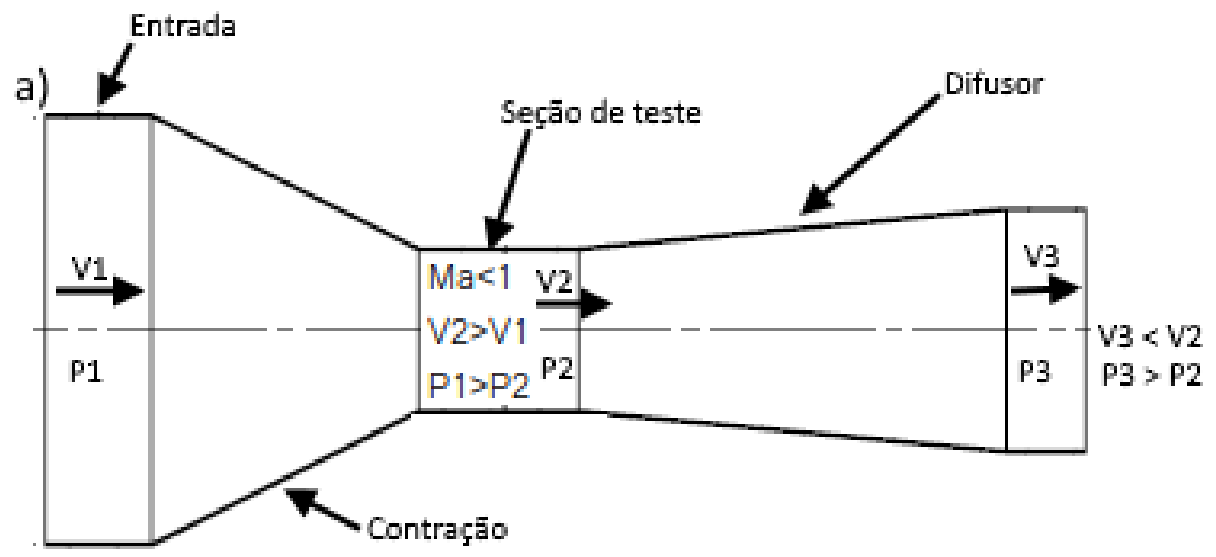

b)

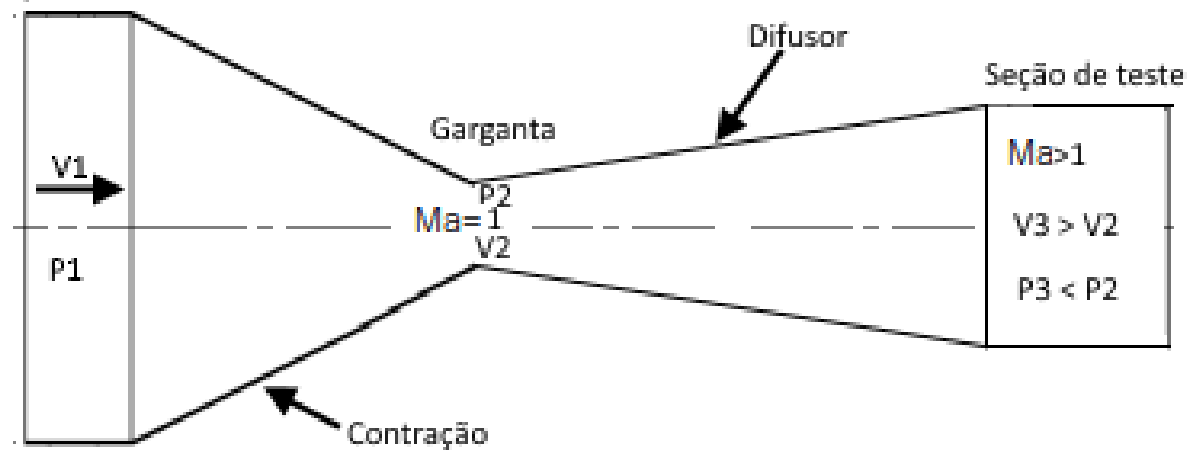

Figura 7 - Tipos de túnel (a) Design do Túnel Subsônico. (b) Design do Túnel Supersônico.

Fonte: Adaptação, tradução do autor dos itens de identificação da figura (HALL, 2015d)

Na figura 7 a) é possível verificar um diagrama demonstrando as alterações no número Mach, velocidade e pressão para uma velocidade subsônica (HALL, 2015d). Quando a vazão de ar chega à seção de teste a velocidade é maior que a velocidade de entrada e a pressão é menor que a pressão de entrada.

Para velocidades o termo $\left(1-M a^{2}\right)$ se altera e se torna negativo, ou seja, $1-M a^{2}<$ 0. Portanto, um aumento na área provoca um aumento na velocidade (HALL, 2015e). Isso ocorre, devido a densidade do ar se alterar pelo princípio da compressibilidade (HALL, 2015e). Dessa forma, tanto a velocidade quanto a densidade se alteram enquanto a área é alterada para conservar a massa.

A pressão estática é a medida da quantidade de energia potencial, a pressão dinâmica é a medida da quantidade de energia cinética, em certas condições a pressão se mantém constante, conforme descrito pela lei de Bernoulli (DOMMELEN, 2013). 
Portanto, para velocidades subsônicas a densidade permanece aproximadamente constante, porém, para velocidades supersônicas quando a área se altera há duas alterações: a velocidade e a densidade. Conforme apresentado na equação 2 .

$$
-\left(M a^{2}\right) \times \frac{d V}{V}=-\frac{d \rho}{\rho}
$$

A equação 2 demonstra que a alteração da densidade é maior que a alteração na velocidade, portanto, para conservar a massa e o momento em um fluxo supersônico, a velocidade aumenta enquanto a densidade diminui quando há um aumento na área (HALL, 2015e). O Design supersônico é descrito na figura 7 b), a qual, na "garganta" após o tubo de contração representa $M a c h=1$ fazendo com que a velocidade aumente quando a área do difusor aumenta, portanto, na seção de teste temos uma velocidade supersônica com Mach>1, dessa forma, a velocidade aumenta e a pressão diminui.

Na figura 7 a) pode-se verificar que a área é diminuída em relação ao tubo de contração, depois, o fluxo sai pelo tubo de difusão. Já na figura 7 b) o ar passa pela "garganta" do túnel onde este está a uma velocidade $M a c h=1$ e deste, vai para o difusor, onde se conecta com a seção de teste já a uma velocidade supersônica. Portanto, é possível verificar a alteração explicita no design, a qual, a seção de teste é colocada logo após o tubo de contração quando deseja-se velocidades subsônicas e logo após o tubo de difusão quando deseja-se velocidades supersônicas. 


\section{OBJETIVO}

O presente trabalho tem por objetivo a montagem de um túnel de vento em circuito aberto para caracterização de pressão dinâmica em modelos específicos. O túnel de vento deve ser equipado com instrumentação necessária para medição e controle de velocidade, além, do sistema para caracterização dos dispositivos do tipo PSP.

\subsection{Objetivos específicos}

- Desenvolver um túnel de vento em circuito aberto;

- Equipar o túnel com instrumentação de controle e medição;

- Desenvolver sistema de monitoramento e aquisição de dados;

- Implementar sistema para caracterização de modelo PSP pela técnica de intensidade. 


\section{JUSTIFICATIVAS}

Sistemas para medição dinâmica é de extrema importância para setores aeroespacial e automotivo. Os sistemas que atualmente são utilizados para medição de pressão aerodinâmica baseados em sensores distribuídos sobre os modelos em testes possuem alto custo, tanto financeiros quanto em tempo. O desenvolvimento de pesquisas relacionadas a PSP (BRAGA, 2016) vem apresentando resultados relevantes para o setor, pois, ao contrário dos sensores distribuídos pelo modelo, provendo informações de forma discreta, tecnologias baseadas em PSP provê informações com alta resolução espacial, já que a tinta é distribuída de forma uniforme no modelo (MATOS, 2011).

Neste contexto, o presente trabalho apresenta a implementação de um túnel de vento, com instrumentação de medição e controle de uso industriais para levantamento das condições de vazão de ar e temperatura no interior do túnel. Os dispositivos de medição são de uso industrial, portanto, possuem alta confiabilidade de medição. Além disso, dados relacionados as condições da seção de teste são armazenados em banco de dados para análise. Também utiliza um modelo com sua superfície recoberta com a tinta PSP desenvolvida por Braga e Salcedo (2018) para análise das reações da superfície do modelo, quando submetidos a variações de velocidade no interior do túnel. Até o presente trabalho não foram desenvolvidos anteriormente testes aerodinâmicos com membranas de PVC contendo moléculas imobilizadas sensíveis de Octaetilporfirina de Platina (PtOEP). 


\section{FUNDAMENTOS TEÓRICOS}

\subsection{Medição de vazão}

A medição de vazão por elementos primários deprimogênios é uma das mais empregadas no mercado industrial (DELMEE, 2003), como por exemplo o tubo de Pitot. Dessa forma, o elemento primário em contato com o fluido, é o primeiro elo de uma malha com o elemento a ser medido. Para completar o sistema de medição, um transmissor de pressão diferencial e um instrumento receptor, como um CLP. Com as equações da continuidade e de Bernoulli é possível calcular a vazão no interior da tubulação.

\subsubsection{Equação da continuidade}

A equação da continuidade aplica-se a fluidos incompressíveis (HALL, 2015b), que fluem e tubulações que em determinado instante a seção varia de $A_{1}$ para $A_{2}$, conforme descrito na figura 8. Em determinado instante o produto da velocidade pela $\mathrm{A}_{1}$ é igual ao produto da velocidade pela $\mathrm{A}_{2}$, essa forma, obtemos a vazão do fluido na tubulação, conforme representado na equação 3 (DELMEE, 2003).

$$
V_{1} A_{1}=V_{2} A_{2}=Q
$$

onde,

- $A_{1}$ : área na seção 1 .

- $V_{1}$ : velocidade na seção 1.

- $A_{2}$ : área na seção 2 .

- $V_{2}$ : velocidade na seção 2 .

- $Q$ : Vazão na tubulação.

\subsubsection{Lei de Bernoulli}

A equação de Bernoulli é válida sobre uma linha de fluxo, quando a viscosidade é desprezível, condições estáveis e quando se trata de fluidos incompressíveis (HALL, 2015b). É normalmente utilizado para calcular a velocidade do fluxo quando as pressões estáticas 
e dinâmicas são conhecidas, normalmente quando utiliza-se sensores que apresentam o diferencial de pressão (DOMMELEN, 2013) (DELMEE, 2003) (LIPTAK, 2003).

Na figura 8 temos uma representação das variáveis utilizadas para realizar o cálculo da velocidade quando houver uma variação de área na passagem de um fluido por uma tubulação.

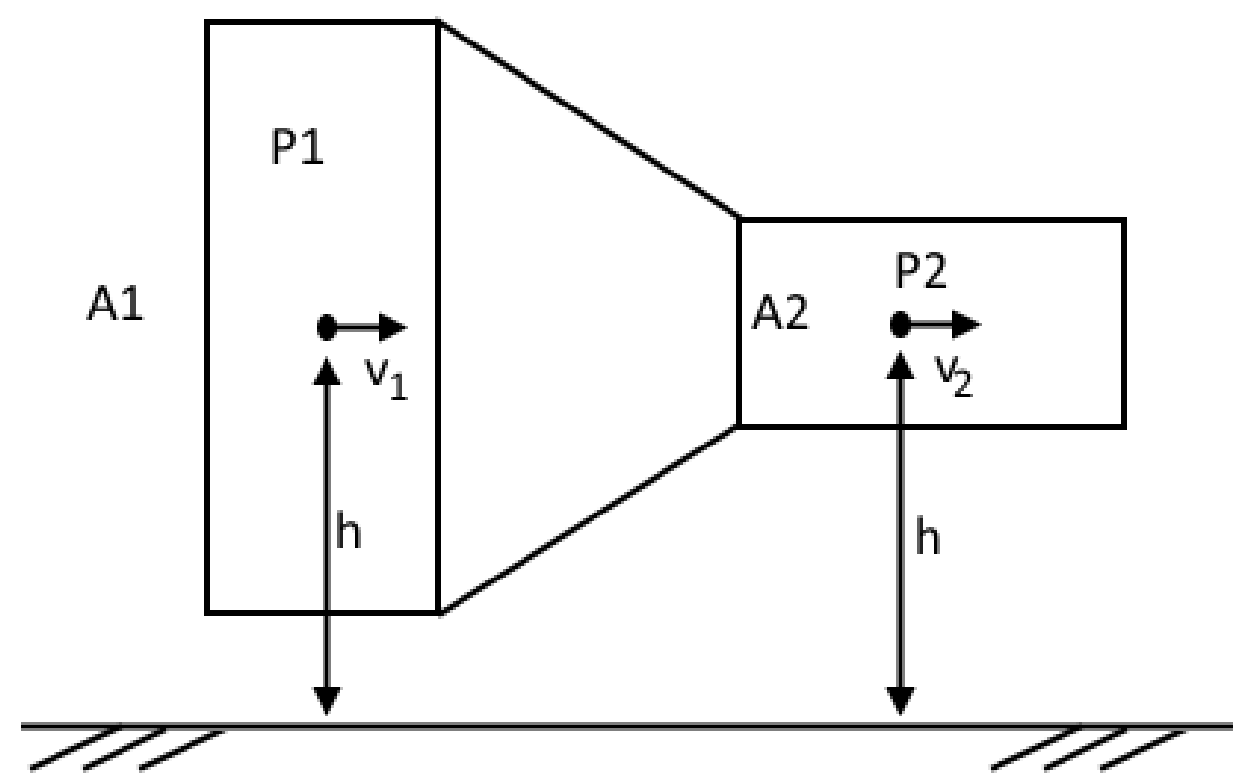

Figura 8 - Velocidade em diferentes áreas de seção transversal da tubulação.

Fonte: Autor

Onde:

- $\mathrm{A}_{1}$ : representa a área de entrada do fluido;

- $\mathrm{A}_{2}$ : área de saída do fluido;

- $\mathrm{V}_{1}$ : velocidade do fluido de entrada;

- $\mathrm{V}_{2}$ : velocidade do fluido na saída;

- $\mathrm{P}_{1}$ : Pressão na $\mathrm{A}_{1}$ da tubulação;

- $\mathrm{P}_{2}$ : Pressão na $\mathrm{A}_{2}$ da tubulação.

- h : Altura referencial.

Com base na análise representada pela figura 8, temos a equação 4, que é a equação de Bernoulli. 


$$
P_{1}+\rho g h+\frac{1}{2} \rho\left(V_{1}\right)^{2}=P_{2}+\rho g h+\frac{1}{2} \rho\left(V_{2}\right)^{2}
$$

onde:

- $P_{1}$ : Pressão estática no nível de referência da entrada do túnel $\left(\mathrm{N} \mathrm{m}^{-2}\right)$;

- $P_{2}$ : Pressão estática no nível de referência da seção de teste $\left(\mathrm{N} \mathrm{m}^{-2}\right)$;

- $\rho$ : densidade $\left(\mathrm{kg} \mathrm{m}^{-3}\right)$;

- $g$ : aceleração da gravidade $\left(\mathrm{m} \mathrm{s}^{-2}\right)$;

- $h$ : altura acima do nível de referência (m);

- $V_{1}$ : velocidade na entrada do túnel $\left(\mathrm{m} \mathrm{s}^{-1}\right)$;

- $V_{2}$ : velocidade na seção de teste $\left(\mathrm{m} \mathrm{s}^{-1}\right)$;

Se a equação 4 for trabalhada analiticamente à figura 8, podemos cortar $\rho$ gh, pois, estão no mesmo ponto referencial de altura.

$$
P_{1}+\rho g \hbar+\frac{1}{2} \rho\left(V_{1}\right)^{2}=P_{2}+\rho g \hbar+\frac{1}{2} \rho\left(V_{2}\right)^{2}
$$

Portanto temos a equação 6.

$$
P_{1}+\frac{1}{2} \rho\left(V_{1}\right)^{2}=P_{2}+\frac{1}{2} \rho\left(V_{2}\right)^{2}
$$

Podemos reagrupar a equação 6 para obter a equação 7 .

$$
P_{1}-P_{2}=\frac{1}{2}\left(\rho\left(V_{2}\right)^{2}-\rho\left(V_{1}\right)^{2}\right)
$$

\subsection{Tubo de Pitot}

O tubo de Pitot é um dispositivo constituído de dois tubos coaxiais, formando um L. Dessa forma, na extremidade interna do tubo coloca-se de frente com a corrente do fluido, denominada região de impacto, a qual, irá receber a pressão total, enquanto a pressão estática é medida através de pequenos orifícios na parede do tubo externo. Na figura 9 temos a representação de um tubo de Pitot com ponta hemisférica (DELMEE, 2003) (LIPTAK, 2003) (KIRK; WEEDON; KIRK, 2006). 


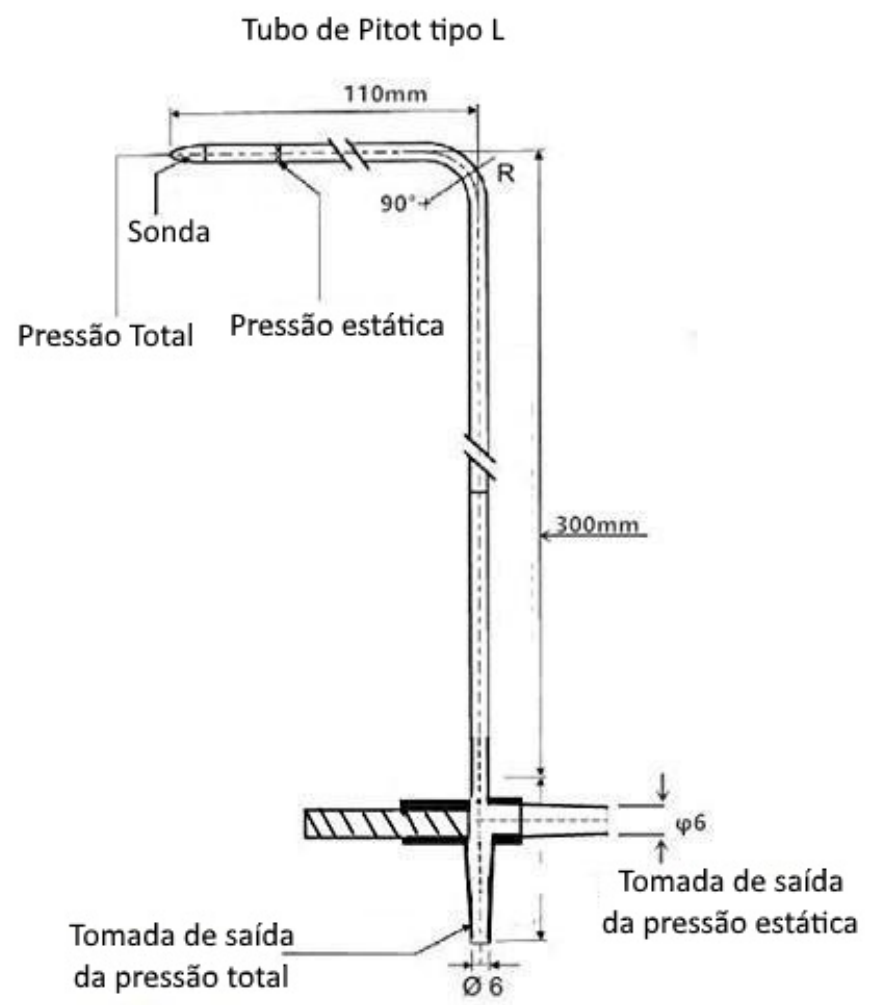

Figura 9 - Tubo de Pitot com ponta hemisférica.

Fonte: Adaptação, tradução do autor dos itens de identificação da figura (PERFECT PRIME, 2018)

Com o tubo de Pitot normalmente se mede a velocidade pontual no interior de uma tubulação, contudo, é possível se calcular a velocidade média em determinada seção da tubulação tomando várias velocidades na seção e dessa forma, tirar a média. Uma representação desta forma de medição é representada na figura 10 (DELMEE, 2003).

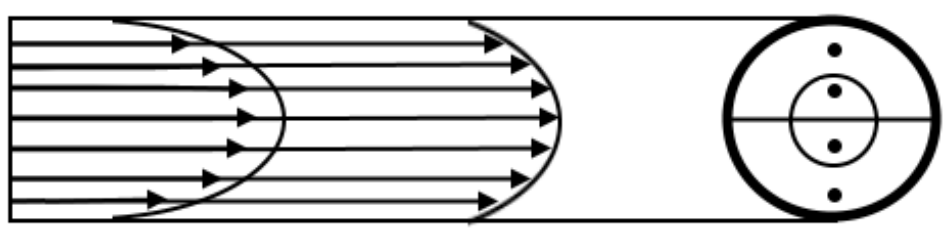

Figura 10 - Pontos de medição de velocidade média com o tubo de Pitot .

Fonte: Adaptação (DELMEE, 2003)

Uma das técnicas utilizadas para medição da velocidade média é o método de Tchebycheff. 
4.2.1 Velocidade média no interior da tubulação

Existem diversos métodos de medição de velocidade média no interior de tubulação, fazendo uso de tubo de Pitot, sendo dois dos mais utilizados:

- Centróides de áreas iguais: Todas as velocidades medidas possuem pesos iguais, e o incremento das áreas de medição são espaçados de forma igual entre os pontos de medição.

- Tchebycheff: os pontos também são espaçados de forma igual e possuem o mesmo peso de medição, porém, esse método produz o menor erro de medição em relação aos demais métodos (DELMEE, 2003) (CARE; BONTHOUX; FONTAINE, 2014).

Na tabela 1 temos as informações para medição da velocidade média de uma tubulação fazendo uso de tubo de Pitot. São apresentados as distâncias do raio em relação ao número de pontos a ser medido. Dessa forma, caso se escolha $n=3$, devem ser medidos 3 pontos acima do raio e 3 pontos abaixo do raio. Esse valor deve ser em relação ao produto do valor da tabela com o raio e ser somado/ subtraído ao raio e efetuar a medida no valor calculado. Quanto maior o valor de n maior a precisão da medida (DELMEE, 2003), porém, mais difícil para efetuar as medições nos valores exatos.

Tabela 1 - Pontos de medição de velocidades em tubulações em função do raio.

\begin{tabular}{c|cc}
\hline \multirow{2}{*}{$\begin{array}{c}\text { Quantidade de pontos } \\
\text { no Raio }\end{array}$} & $\begin{array}{c}\mid c \\
\text { Raio(mm) } \\
\text { Centróides de área } \\
\text { iguais }\end{array}$ & "Tchebychef" \\
\cline { 2 - 3 } $\mathrm{n}=2$ & 0,500 & 0,4597 \\
& 0,866 & 0,8881 \\
\hline \multirow{2}{*}{$\mathrm{n}=3$} & 0,4082 & 0,3827 \\
& 0,7071 & 0,7071 \\
& 0,9129 & 0,9239 \\
\hline \multirow{2}{*}{$\mathrm{n}=4$} & 0,3536 & 0,3203 \\
& 0,6124 & 0,6383 \\
& 0,7906 & 0,7699 \\
& 0,9354 & 0,9473 \\
\hline
\end{tabular}

Fonte: Adaptação (DELMEE, 2003) 


\subsection{Tubo de Pitot de média}

A finalidade do tubo de Pitot de média é tomar ao mesmo tempo as pressões dinâmicas relativas a quatro, seis ou oito velocidades ao longo do diâmetro da tubulação. Os pontos de medição no tubo são efetuados de acordo com a teoria estatística de Tchebycheff (DELMEE, 2003).

A equação é a mesma para o cálculo da vazão utilizado em tubulações industriais, porém, afetado por um fator $\mathrm{K}$, devido apresentar um diferencial de pressão maior que um tubo de Pitot comum (DELMEE, 2003) (LIPTAK, 2003). A medição da vazão por um tubo de Pitot de média é apresentado na equação 8 (ROSEMOUNT, 2009).

$$
Q=K \times \sqrt{\Delta P}
$$

onde,

- Q: Vazão em $\mathrm{m}^{3} \mathrm{~s}^{-1}$;

- $K$ : Fator $\mathrm{K}$ de correção da função que pode ser tomado experimentalmente ou via manual do fabricante;

- $\Delta P$ : Pressão diferencial em $P a$.

\subsubsection{Annubar}

Uma variação do tubo de Pitot de média foi desenvolvido pela empresa Rosemount e chamado de Annubar, seu funcionamento é representado na figura 11.

Onde:

- $P_{H}$ : Pressão total;

- $P_{L}$ : Pressão estática. 


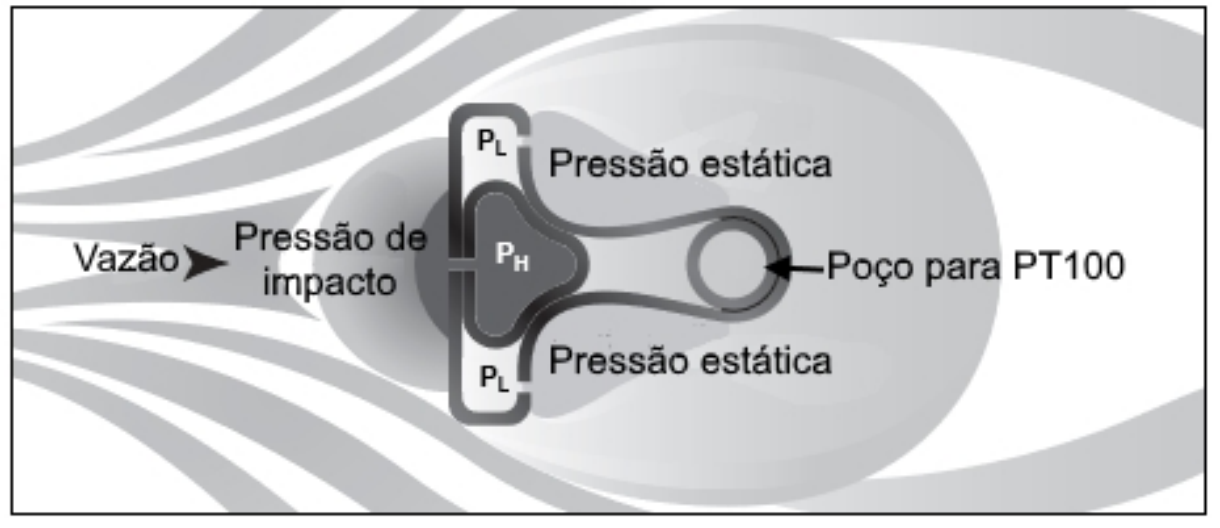

Figura 11 - Princípio de funcionamento do Annubar.

Fonte: Adaptação, tradução do autor dos itens de identificação da figura (ROSEMOUNT, 2009)

Conforme apresentado na figura 11 o Annubar gera uma pressão diferencial criando bloqueio no tubo e agindo como uma obstrução ao fluido. A velocidade do fluido é diminuída e parada quando atinge a superfície frontal do sensor do Annubar, criando o impacto de alta pressão, dessa forma, o Annubar detecta a pressão de impacto utilizando uma fissura frontal $\left(\mathrm{P}_{\mathrm{H}}\right)$ (ROSEMOUNT, 2009), que se abre para o alto da câmara de pressão. Esta câmara de alta pressão se conecta diretamente à tomada de pressão alta do transmissor. A referência de pressão baixa $\left(\mathrm{P}_{\mathrm{L}}\right)$ é obtida por perfurações na região traseira do sensor e se conecta diretamente à tomada de pressão baixa do transmissor. Além disso, possui um poço para inserir o sensor de temperatura PT100 para compensar a variação de temperatura no interior da tubulação, pois, a densidade $(\rho)$ do fluido depende da temperatura a qual é submetido (ROSEMOUNT, 2009).

\subsection{Interface IO-Link}

O IO-Link é um dispositivo de conexão ponto-a-ponto serial e bidirecional para transmissão de sinal e suprimento de energia sob quaisquer redes ou barramentos de backplane (COMMUNITY, 2013).

O IO-link consiste nos seguintes componentes básicos:

- Mestre IO-Link;

- Dispositivo IO-Link;

- Cabo sem blindagem de 3 ou 5 vias; 
- Ferramenta de engenharia para configuração dos parâmetros de rede.

Na figura 12 temos o exemplo de uma topologia IO-link com 3 mestres IO-Link em campo e 8 dispositivos IO-Link trocando informações com os mestres da rede.

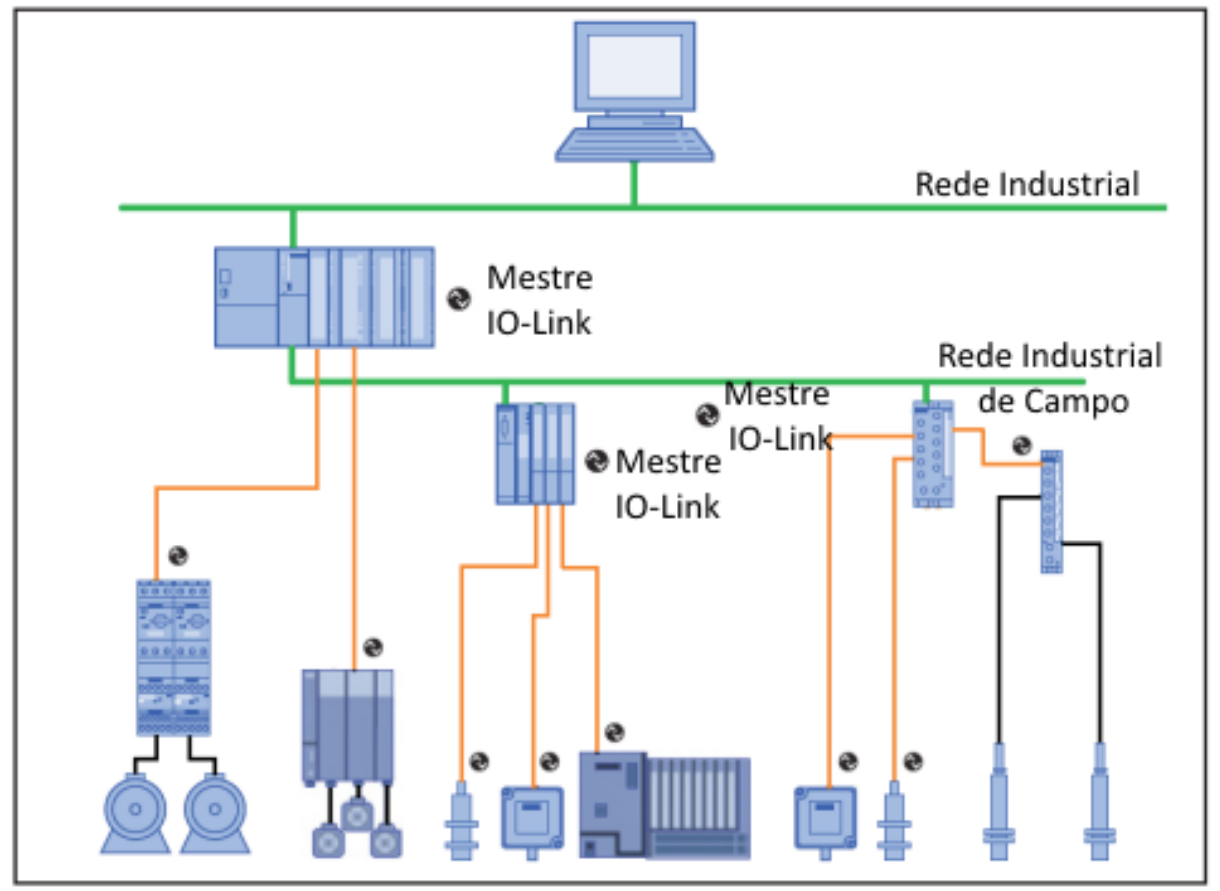

Figura 12 - Topologia da rede IO-Link.

Fonte: Adaptação, tradução do autor dos itens de identificação da figura (COMMUNITY, 2013)

\subsubsection{Conexão}

A conexão entre os dispositivos com essa tecnologia possui diversas possibilidades, dentre elas, via conector M12, pois, o sensor possui 4 terminais de ligação e atuadores possuem 5 terminais de ligação. Os mestres IO-link possuem um Socket de conexão M12 com 5 pinos para conectar os dispositivos de campo (COMMUNITY, 2013).

Na figura 13 temos uma representação geral de ligação dos dispositivos IO-Link, a qual, apresenta os terminais de alimentação da rede que é provida pelos canais 1 e 3 , e o canal 4 provê as informações de leitura de I/O e os pacotes da rede IO-Link. 


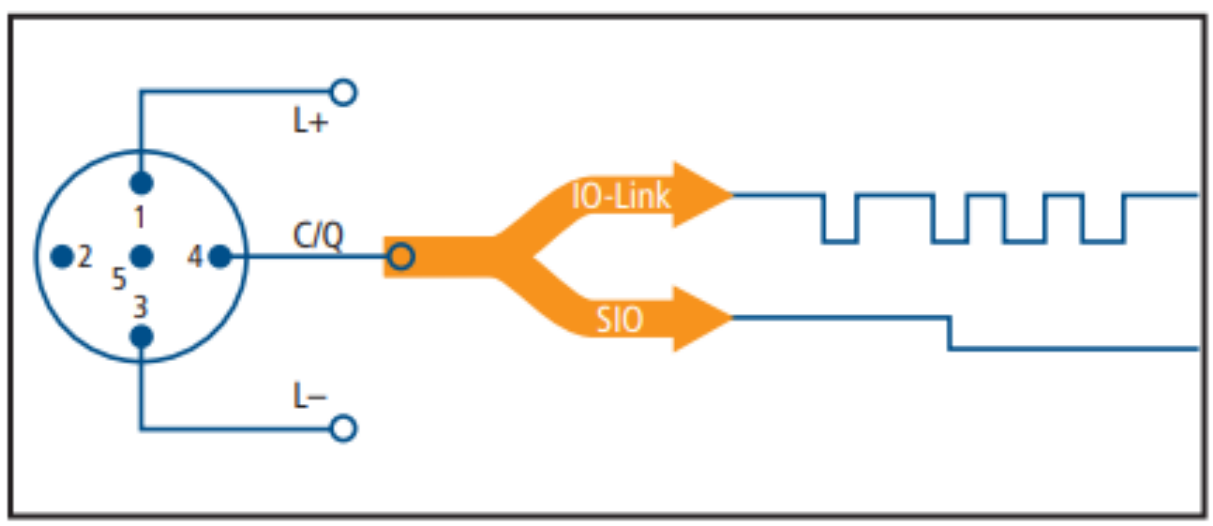

Figura 13 - Pinos de conexão IO-Link.

Fonte: Adaptação, tradução do autor dos itens de identificação da figura (COMMUNITY, 2013)

\subsection{Controlador Lógico Programável}

O Controlador Lógico Programável (CLP) é um uma forma especial de controlador microprocessado, que utiliza uma memória de programa para armazenar instruções e implementar funções lógicas, sequenciais, temporais, contadores e aritméticas, com objetivo de controlar máquinas e processos. Na figura 14 é apresentado o diagrama de funcionamento do CLP (BOLTON, 2006).

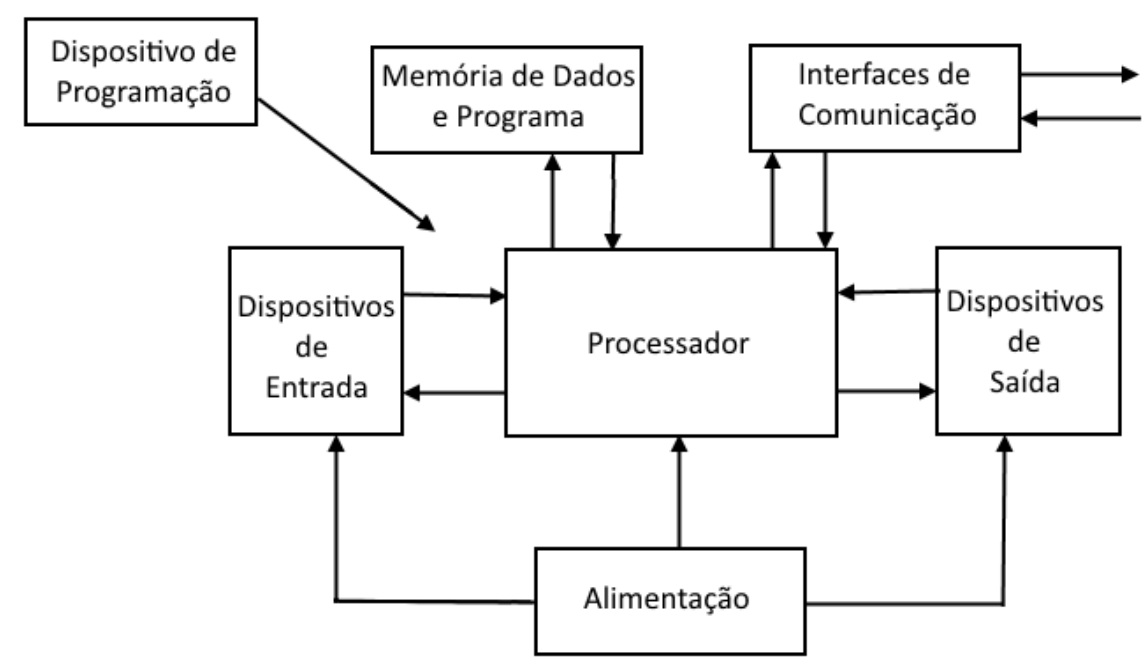

Figura 14 - Diagrama de funcionamento do CLP.

Fonte: Adaptação, tradução do autor dos itens de identificação da figura (BOLTON, 2006) 
Conforme descrito na figura 14 temos o diagrama de funcionamento do CLP, o qual (BOLTON, 2006):

- Dispositivo de Programação: Computador com sistema de programação do CLP;

- Memória de dados e de programa: Local de armazenamento das instruções do programa, o qual, o processador acessa para consultar e armazenar informações de controle;

- Interfaces de comunicação: Dispositivos integrados ao CLP para que ele possa se comunicar com periféricos, como inversores e outros CLPs.

- Dispositivos de Entrada: Sensores, IHM's, botoeiras que enviam informações ao CLP para tomadas de decisões;

- Dispositivos de saída: Sinalizações e atuadores, cujo, o sistema indica e atua de acordo com os parâmetros pré-estabelecidos.

- Processador: Responsável pelo controle, verifica as informações de entrada, processa e atua, de acordo com o controle, através dos dispositivos de saída.

O CLP deve ser selecionado de acordo com o nível de complexidade de sua aplicação (SIEMENS, 2016).

Na figura 15 é apresentado um exemplo (das linhas de CLPs da fabricante SIEMENS), que relaciona sua utilização de acordo com sua performance e nível de complexidade do sistema em que será aplicado.

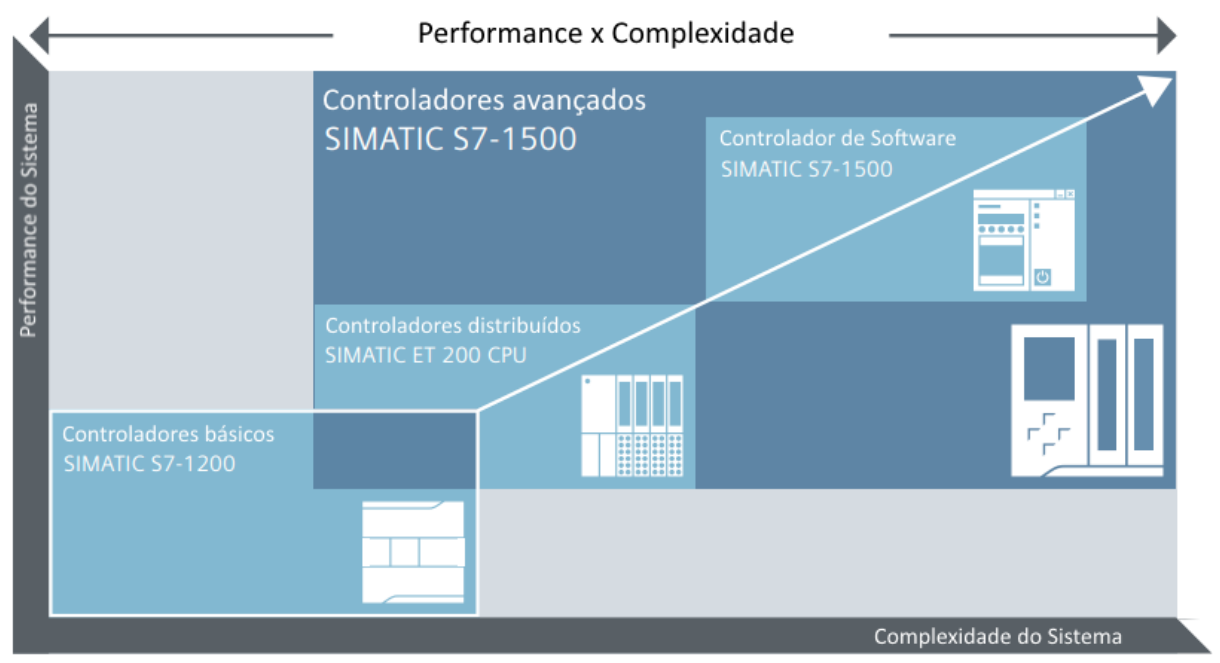

Figura 15 - Relação Performance x Complexidade CLP SIEMENS.

Fonte: Adaptação, tradução do autor dos itens de identificação da figura (SIEMENS, 2016) 


\subsection{Banco de dados}

Informações relevantes de processos são armazenados em banco de dados, que nada mais é do que um conjunto de dados que podem ser relacionados entre si. O banco de dados é formado por um conjunto de tabelas que podem se relacionar ou não, porém, torna o acesso a seus conteúdos de forma rápida e precisa, não importando a quantidade de informações armazenadas, pois, caso esteja bem estruturado o acesso a informação se torna quase que imediado (DATE, 2013) (SILBERSCHATZ; KORTH; SUDARSHAN, 2011).

\subsubsection{Banco de dados Relacional}

O modelo relacional é um dos principais modelos de dados para aplicativos comerciais de processamento de dados. Isso, devido sua simplicidade, que acaba por facilitar o trabalho de programadores em comparação com modelos de dados existentes até então, como o modelo de rede ou o modelo hierárquico (SILBERSCHATZ; KORTH; SUDARSHAN, 2011).

Um banco de dados relacional consiste em uma coleção de tabelas, onde são atribuídos nomes únicos. Como por exemplo uma tabela de usuário e endereços, as quais, os endereços possam se relacionar para vários usuários, por meio, de uma chave ID (SILBERSCHATZ; KORTH; SUDARSHAN, 2011).

Na figura 16 temos o exemplo de uma arquitetura de banco de dados em uma rede local, a qual, a aplicação alocada nos computadores acessam a rede para consultar, alterar e armazenar informações no banco de dados. 


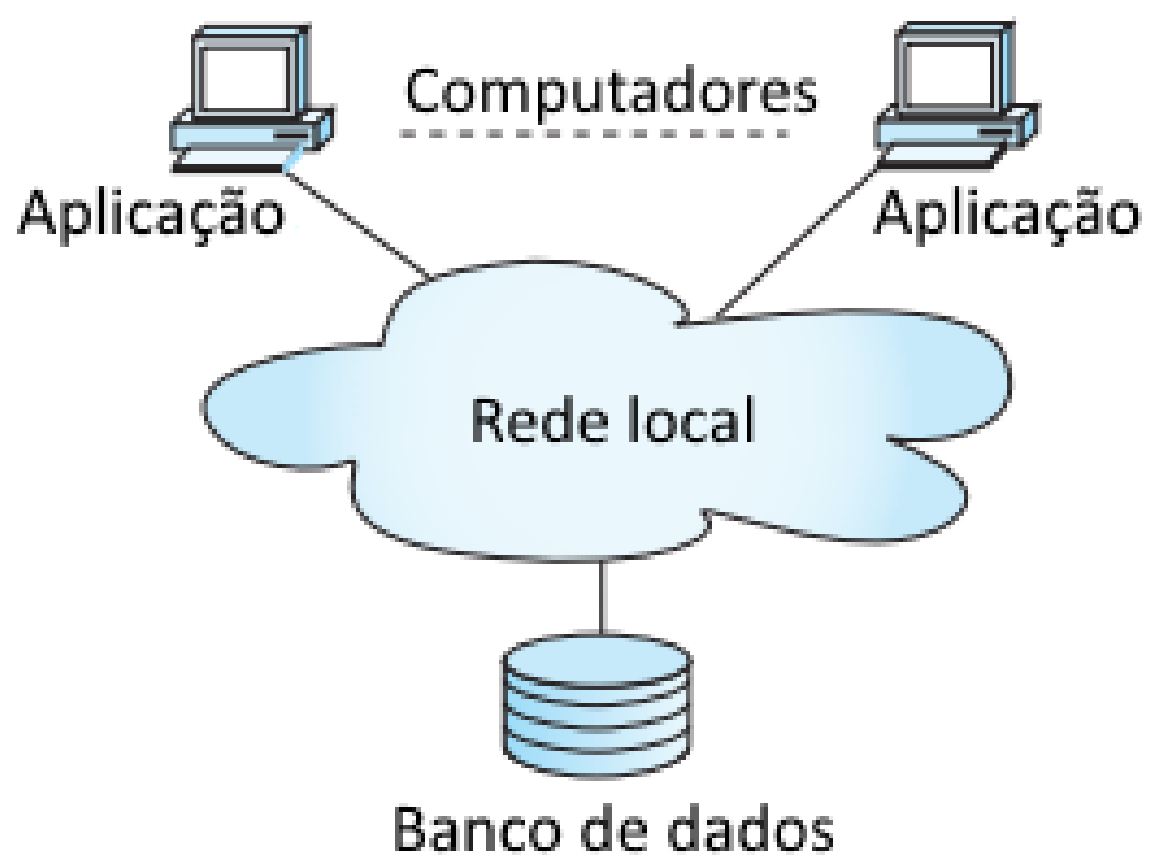

Figura 16 - Banco de dados em rede local.

Fonte: Adaptação, tradução do autor dos itens de identificação da figura (SILBERSCHATZ; KORTH; SUDARSHAN, 2011)

Como banco de dados relacionais podemos citar, Microsoft SQL Server, Oracle, $M y S Q L$, PostgreSQL, entre outros.

\subsubsection{Banco de dados não relacional}

Bancos de dados não relacionais permitem armazenar e recuperar dados não estruturados usando um esquema dinâmico. O NoSQL é popularmente usado por sua capacidade flexível de criar uma estrutura exclusiva e pode ser documento, gráfico, coluna ou mesmo chave organizado como uma estrutura de dados (SCALEGRID, 2019).

O $S Q L$ tem uma grande vantagem sobre as alternativas não relacionais há décadas, mas o NoSQL está rapidamente diminuindo a diferença com bancos de dados populares, como MongoDB, Redis e Cassandra. Embora muitas organizações optem por migrar de bancos de dados herdados, como o Oracle, nem todas estão migrando para o NoSQL (SCALEGRID, 2019). 
4.6.3 Banco de dados existentes

Existem diversos tipos de bancos de dados disponíveis no mercado, sejam eles relacionais, ou não relacionais. Os bancos de dados relacionais ainda se encontram a frente dos bancos de dados não relacionais, como podemos verificar no ranking $D B$-Engines, que é um relatório de popularidade da tendência de uso de banco de dados no mercado. No gráfico 1 é apresentado o ranking de popularidade dos bancos de dados em 2019, tendo o Oracle como o primeiro colocado, seguido pelo mySQL e pelo Microsoft SQL Server.

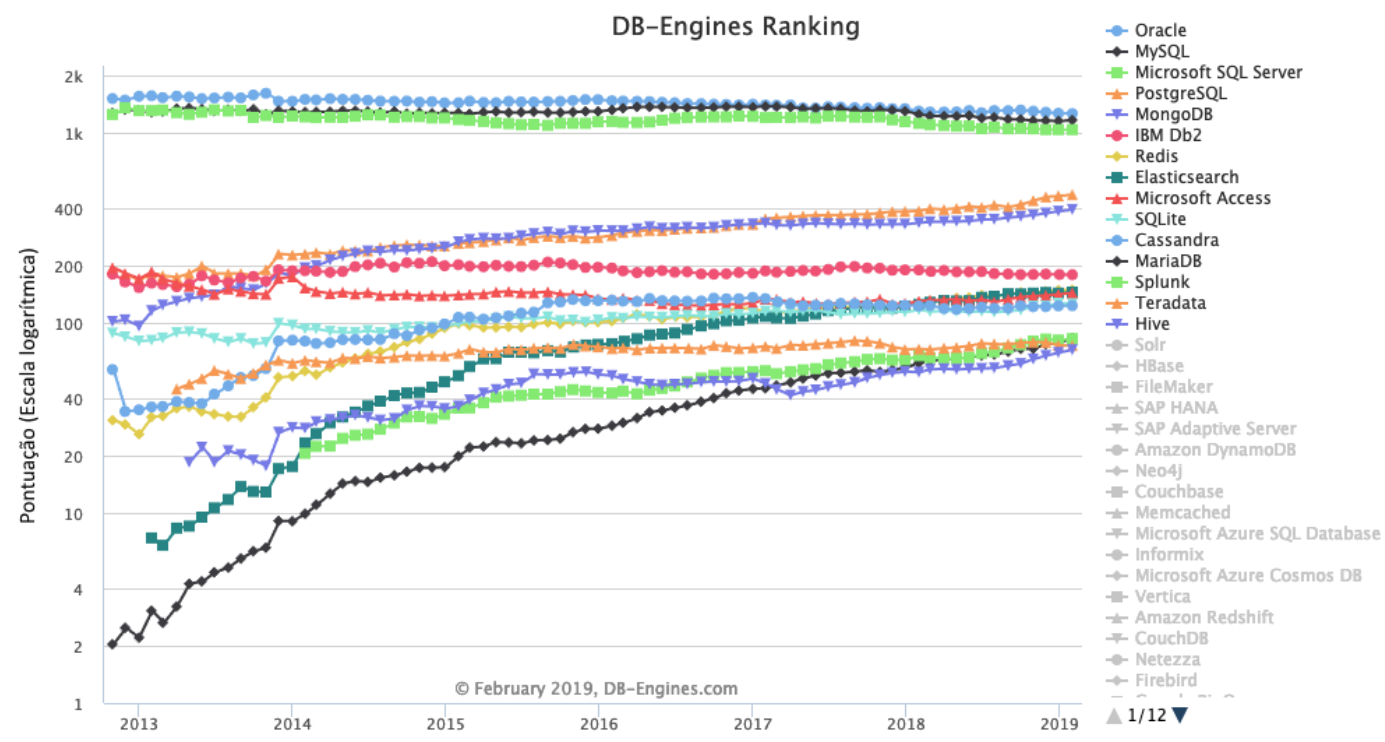

Gráfico 1 - Tendência dos bancos de dados mais populares.

Fonte: Adaptação, tradução do autor dos itens de identificação do gráfico (SCALEGRID, 2019) 


\section{MATERIAIS E MÉTODOS}

O desenvolvimento do projeto ocorreu da seguinte maneira:

- Desenvolvimento e montagem do túnel de vento;

- Implementação da instrumentação de medição e controle;

- Testes nos modelos PSP.

\subsection{Componentes do túnel de vento}

O túnel de vento subsônico em circuito aberto é composto de 5 partes principais: Cone de contração, câmara de ajuste, seção de teste, difusor, câmara de ventilação com motor de velocidade variável (BENSON, 2014) (SPAHN; STEELMAN, 2015).

- Cone de contração - Este módulo do túnel é a parte onde é coletado o fluxo de ar a baixa velocidade e durante a diminuição da área ocorre um aumento na velocidade;

- Câmara de Ajuste - Possui a função de laminar o fluxo de ar, ou seja, diminuir a turbulência;

- Seção de Teste - É o compartimento, no qual, será alocado o objeto cujo testes aerodinâmicos serão efetuados;

- Difusor - Tem por função eliminar qualquer turbulência de ar que possa voltar para a câmara e influenciar negativamente o teste, além disso, diminui a velocidade de ar que segue para a câmara de ventilação.

- Câmara de Ventilação - Local onde é alocado a turbina para controlar a velocidade do vento dentro do túnel de vento.

\subsubsection{Simulações}

Antes de efetuar a implementação do túnel de vento, simulações foram realizadas fazendo uso do software COMSOL Multiphysics. O total de três simulações foram geradas, sendo uma com o túnel em formato retangular, que é o formato dos principais túneis de vento levantado na bibliografia pesquisada, e outros 2 em formatos cilíndricos. As primeiras simulações, foram geradas para velocidades de cerca de $200 \mathrm{~km} \mathrm{~h}^{-1}$ no interior da seção de testes, porém, o motor utilizado foi aquém do necessário para atingir tais velocidades. 
Portanto, devido as limitações no sistema de ventilação, e para obter resultados próximo do túnel desenvolvido, um valor de fluxo laminar de entrada de $1,5 \mathrm{~ms}^{-1}$ foi definido para as simulações. A primeira simulação gerada foi do túnel com dimensões retangulares, na figura 17 é apresentado o túnel com sessão de teste com dimensões de 300 x 300 mm de diâmetro. Na simulação é possível verificar a distribuição de velocidade no interior do túnel de vento durante a primeira simulação. Verificamos que nas regiões das bordas da seção de teste a velocidade é baixa, devido a uma situação conhecida como camada limite (boundary layers), nessa região a velocidade tende a zero (HERNANDEZ et al., 2013) (DOMMELEN, 2013).

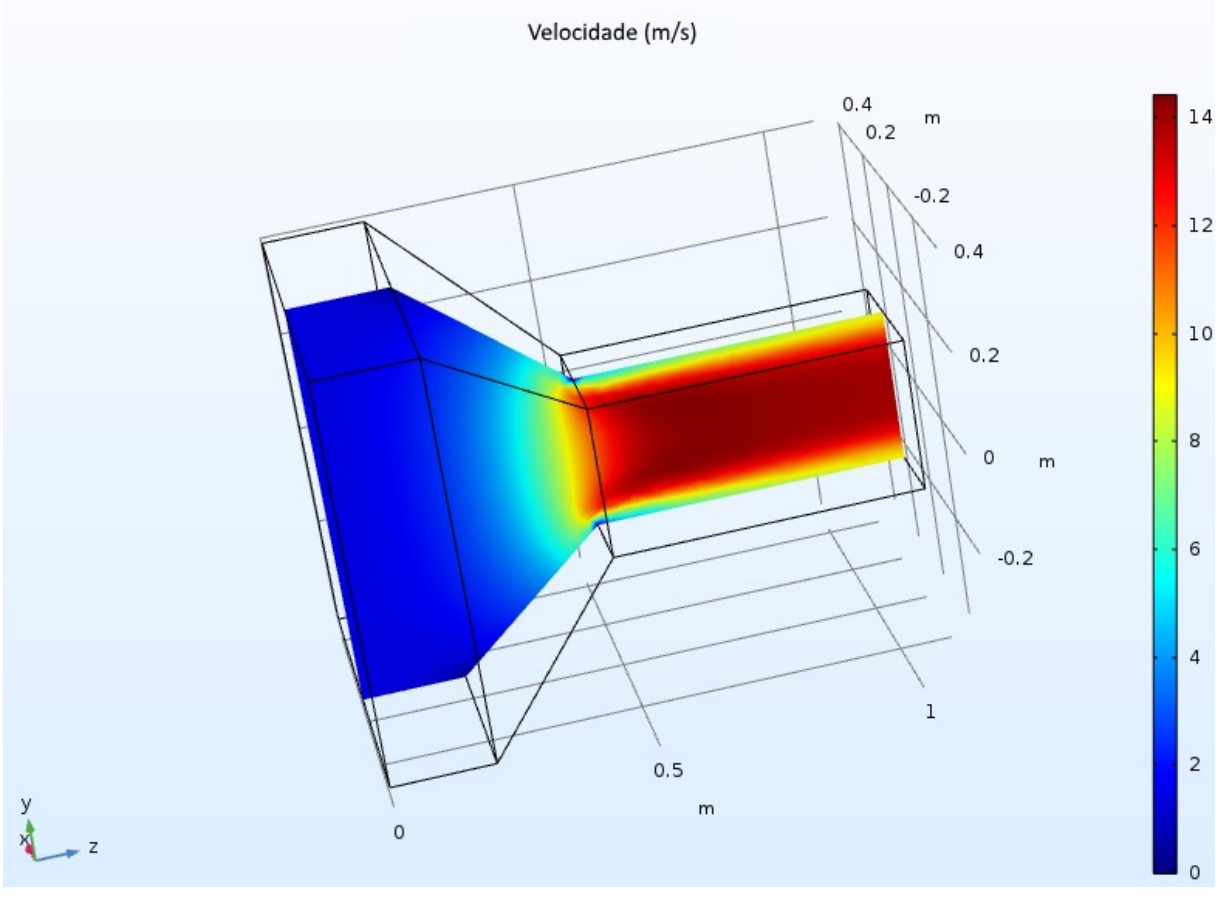

Figura 17 - Simulação do túnel com seção de teste de 300x300 mm.

Fonte: Autor

Na entrada da seção de testes, na região central percebemos um aumento considerável da velocidade em torno de $14 \mathrm{~m} \mathrm{~s}^{-1}$ que pode ser calculado fazendo uso da equação 4, tratado na seção 4.1.2. Além disso, no limiar da saída do cone de contração com a entrada da seção de testes vemos um aumento na velocidade no interior do túnel, conforme demonstrado pela equação 1. Porém, a velocidade de saída de $14 \mathrm{~m} \mathrm{~s}^{-1}\left(50,4 \mathrm{~km} \mathrm{~h}^{-1}\right)$ está aquém da velocidade mínima desejada, que seria acima de $30 \mathrm{~m} \mathrm{~s}^{-1}$.

Na segunda simulação foi decidido por alterar o design do túnel para um formato tubular e, dessa forma, verificar melhorias em relação à dinâmica da velocidade no interior 
do túnel. O diâmetro da seção de testes deste túnel é de $200 \mathrm{~mm}$. Na figura 18 temos os resultados da segunda simulação, onde percebe-se que a velocidade máxima no interior da seção de teste superou os valores de $30 \mathrm{~m} \mathrm{~s}^{-1}$. Lembrando que esse valor é apresentado logo após a entrada na seção de teste, na região central da seção de testes a velocidade se mantém superir a $27 \mathrm{~m} \mathrm{~s}^{-1}$. Os resultados deste modelo de túnel superaram em pelo menos 2 vezes os resultados obtidos na primeira simulação.

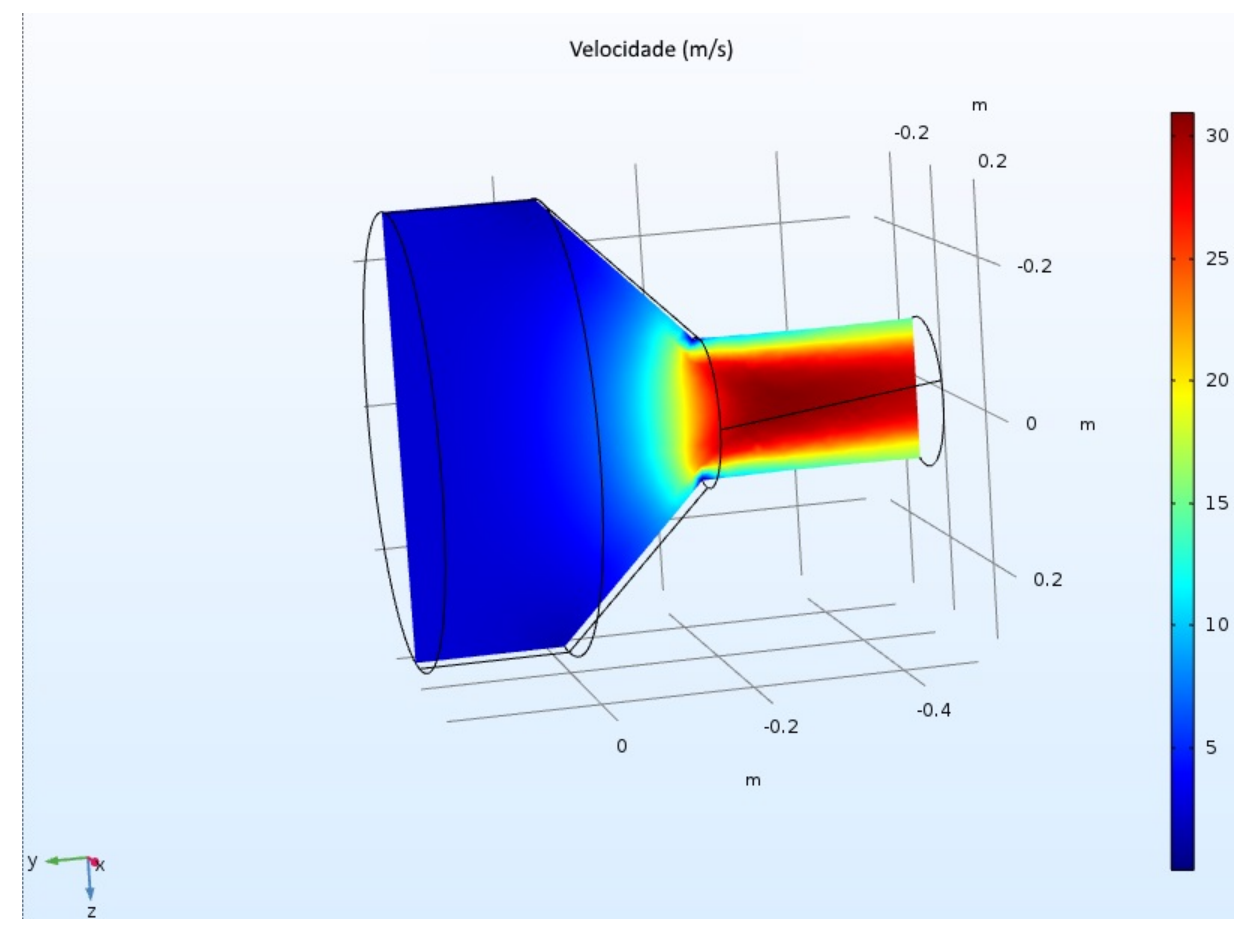

Figura 18 - Simulação do túnel com seção de teste de $200 \mathrm{~mm}$.

\section{Fonte: Autor}

Na terceira e última simulação foi realizada a simulação do túnel com seção de teste com diâmetro de $150 \mathrm{~mm}$, que é apresentado na figura 19, nela podemos verificar que a velocidade atingiu valores ligeiramente superiores às atingidas durante a simulação anterior, cerca de $35 \mathrm{~m} \mathrm{~s}^{-1}$. Além disso, como suas dimensões são menores, podemos verificar que a velocidade começa a diminuir a partir da metade da seção de testes. Essa situação ocorre, pois, quanto menor a contração do túnel maior será a perda de carga (DELMEE, 2003). 


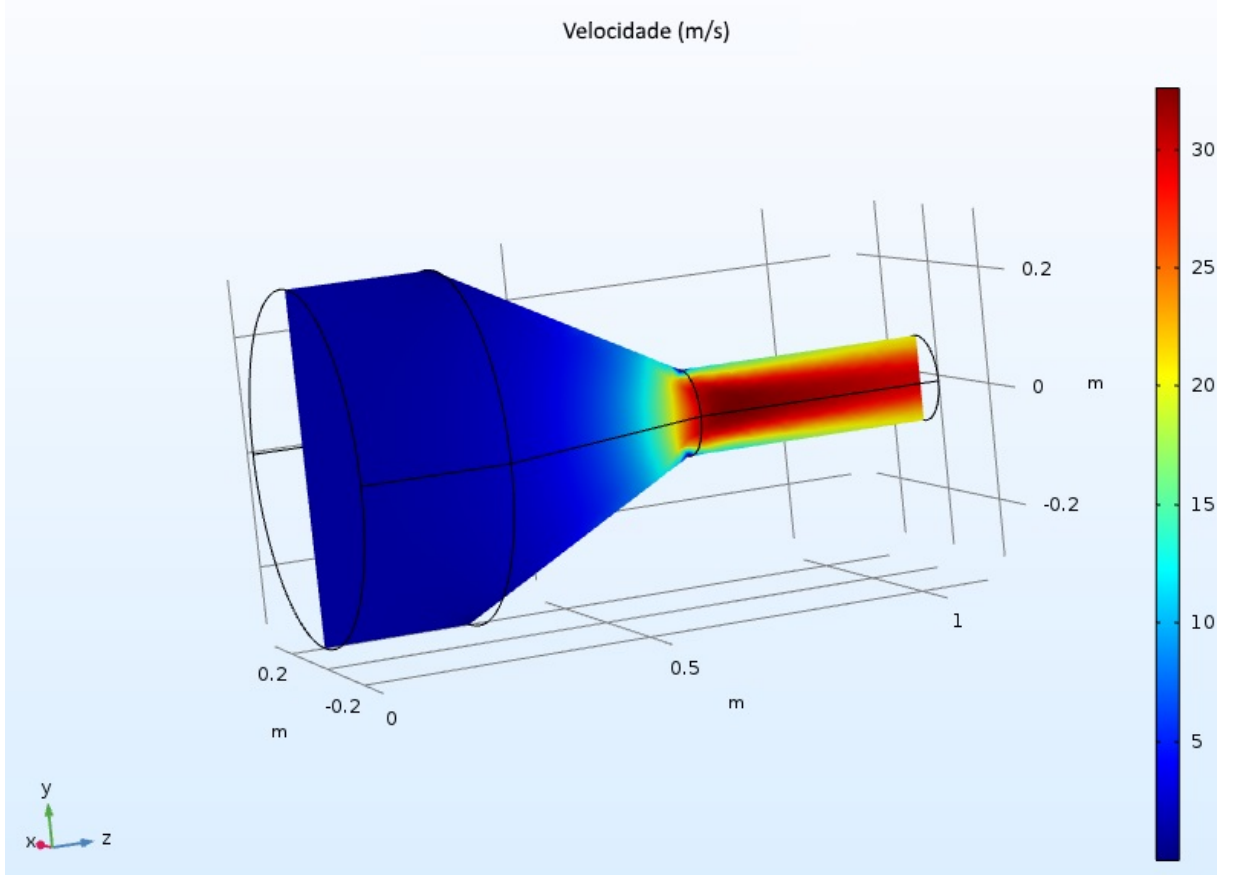

Figura 19 - Simulação do túnel com seção de teste de 150 mm.

\section{Fonte: Autor}

Mesmo que a simulação com um túnel menor fosse efetuada, além da perda de carga, estaríamos limitados pela instrumentação, um dos instrumentos de medição da velocidade do vento, o Annubar é para tubulações de no mínimo $150 \mathrm{~mm}$ de diâmetro.

Portanto, o túnel apresentado na figura 19 foi o ideal para realizar a montagem física para os testes.

\subsubsection{Montagem do túnel}

Conforme discutido na seção 5.1.1 o formato e dimensões do túnel construído foi idealizado a partir dos resultados obtidos na terceira simulação. Como o túnel será no formato cilíndrico ele foi montado a partir de folhas de chapas galvanizadas e fixadas com rebites.

\subsubsection{Túnel de contração}

A razão da área de entrada do túnel para a saída do túnel de contração é de suma importância (BENSON, 2014), pois, caso se utilize de valores abaixo de 6, haverá uma 
excessiva perda de pressão. Portanto, a razão da área de entrada do cone de contração para a saída para o túnel proposto foi de 16 (ARIFUZZAMAN, 2012), conforme apresentado na equação 9 .

$$
\frac{A 1\left(m m^{2}\right)}{A 2\left(m m^{2}\right)}=16
$$

Porém, uma das especificações citadas por Arifuzzaman (2012) acabou não sendo seguida, a qual, orienta que o comprimento do túnel de contração deve variar entre 0,15 e 1 vezes o raio de entrada do túnel de contração para minimizar a turbulência na seção de testes. Pois, em nosso caso o comprimento é de $500 \mathrm{~mm}$ que é superior a faixa recomendada. Esse fato ocorreu devido as dificuldades de diminuir esse comprimento, já que o tubo de contração foi dobrado de forma manual e fixado com rebites.

\subsubsection{Seção de Teste}

Para a seção de teste recomenda-se que seu comprimento seja em torno de 0,5 à 3 vezes o diâmetro hidráulico da seção, isso é necessário para que a saída da vazão de ar seja aproximadamente uniforme, dessa forma, quanto maior for o comprimento da seção de teste, pode haver um incremento na camada limite (boundary layer), ou seja, regiões a qual, a velocidade é diminuída, causando com isso, velocidades não uniformes na saída da seção de teste, devido diferentes velocidades causadas pelo incremento da camada limite. Para o presente projeto a relação comprimento x diâmetro hidráulico foi de aproximadamente 3 (ARIFUZZAMAN, 2012). Essa relação foi escolhida devido as pequenas dimensões da seção de testes, problemas para a instalação da instrumentação de medição poderiam ser encontrados, além de possíveis dificuldades para instalar as janelas de inspeção do $P S P$ poderiam ser enfrentadas.

\subsubsection{Montagem}

Na figura 20 temos as dimensões do túnel de vento desenvolvido. O túnel possui formato cônico e montado em folhas de chapa galvanizada, como discutido anteriormente. 


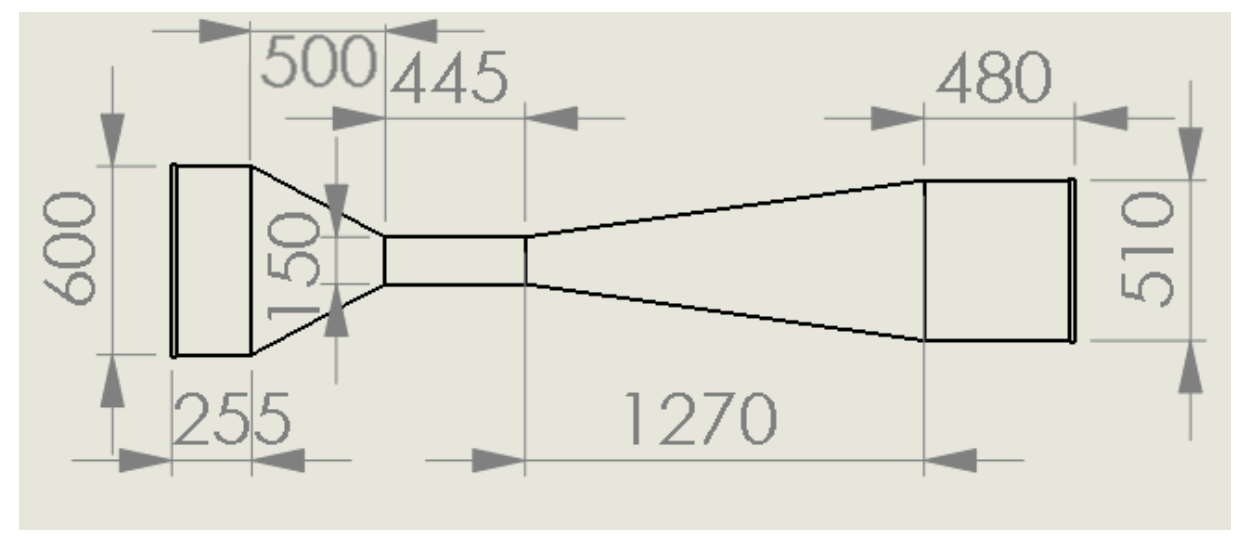

Figura 20 - Dimensões do túnel de vento desenvolvido em mm.

Fonte: Autor

As junções das partes do túnel devem possuir conexões arredondadas (HERNANDEZ et al., 2013), afim de diminuir a turbulência em que o túnel pode ser submetido. Porém, devido dificuldades construtivas, neste modelo as partes do túnel foram unidas por meio de pequenas bordas retas e rebitadas. Portanto, o formato das juntas do túnel apresentam partes retas, conforme apresentado na figura 20.

O difusor possui a função de diminuir a velocidade do vento após a saída da seção de teste até a câmara de ventilação, ou seja, quanto mais longo o comprimento do difusor menor a velocidade na câmara de ventilação (ARIFUZZAMAN, 2012), no caso, o comprimento do difusor é de $1270 \mathrm{~mm}$.

O motor e o ventilador foram instalados na câmara de ventilação. Possui dimensões de $480 \mathrm{~mm}$ de comprimento por $510 \mathrm{~mm}$ de diâmetro, esses valores foram definidos de acordo com dimensões do motor e ventilador disponíveis. Como foram adquiridos em sucata, a câmara de ventilação foi montada nas dimensões mínimas possíveis para alocar o ventilador em seu interior. Essa parte do túnel foi dimensionado de acordo com o material disponível, devido as dificuldades de se conseguir outro ventilador em outras dimensões.

Na figura 21 é apresentado o sistema motor X ventilador, com as barras de fixação no interior do túnel. O motor foi fixado em uma estrutura feita com barras Metalon de 40mm x 40mm de espessura, pelo fato do sistema conter partes móveis e estar submetido a grandes vibrações. Essa é uma das partes que exige segurança na hora de operação do motor, pois, caso seja mal fixado o ventilador pode soltar e causar um acidente. 


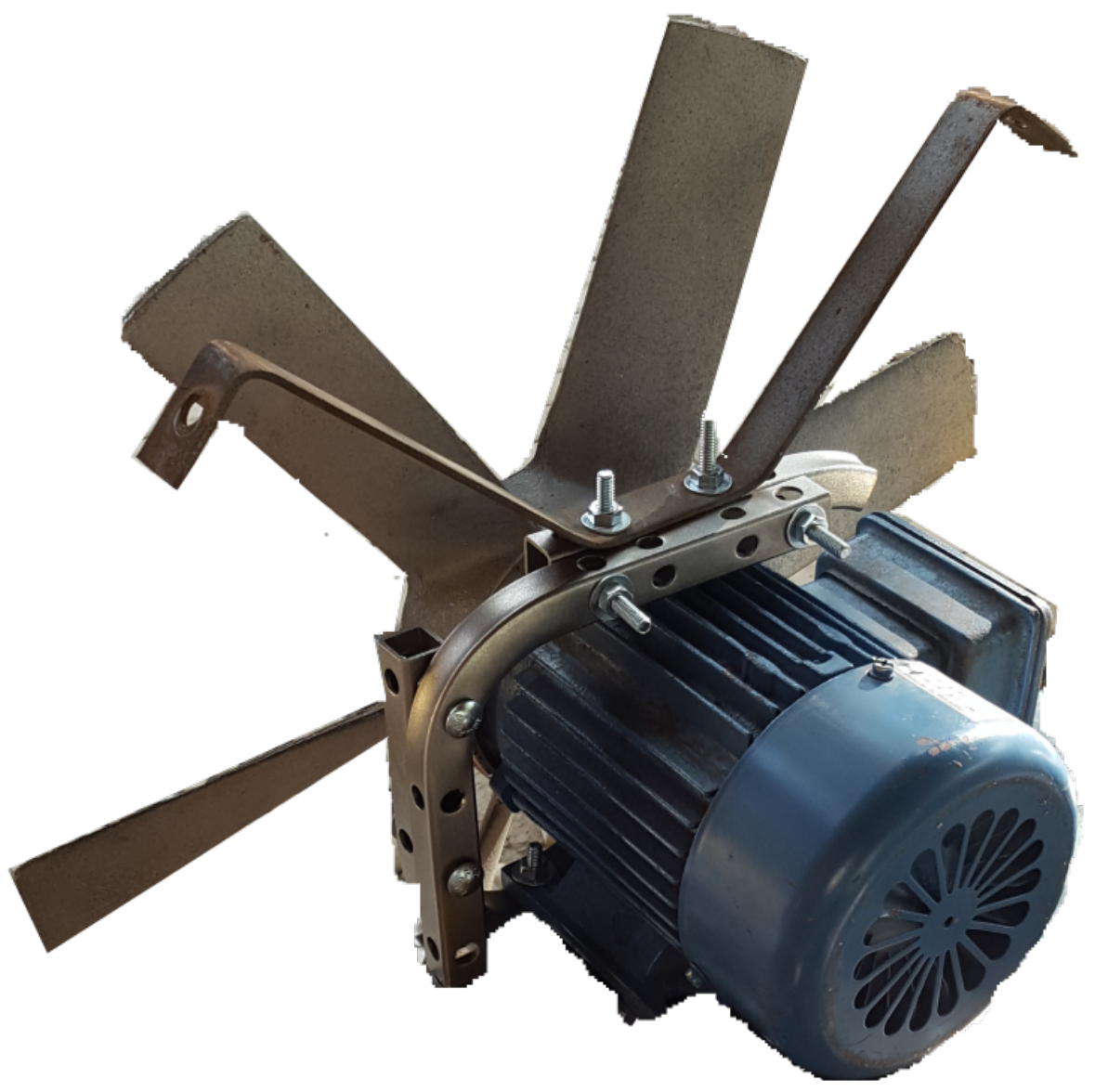

Figura 21 - Sistema de ventilação.

Fonte: Autor

\subsubsection{Sistema de medição e controle}

Assim que as dimensões do túnel foram definidas, a malha de controle e um diagrama de blocos foram elaborados para representar o sistema de controle. Na figura 22 é apresentado o diagrama de blocos do controle do processo. 


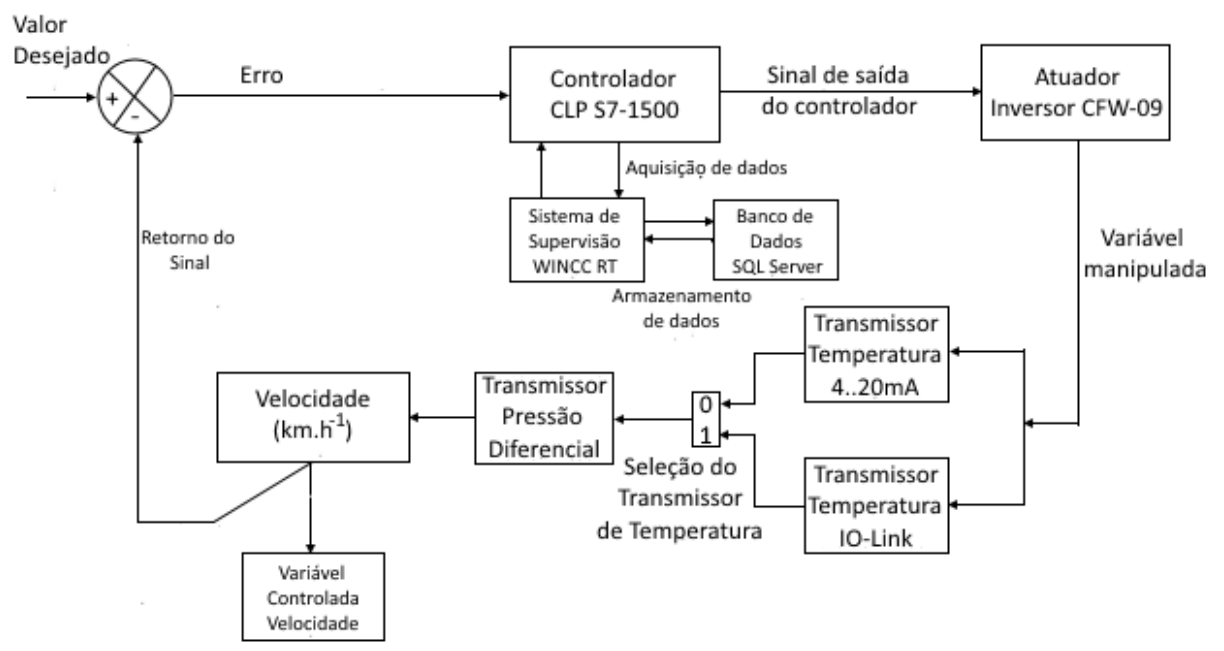

Figura 22 - Diagrama de blocos do controle em malha fechada.

Fonte: Autor

Conforme apresentado na figura 22 o sistema é alimentado com o Valor desejado, variável conhecida como Setpoint, o valor é comparado com o retorno do sinal, que irá retornar um erro, o qual, o CLP irá processar a informação, apresentar na tela de supervisão e armazenar os dados em uma base de dados $S Q L$ Server, após processar a informação o CLP irá enviar um sinal ao atuador, no caso, um inversor de frequência que irá aumentar ou diminuir a velocidade do motor, dependendo do erro do sistema. No sistema de supervisão deve ser selecionado qual o transmissor de temperatura que estará sendo utilizado para o cálculo da velocidade, se o transmissor $4 . .20 \mathrm{~mA}$ ou transmissor IO-Link. Após isso, o sistema verifica o diferencial de pressão e efetua o cálculo da velocidade $\mathrm{em}_{\mathrm{km} \mathrm{h}}^{-1}$, apresenta o valor na tela de supervisão e envia o retorno de sinal ao comparador para efetuar as devidas correções do sistema. Esse controle é conhecido como sistema em malha fechada (GARCIA, 2005).

Além disso, o diagrama P\&ID da malha de controle foi desenvolvido seguindo a norma ISA 5.01-2009 (ISA, 2009), conforme apresentado na figura 23. 


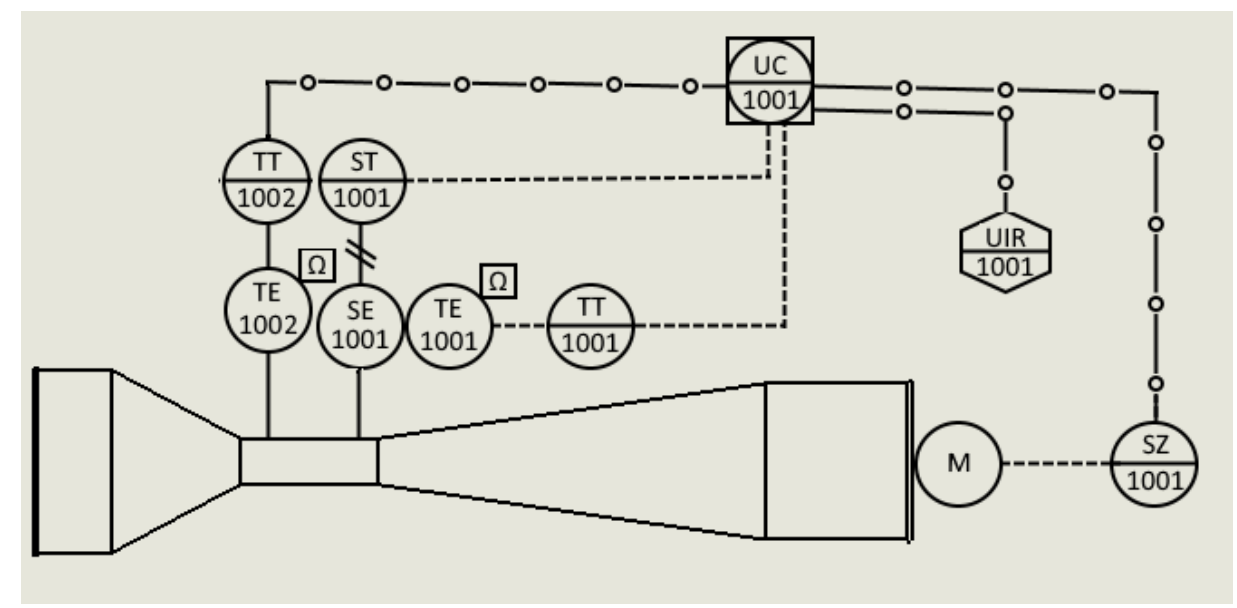

Figura 23 - Diagrama P\&ID da malha de controle do sistema.

Fonte: Autor

O sistema de controle descrito na figura 23 apresentam as abreviaturas da instrumentação seguindo o padrão inglês conforme descrito na norma (ISA, 2009). O significado das siglas está descrito a seguir:

- ST-1001 (Speed Transmitter): Transmissor de Velocidade. Esse transmissor é um transmissor de pressão diferencial, porém, sua função na malha é enviar o sinal diferencial de pressão para calcular a velocidade no interior da seção de teste;

- SE-1001 (Speed Sensor): Sensor de Velocidade. Este é o tubo de Pitot ou o Annubar que envia o diferencial de pressão para para o transmissor que, por sua vez, envia ao controlador;

- TT-1001 (Temperature Transmitter): Transmissor de Temperatura. Verifica a temperatura enviada pelo sensor de temperatura e envia um sinal 4 a $20 \mathrm{~mA}$ ao controlador, referente a temperatura do sistema;

- TE-1001 (Temperature Sensor - PT100): Sensor de Temperatura RTD(PT100). Esse sensor de temperatura é acoplado no Annubar, é utilizado para compensar a velocidade de acordo com a variação da temperatura;

- TT-1002 (Temperature Transmitter): Transmissor de Temperatura IO-Link. Este é o transmissor de temperatura com comunicação digital IO-Link, para captar a temperatura na seção de teste quando não está sendo utilizado o Annubar. Foi selecionado devido a inovação tecnológica a nível do transmissor;

- TE-1002 (Tempeature Sensor): Sensor de Temperatura acoplado ao transmissor IO-Link; 
- SZ-1001 (Speed Actuator): Atuador de Velocidade. Este é o inversor de frequência que recebe um sinal do controlador, aumentando ou diminuindo a velocidade do motor, de acordo com o sistema de controle;

- $M$ (Motor): Motor do ventilador. Gera o fluxo de ar no interior do túnel;

- UIR-1001 (Multivariable Indicator and Register): Indicador e Registrador Multivariável. É o sistema de supervisão que coleta os dados e armazena em uma base de dados SQL Server;

- UC-1001 (Multivariable Controller): Controlador Multivariável. Esse é o CLP S71500 que capta as informações de medição do processo, efetua os cálculos de controle e atualiza a saída para manter o controle da velocidade desejada.

\subsubsection{Instrumentação selecionada}

A seguir são apresentados os instrumentos para medição e controle do sistema.

\subsubsection{Annubar}

O Annubar é um elemento de medição de vazão secundário, utilizado para medição de velocidade de gases em tubulações industriais, além de ser dotado de um poço com um sensor de temperatura RTD para efetuar a compensação da velocidade do fluxo. Na figura 24 é apresentado o Annubar Rosemount 485 de $150 \mathrm{~mm}$, utilizado para medição de vazão em tubulações de 150 mm (ROSEMOUNT, 2009). 


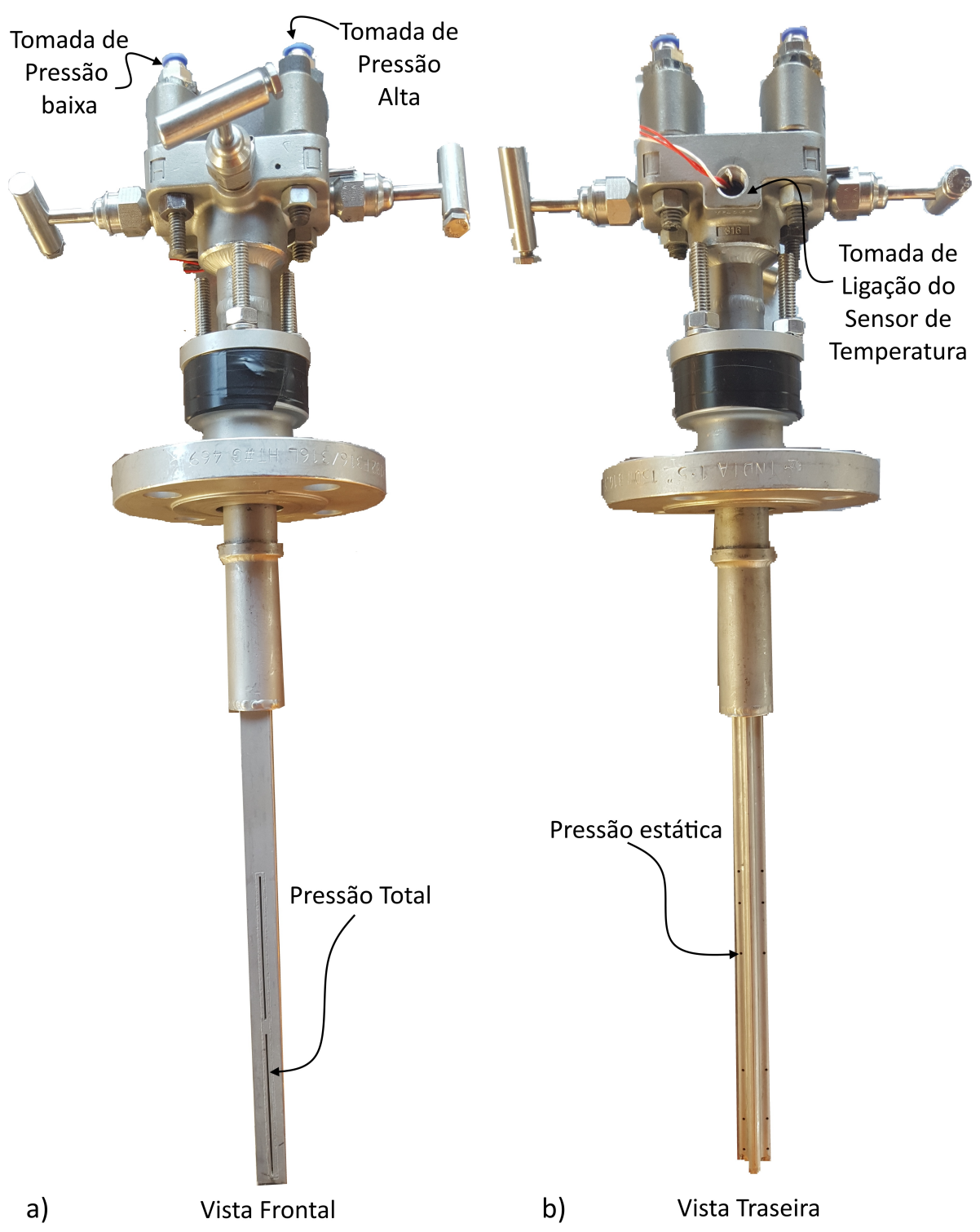

Figura 24 - Annubar utilizado. a) Vista frontal; b) Vista traseira

Fonte: Autor

Conforme apresentado na figura 24 a) o Annubar é dotado de duas tomadas de alta e baixa pressão, para que seja possível medir a pressão diferencial a qual ele é submetido, também pode ser visto a área sensora de pressão dinâmica. Na figura 24 b) é possível ver a tomada de ligação do sensor de temperatura e a área sensora de pressão estática.

Como o Annubar é um dispositivo de medição de velocidade média no interior da tubulação, seu $\Delta \mathrm{P}$ será superior a de um tubo de Pitot hemisférico, portanto, é necessário um fator K para correção, o qual, foi utilizado um tubo de Pitot hemisférico para encontrar o fator K, para correção da velocidade (DELMEE, 2003). 


\subsubsection{Tubo de Pitot}

Para obter o fator de correção K do Annubar foi selecionado um tubo de Pitot do tipo L com ponta hemisférica, também utilizado para medição de vazão em tubulações industriais. O modelo do tubo de Pitot é PT6300 304 STAINLESS STEEL 300mm X 110mm, com precisão (Fator K) entre 0,998 e 1,001 (+/- 0,1\%) (PERFECT PRIME, 2018). Na figura 25 é apresentado o tubo de Pitot tipo L utilizado na aplicação apresentada.

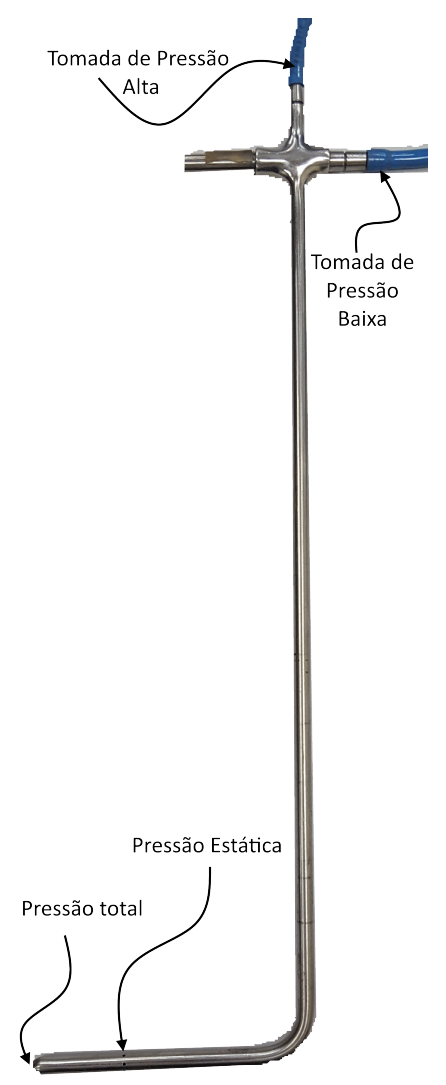

Figura 25 - Tubo de Pitot com ponta hemisférica.

Fonte: Autor

\subsubsection{Transmissor de Pressão}

Para efetuar a medição de pressão diferencial tanto do Annubar quanto do tubo de Pitot foi selecionado um transmissor de pressão Rosemount 2051, conforme apresentado na figura 26. 


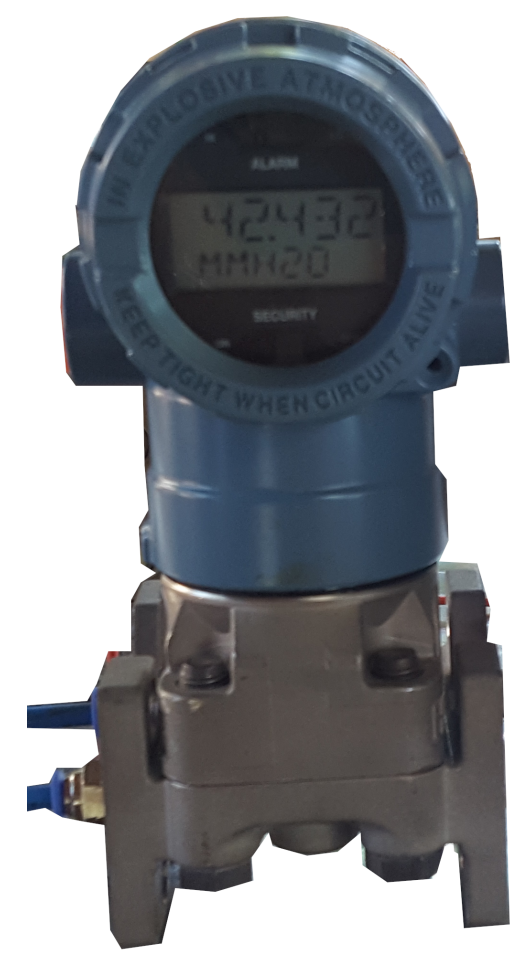

Figura 26 - Transmissor de pressão Rosemount 2051.

\section{Fonte: Autor}

Na figura 26 é apresentado o transmissor de pressão diferencial, o qual, possui uma tomada de pressão baixa e outra de alta, para conexão do sensor de velocidade, o sinal de saída é de 4 a 20 mA. Foi ajustado para um diferencial de pressão de 0 a 14,7 mbar, por meio de um configurador HART 475 da Emerson.

As especificações do transmissor de pressão diferencial são:

- modelo: 2051CG2A02A1AH2BAL4M5DFQ4;

- Calibração de fábrica: 0 a 50 mbar;

- Sinal de saída: 4 a 20 mA HART.

\subsubsection{Controlador Lógico Programável}

O CLP selecionado foi o S7-1512C da linha 1500 da Siemens, utilizado para aplicações de alta performance na indústria (SIEMENS, 2016).

Na figura 27 temos a imagem do CLP S7-1500 utilizado no presente projeto. 


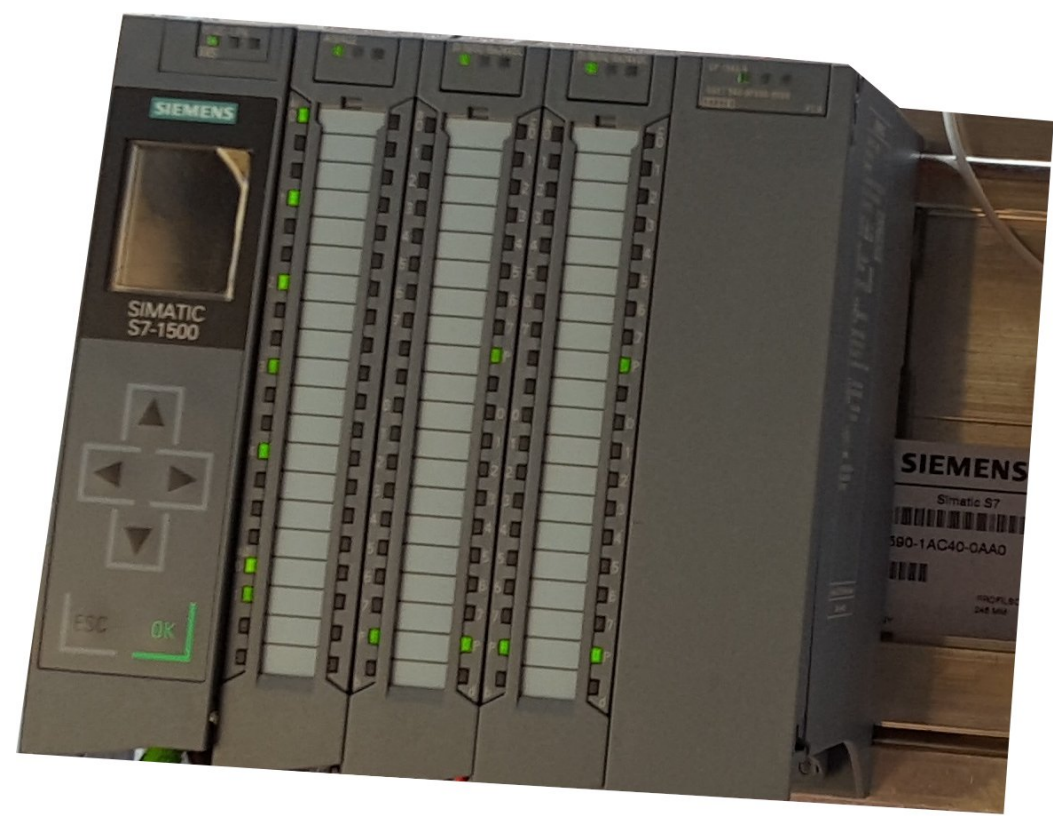

Figura 27 - Controlador Lógico Programável - S7-1500.

Fonte: Autor

A aplicação foi desenvolvida fazendo uso do ambiente de desenvolvimento da SIEMENS TIA Portal, tendo a lógica desenvolvida em Ladder e SCL, com a aplicação sendo apresentada no apêndice A.

\subsubsection{Inversor de frequência}

O inversor de frequência CFW09 da WEG, com um cartão PROFIBUS Anybus foi utilizado no controle da velocidade do motor. É um inversor para motores de $3 \mathrm{cv}$, porém, foi ligado a um motor de 0,75 cv que estava disponível.

A frequência máxima ajustada para o inversor foi de $3070 \mathrm{rpm}$, que foi a frequência máxima a qual, o motor não perderia o torque. Nesta frequência foi obtida a velocidade máxima no interior do túnel de $107 \mathrm{~km} \mathrm{~h}^{-1}$.

Sua velocidade foi controlada via rede PROFIBUS, ligado ao módulo PROFIBUS no CLP.

A comunicação PROFIBUS foi estabelecida alterando os seguintes parâmetros (WEG, 2006a):

- P309 = 3: Comunicação Fieldbus - PROFIBUS DP - 6 I/O;

- P313 = 0: Parar o motor caso ocorrer perda de comunicação; 
- P222 = 10: Referência de velocidade em modo remoto enviado via Fieldbus;

- P226 = 7: Sentido de giro enviado via Fieldbus, com padrão em sentido horário;

- P227 = 3: Gira/Pára em modo remoto enviado via Fieldbus.

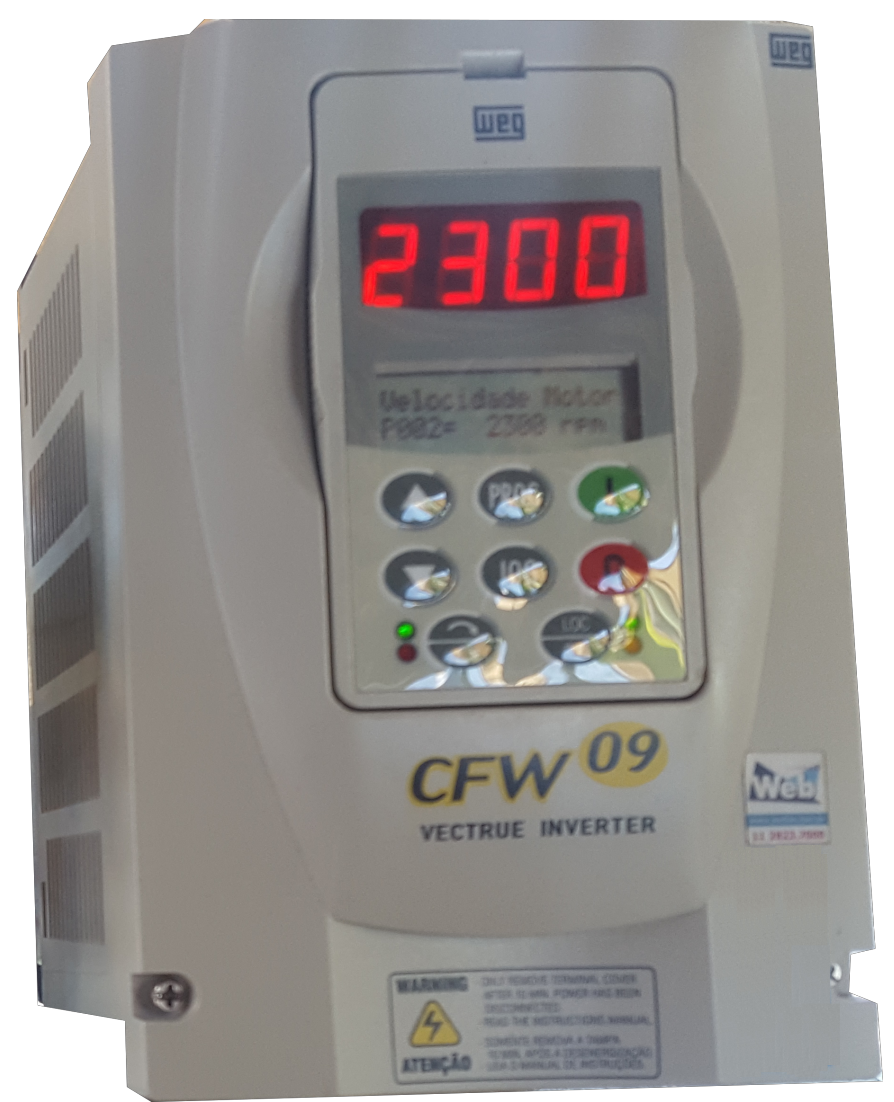

Figura 28 - Inversor de frequência CFW09.

Fonte: Autor

\subsubsection{Dispositivos IO-Link}

Na figura 29 é apresentado os dispositivos IO-link utilizados no presente projeto. 


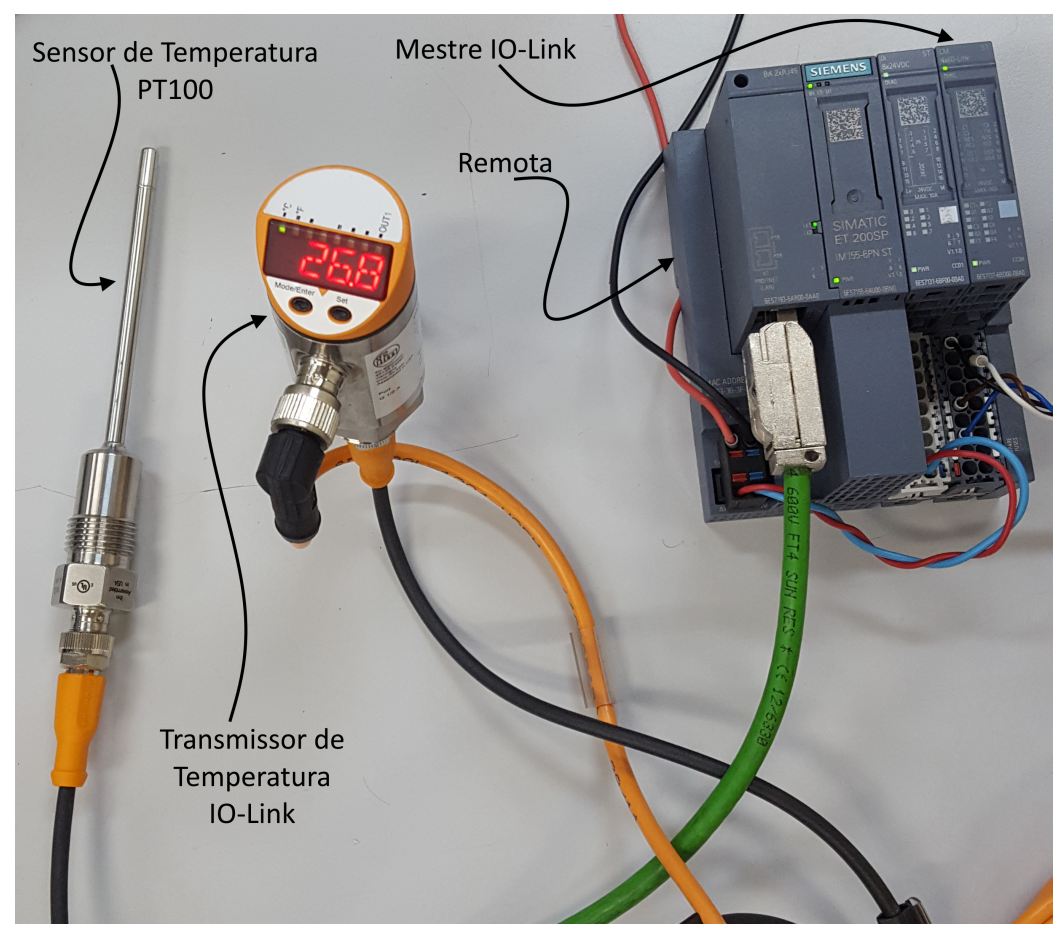

Figura 29 - Dispositivos IO-Link utilizados.

Fonte: Autor

O sistema composto para integração dos módulos IO-link é composto por um mestre e dispositivos IO-link (COMMUNITY, 2013).

Como mestre da rede IO-link foi utilizado o cartão Communication Module (CM 4xIO-link) que é um cartão que possui 4 canais de comunicação com dispositivos IO-link (SIEMENS, 2017a). Por se tratar de um cartão ele deve ser acoplado a um dispositivo remoto. Para integrar o cartão à rede estamos utilizando uma remota PROFINET ET200SP IM155-6PN ST (SIEMENS, 2017b).

O dispositivo de campo IO-link é o transmissor de temperatura TR-2432 da fabricante IFM, além de comunicação IO-link ele também comunica 4 a 20 mA, porém, comunicando em rede IO-Link, além das informações de processo ainda envia informações de diagnóstico e do dispositivo (IFM, 2011) (IFM, 2012).

O pacote de informações pode conter até 232 bytes de dados (IFM, 2012) (COMMUNITY, 2013). Essas informações podem ser utilizadas pelo gerenciador de ativos da empresa e também para efetuar análises diagnósticas e programar ações preditivas, evitando, dessa forma, parada desnecessária do processo. 
O bloco principal de programação é o FB50001 (IO_LINK_DEVICE) (SIEMENS, 2018) e toda a parametrização do bloco está descrita no apêndice A.

\subsection{Sistema de supervisão}

O sistema de supervisão do túnel de vento foi desenvolvido com o WINCC RT Advanced, o sistema é apresentado na figura 30.

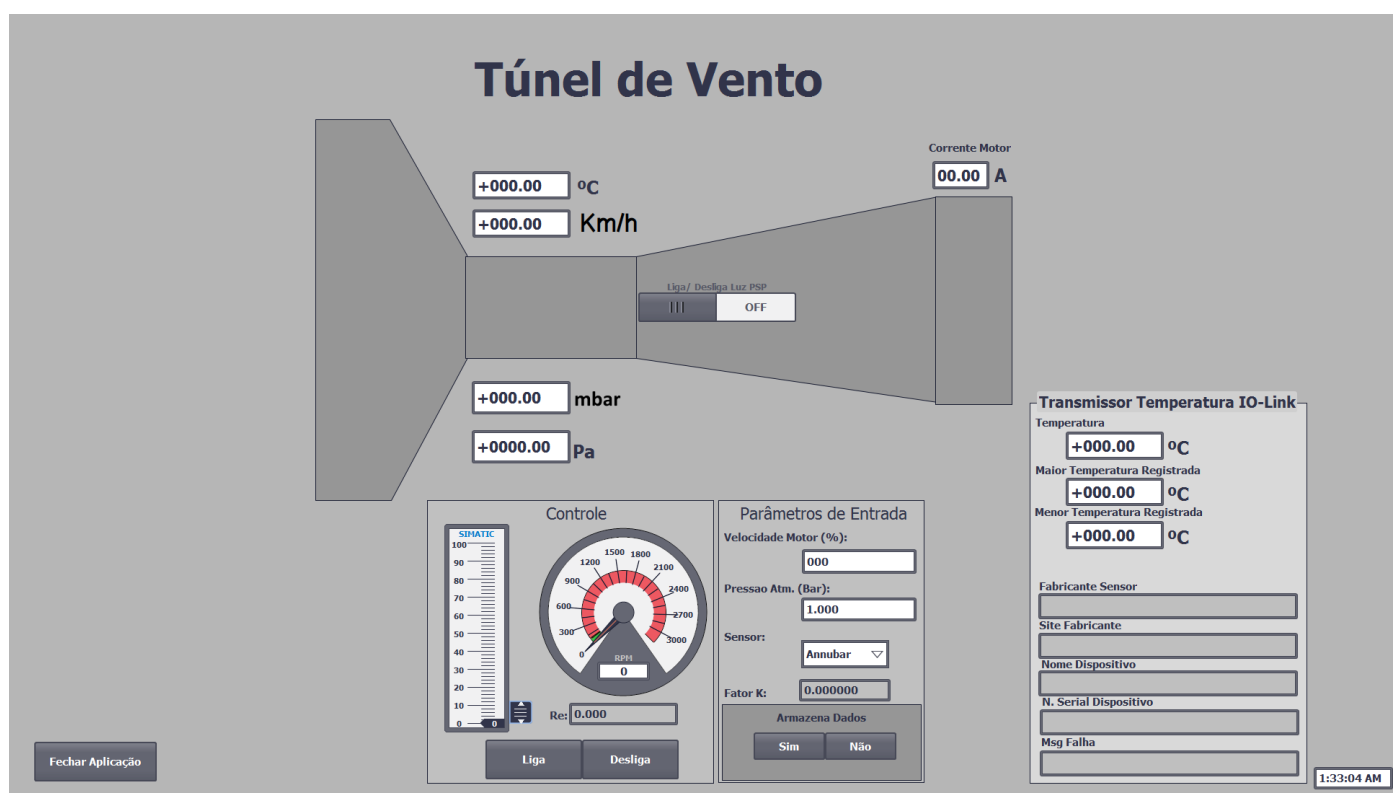

Figura 30 - Sistema de supervisão.

\section{Fonte: Autor}

Como podemos verificar na figura 30 a tela é constituída pela imagem de um túnel, onde, são apresentadas as informações de temperatura, velocidade, além do diferencial de pressão em mbar e em $\mathrm{Pa}$ (que é a unidade utilizada para os cálculos). Todas essas informações são calculadas, a partir dos dados coletados pelo CLP, esses cálculos constam nas rotinas apresentadas no apêndice A.

Também apresenta ferramentas para controle e monitoração do motor, como os componentes Gauge, que monitora a rotação do motor e o Slider, que envia um comando para o motor entre 0 e $100 \%$ da velocidade parametrizada no inversor, no caso, entre 0 e $3070 \mathrm{rpm}$. Os botões de liga e desliga do motor se encontram pouco abaixo do Slider e do Gauge. 
Além disso, nessa tela constam os parâmetros do tipo de sensor que está sendo utilizado, se o Annubar ou o tubo de Pitot, lembrando que, caso seja selecionado o Annubar um fator de correção (K) de 0,661364 deve ser aplicado para correção do valor de velocidade. Também é possível ligar ou desligar o armazenamento de dados no banco. Essa funcionalidade foi implementada para evitar o armazenamento de informações desnecessárias na base de dados. Quando o armazenamento em banco é acionado, um gatilho na aplicação ativa a conexão com o banco e os dados são armazenados via $V B$-Script descrito no apêndice B.

Por fim, constam as informações do sensor IO-Link, cuja grande vantagem deste tipo de comunicação é a possibilidade de receber informações além da variável primária, que é a temperatura. No caso, além da temperatura, é apresentada a informação de máxima e mínima temperatura registrada pelo dispositivo, fabricante, site, nome do dispositivo, série do dispositivo e mensagem de falha (IFM, 2012). Essas informações são importantes tanto para análise preditiva de falha do sensor, quanto para gerenciamento de ativos (COMMUNITY, 2013).

Toda a lógica de controle e monitoramento desenvolvido encontra-se descrito no apêndice A.

\subsection{Topologia da rede}

Os dispositivos da rede Industrial foram integrados via rede, senso que o CLP, com o sistema de supervisão e o metre IO-Link se comunicam via rede PROFINET e o inversor com o CLP se comunica via rede PROFIBUS.

Na figura 31 temos a topologia da rede de comunicação entre os dispositivos, implementada no TIA Portal V14. Os demais instrumentos apresentados no presente projeto, se comunicam via 4 a $20 \mathrm{~mA}$ e não faz parte da topologia, pois, são ligados diretamente na entrada analógica do CLP. 


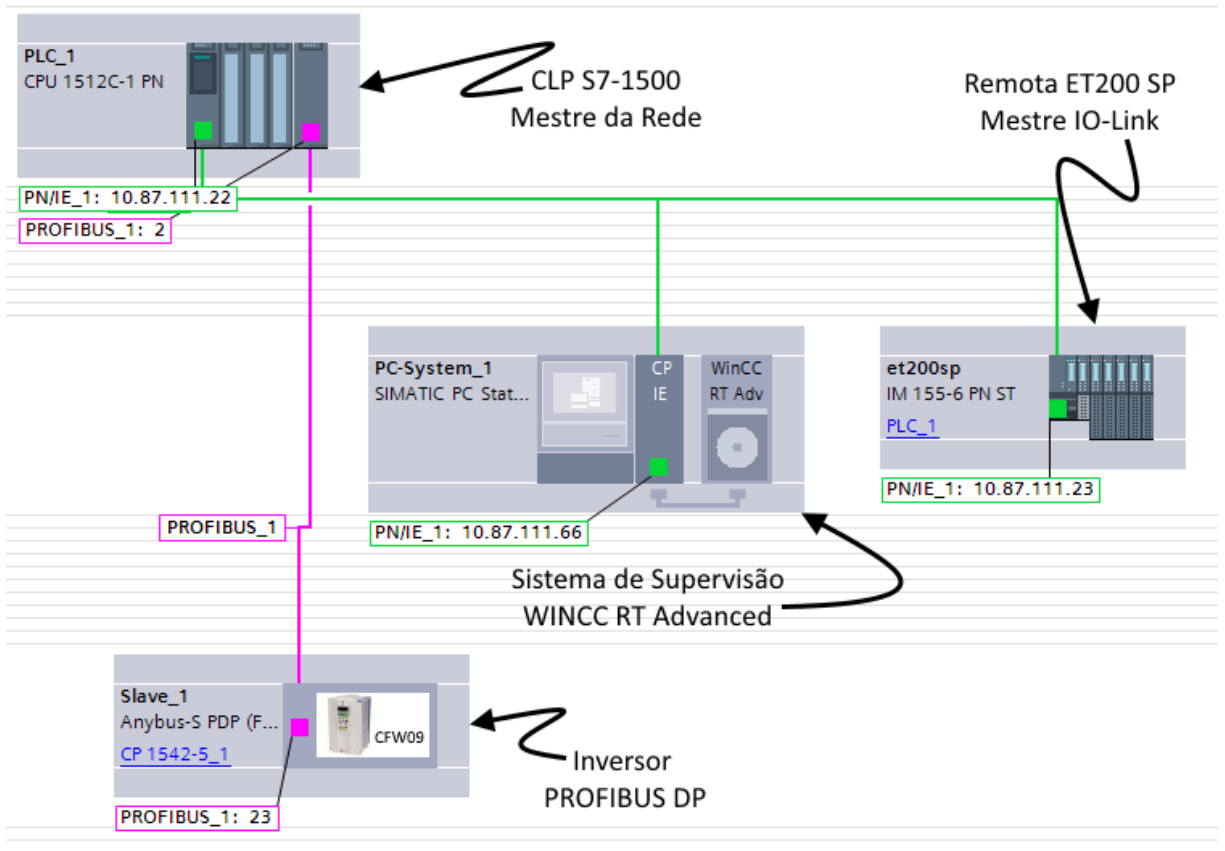

Figura 31 - Topologia da rede.

Fonte: Autor

\subsection{Coleta de dados}

\subsubsection{Armazenamento de dados}

O armazenamento de dados do túnel de vento desenvolvido é efetuado em um banco de dados relacional Microsoft SQL Express, como critério para escolha do banco foi:

- Aplicação sem custo;

- Armazenamento de $10 \mathrm{~GB}$ de dados;

- Menor curva de aprendizagem.

A linha do Microsoft SQL Express é uma linha gratuita oferecida pela Microsoft, de fácil instalação e manuseio, com possibilidade de armazenamento de dados de até 10 GB. Além de apresentar a menor curva de aprendizagem, devido ao uso frequente da plataforma.

A conexão entre o banco e o WinCC RT Advanced foi criado via acesso ODBC, que cria o alias de conexão entre a aplicação e o banco de dados. 
Um banco de dados chamado DB_Dados_Tunel foi criado e adicionada uma tabela chamada "DadosTestes", para armazenar as informações de controle do túnel de vento, a estrutura de informações da tabela está descrito no apêndice C.

\subsubsection{Calibração do Annubar}

Para efetuar calibração do Annubar que é um tubo de Pitot de média, foi utilizado um tubo de Pitot de ponta hemisférica. Para isso, a média da velocidade do túnel deve ser calculada fazendo uso do tubo de Pitot. O método selecionado para calcular a média no interior da seção de testes, foi o Tchebycheff (DELMEE, 2003), tratado na seção 4.2.1.

O fator $\mathrm{n}$ selecionado foi $\mathrm{n}=3$, conforme tabela 1 , o qual devem ser tomados 3 pontos acima do raio da seção de testes e 3 pontos baixo do raio da seção de testes do túnel. Após o cálculo da média, ela deve ser utilizada para se encontrar o fator $\mathrm{K}$ do Annubar (DELMEE, 2003) (ROSEMOUNT, 2009). A função para calcular o fator k é descrito na equação 10. Esse fator é utilizado para efetuar uma correção na velocidade devido ao $\Delta P$ do Annubar apresentar um valor superior ao tubo de Pitot.

$$
K=\frac{V_{P} \text { itot }}{V_{A} \text { nnubar }}
$$

onde,

- $K$ : Fator de correção de velocidade do Annubar;

- $V_{\text {Pitot }}$ : Média de velocidade do Tubo de Pitot;

- $V_{\text {Annubar: }}$ Velocidade medida pelo Annubar.

Dessa forma, assim que a velocidade média no tubo de Pitot for definida o valor da velocidade do Annubar é medido e como a velocidade apresentada é superior a do tubo de Pitot, esse valor é utilizado para a correção fazendo uso da equação 10.

Como $\mathrm{n}=3$ a equação para definir os pontos superiores e inferiores do raio da seção de teste pode ser definida como:

$$
d=\left(n_{n} \times r_{\text {tunel }}\right) \pm r_{\text {tunel }}
$$

onde,

- $d$ : distância do raio; 
- $r_{\text {tunel }}$ : raio da seção de testes do túnel;

- $n_{\mathrm{n}}$ : fator $\mathrm{n}$ de acordo com a tabela 1 , no caso foi selecionado $\mathrm{n}=3$.

Como o diâmetro da seção de testes da tubulação é de $75 \mathrm{~mm}$, calculamos os pontos acima e abaixo do raio da seção de testes fazendo uso da equação 11. Dessa forma, obtemos a tabela 2 .

Tabela 2 - Pontos de medição de velocidades na seção de teste.

\begin{tabular}{c|cc}
\hline $\begin{array}{c}\text { Quantidade de pontos } \\
\text { no Raio }\end{array}$ & Método de Tchebycheff \\
$\mathrm{n}=3$ & $\begin{array}{c}\text { Distância } \\
\text { em mm }\end{array}$ \\
\hline & 0,9239 & 5,7 \\
Pontos acima & 0,7071 & 21,97 \\
& 0,3827 & 46,3 \\
\hline & 0,3827 & 103,7 \\
Pontos abaixo & 0,7071 & 128,03 \\
& 0,9239 & 144,29 \\
\hline
\end{tabular}

Fonte: Autor

\subsubsection{Definição da rotação do motor}

Para verificar a maior velocidade que a turbina montada responde a determinada rotação do motor, foram aplicados testes variando entre 0 e $3200 \mathrm{rpm}$, pois, como o motor é fabricado para $1720 \mathrm{rpm}$, com corrente de operação de 2,9A e, ao aplicar uma rotação acima das especificações de fábrica, ocorre a perda de torque do motor (WEG, 2006b).

Os valores de velocidade de rotação do motor são apresentados tabela 3. Em cada uma das rotações apresentadas, foi deixado um período de 1 minuto para verificar variações de velocidade no interior do túnel. A partir de $3000 \mathrm{rpm}$, foram feitos testes com intervalos menores, pois, na faixa dos $3000 \mathrm{rpm}$ foi o momento que o motor começou a perder torque. Dessa forma, a partir dos $3000 \mathrm{rpm}$ que encontrava-se o limiar da velocidade máxima do sistema de ventilação do motor. 
Tabela 3 - Rotações aplicadas ao motor no intervalo de 1 minuto

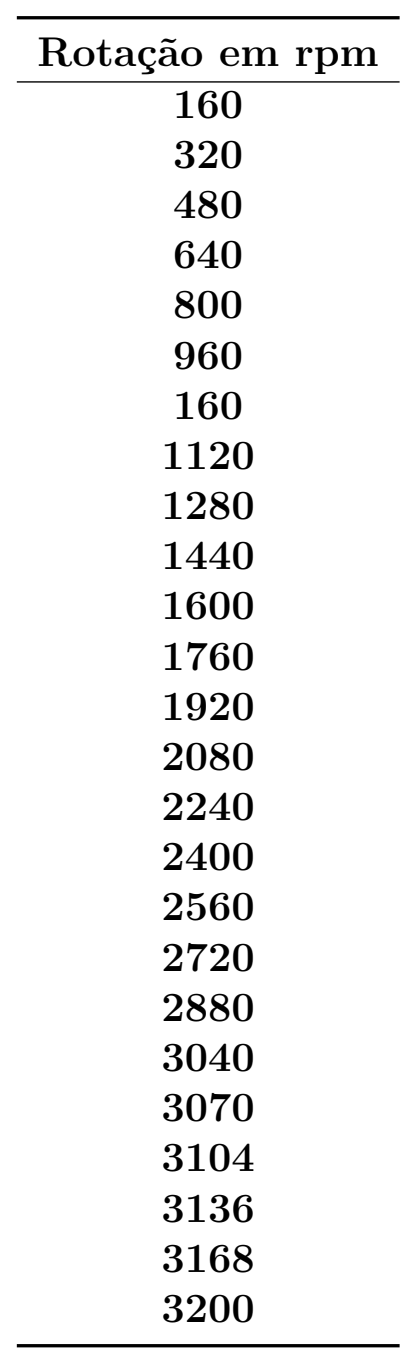

Fonte: Autor

A partir desses dados a rotação máxima estabelecida para o motor foi de $3070 \mathrm{rpm}$, portanto, a rotação máxima parametrizada no inversor de frequência foi de $3070 \mathrm{rpm}$, dessa forma, evita que o inversor ultrapasse esse limite, deixando a referência de controle na escala de velocidade parametrizada, entre 0 e 3070 rpm (WEG, 2006a).

\subsection{Captação de imagens}

Ao captar a imagem da reação do corpo com PSP depositado, quando este estiver submetido a um fluxo de ar no interior do túnel, deve ser utilizado tanto um filtro no 
sistema da excitação da molécula quanto no sistema de receptor (BRAGA; SALCEDO, 2018).

\subsubsection{Excitação da molécula}

No sistema de excitação a molécula foi utilizado um LED UV alimentado com $5,10 \mathrm{~V}$, modelo:

- VL380-5-15

Na figura 32 a) é possível verificar o encapsulamento do LED, onde, foi utilizado um tubo de caneta para fixá-lo no suporte, no qual, 2 resistores de $100 \Omega$ foram ligados em série com o led para limitar a corrente a 25,5 mA e manter alta a intensidade no LED (GREGORY. et al., 2014).

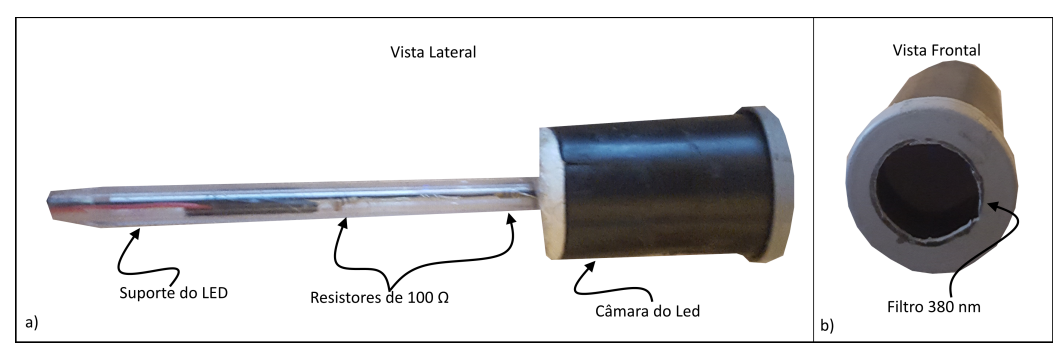

Figura 32 - Encapsulamento do LED de $380 \mathrm{~nm}$.

Fonte: Autor

Como podemos verificar na figura 32 b) um filtro ótico de $380 \mathrm{~nm}$, modelo QB29 com transmitância de $85 \%$ foi alocado na saída do encapsulamento do LED, para minimizar fontes luminosas externas ao sistema. No gráfico 2 é apresentado a transmitância do filtro utilizado. 


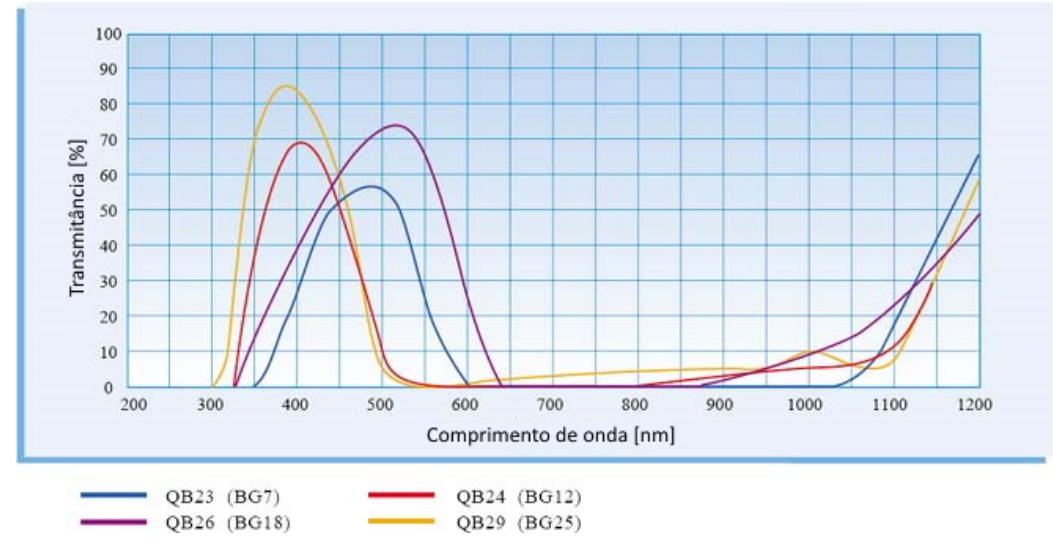

Gráfico 2 - Transmitância do filtro QB29 de $380 \mathrm{~nm}$.

Fonte: Adaptação, tradução do autor dos itens de identificação do gráfico (EBAY, 2018)

As especificações do filtro utilizado são:

- Modelo: QB29;

- Característica: Luz azul;

- Transmitância: 85\%;

- Diâmetro: $25 \mathrm{~mm}$;

- Espessura: $2 \mathrm{~mm}$.

O filtro não possui anel de proteção em seu entorno, portanto, cuidados em seu manuseio devem ser tomados.

\subsubsection{Medição da resposta da molécula}

Os trabalhos levantados sobre PSP, durante o desenvolvimento do presente projeto, utilizaram câmera científica com sensor CCD, porém, recentemente câmeras com sensor CMOS para medição em sistemas PSP foram desenvolvidas pela CSEM e PCO (YORITA et al., 2019).

As imagens foram captadas por uma câmera NIKON D5100, semi-profissional. Não foi utilizada uma câmera CCD específica para PSP, conforme apresentado nos trabalhos pesquisados, devido aos altos custos para aquisição.

$\mathrm{Na}$ figura 33 temos a imagem da câmera utilizada durante os testes com a amostra de PSP, suas especificações técnicas estão descritas no anexo A (NIKON, 2011). 


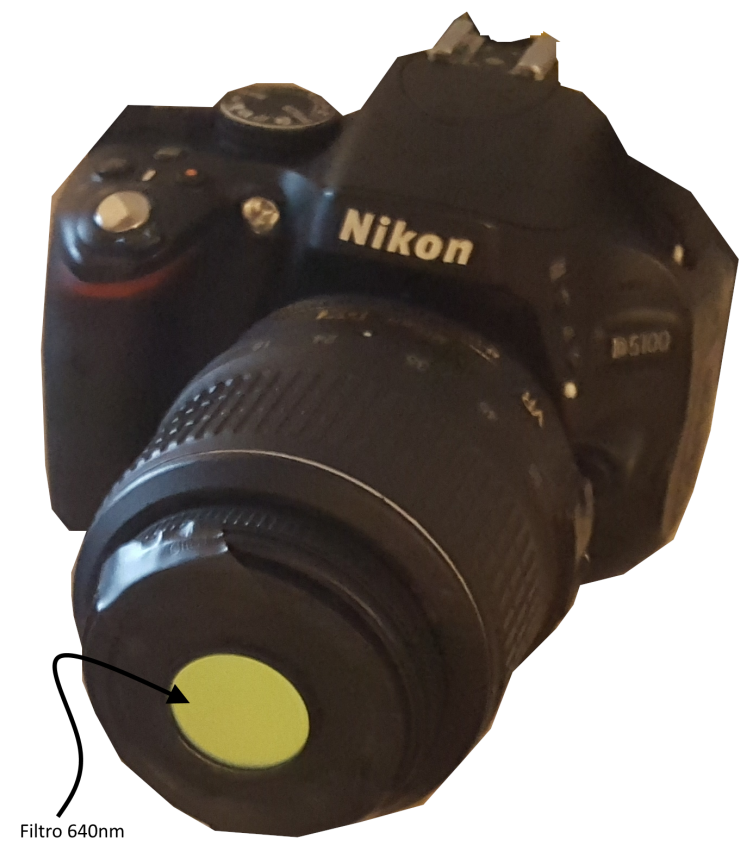

Figura 33 - Câmera NIKON D5100.

Fonte: Autor

Além disso, é possível verificar o filtro ótico de $640 \mathrm{~nm}$ adaptado na objetiva da câmera apresentada na figura 33 .

Esse filtro possui as seguintes especificações:

- Filtro: Carl Zeiss;

- Modelo: BP640/30;

- Transmitância: $88 \%$;

- Referência: EB00499B;

- diâmetro: 25 mm;

- espessura: $4 \mathrm{~mm}$.

No gráfico 3 é apresentado o comprimento de onda da transmitância do filtro adaptado na câmera, além disso, é possível verificar que o filtro está próximo de $90 \%$ de transmitância. 


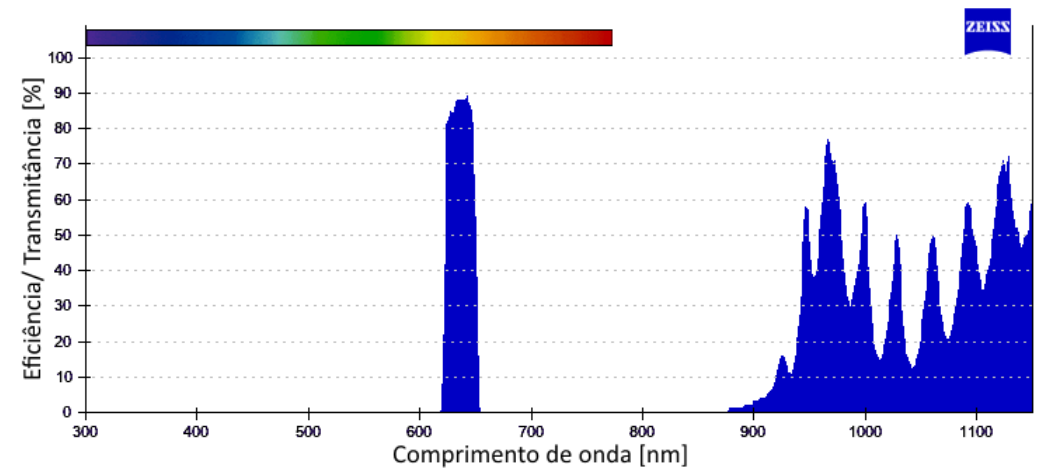

Gráfico 3 - Transmitância do filtro de $640 \mathrm{~nm}$.

Fonte: Adaptação, tradução do autor dos itens de identificação da figura (CARL ZEISS, 2018).

Esse filtro possui anel de fixação.

\subsection{Filme PSP}

Para composição dos sensores de PSP foram depositadas, sobre as superfícies ativas das lâminas de vidro e do aerofólio (asa), membranas de PVC, contendo moléculas imobilizadas sensíveis de Octaetilporfirina de Platina (PtOEP). As membranas foram compostas por 2,5 mg de PtOEP dissolvidos em $1.5 \mathrm{~mL}$ de tetrahidrofurano (THF) $2,29 \times 10^{-3} \mathrm{~mol} \mathrm{~L}^{-1}$. Adicionalmente, foram utilizados $20 \mathrm{mg}$ e $38 \mathrm{mg}$ de PVC com $43 \mu \mathrm{L}$ e $82 \mu \mathrm{L}$ de Bis (2-ethylhexyl) sebacate (DOS), apresentados respectivamente nas Figuras 34 a) e b) (BRAGA; SALCEDO, 2018).

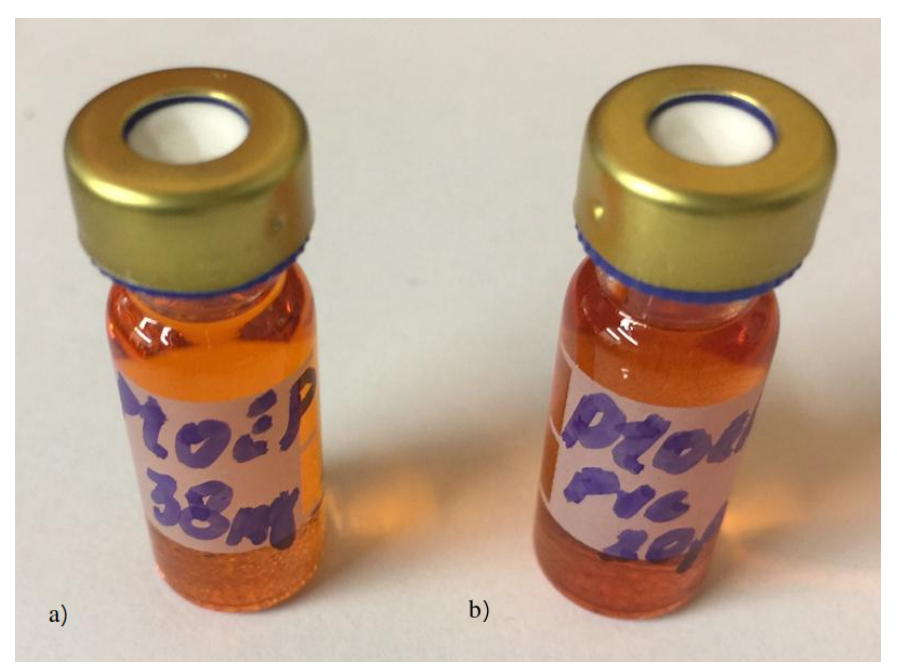

Figura 34 - Amostras desenvolvidas.

Fonte: Autor 
Para homogeneização e diluição completa do PtOEP, ambas as misturas foram submetidas em agitação mecânica, por ultrassom, durante 30 minutos (BRAGA; SALCEDO, 2018). Os filmes foram depositados pelo processo de imersão denominado de dip-coating para formação das membranas ativas de PtOEP-PVC fixadas diretamente no lado superior das amostras de vidro. Para a deposição sobre o modelo aerofólio desenvolvido, a amostra de $38 \mathrm{mg}$ foi depositada sobre o modelo e espalhada por um pincel utilizado em pintura a óleo. Na figura 38 é possível verificar o resultado da deposição da amostra.

\subsubsection{Superfícies utilizadas}

Os testes foram desenvolvidos com duas estratégias diferentes:

- Deposição em lâminas de microscopia;

- Deposição em um modelo de ASA impresso em impressora 3D;

\subsubsection{Deposição em lâminas de microscopia}

Nos primeiros testes foram separadas 5 lâminas, utilizadas em microscopia, e cortadas em formato quadrado no tamanho de $10 \mathrm{~mm}$ X $10 \mathrm{~mm}$, totalizando 18 pequenas lâminas que foram utilizadas na deposição do reagente desenvolvido.

Foram utilizados 2 métodos para deposição do reagente nas lâminas:

- Spin;

- Gotejamento.

No método de deposição por Spin uma gota do reagente é depositado sobre a lâmina e rotacionada para homogeneização da amostra sobre a superfíce. Nesse processo foi utilizado um conjunto de motor trifásico e inversor de frequência CFW09 da WEG, pois, dessa forma é possível controlar a velocidade de rotação com precisão de $0,5 \%$ quando não existem variações de carga (WEG, 2014). O inversor de frequência foi ajustado nas seguintes rotações durante 30 segundos:

- $3000 \mathrm{rpm}$;

- $2000 \mathrm{rpm}$;

- $1000 \mathrm{rpm}$; 
- $500 \mathrm{rpm}$.

Em cada uma das velocidades, citadas acima, foram geradas 3 amostras. A deposição em duas das três amostras foram feitas em concentração de 38 mg e uma em 20 mg.

O método por gotejamento foi depositado em 6 lâminas, duas gotas foram depositadas em cada lâmina fazendo uso de uma pipeta. Sendo que, quatro dessas amostras foram depositadas com 38 mg de concentração e duas com 20 mg de concentração.

Todas as amostras foram levadas ao forno durante 1 hora a uma temperatura de $60{ }^{\circ} \mathrm{C}$

\subsubsection{Modelo}

Um modelo impresso em impressora 3D em formato geométrico de um aerofólio de avião foi desenvolvido. Dessa forma, uma maior variação fotoluminescente é esperada se comparado com as lâminas utilizadas, devido sua geometria não uniforme. Nas figuras 35 e 36 temos o projeto com as dimensões de construção do aerofólio impresso em 3D.

Sendo que a figura 35 é apresentado o aerofólio em vista superior com diâmetro de $30 \mathrm{~mm}$.

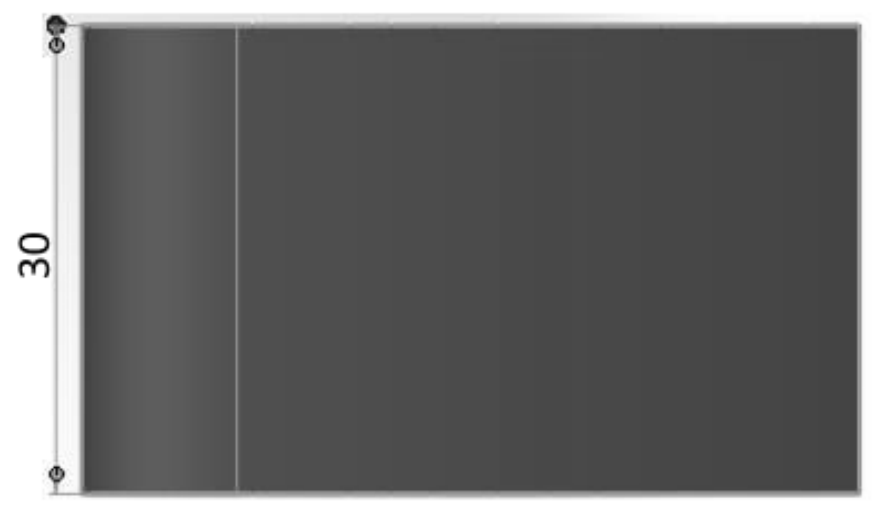

Figura 35 - Vista superior do projeto do aerofólio impresso com dimensões em mm.

Fonte: Autor

Já a figura 36 é apresentado o projeto dimensional do aerofólio com vista lateral e com comprimento total de $50 \mathrm{~mm}$ e altura de $10 \mathrm{~mm}$. 


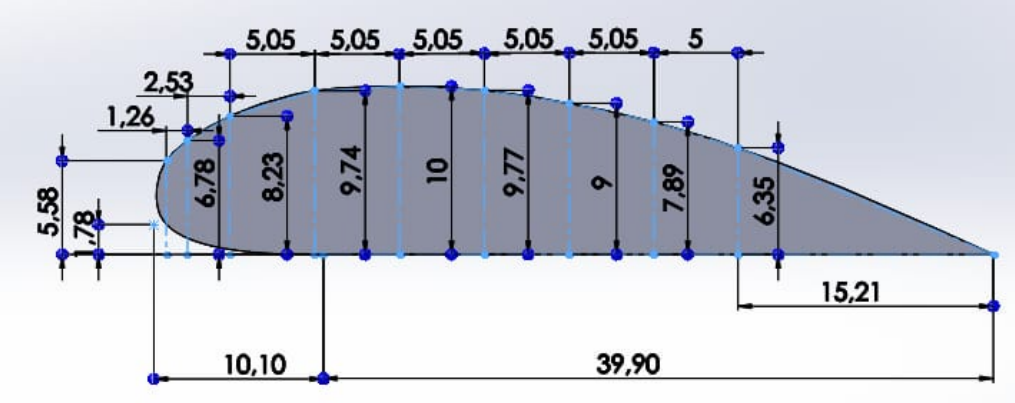

Figura 36 - Vista lateral do projeto do aerofólio impresso com dimensões em mm.

Fonte: Autor

Na figura 37 temos a imagem do aerofólio impresso e lixado com lixa fina 180, a fim de deixar a superfície lisa para a deposição do filme PSP.

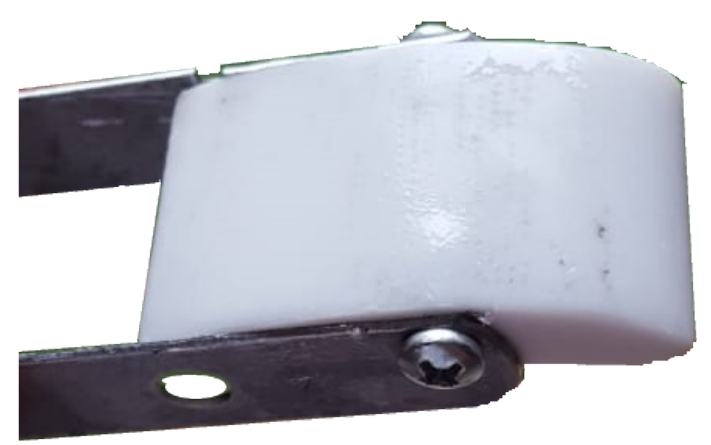

Figura 37 - Modelo em formato de aerofólio desenvolvido para testes.

Fonte: Autor

A amostra utilizada para a deposição sobre a superfície possui uma concentração de $38 \mathrm{mg}$ de PVC. Na figura 38 temos a imagem do modelo já com o filme depositado sobre sua superfície.

A deposição na amostra foi efetuada fazendo uso de uma pipeta e um pincel, dessa forma, com a pipeta foi gotejado o filme e com o pincel espalhado sobre a superfície do modelo. Como podemos verificar na figura 38 a deposição apresentou variações de espessura da tinta sobre sua superfície, devido à baixa eficácia do método de deposição utilizado. Porém, durante os testes, com a variação da velocidade ela apresentou diferentes intensidades, essas variações acabou por favorecer os resultados, pois, a câmera foi capaz de captar as diferentes intensidades apresentadas no modelo. 


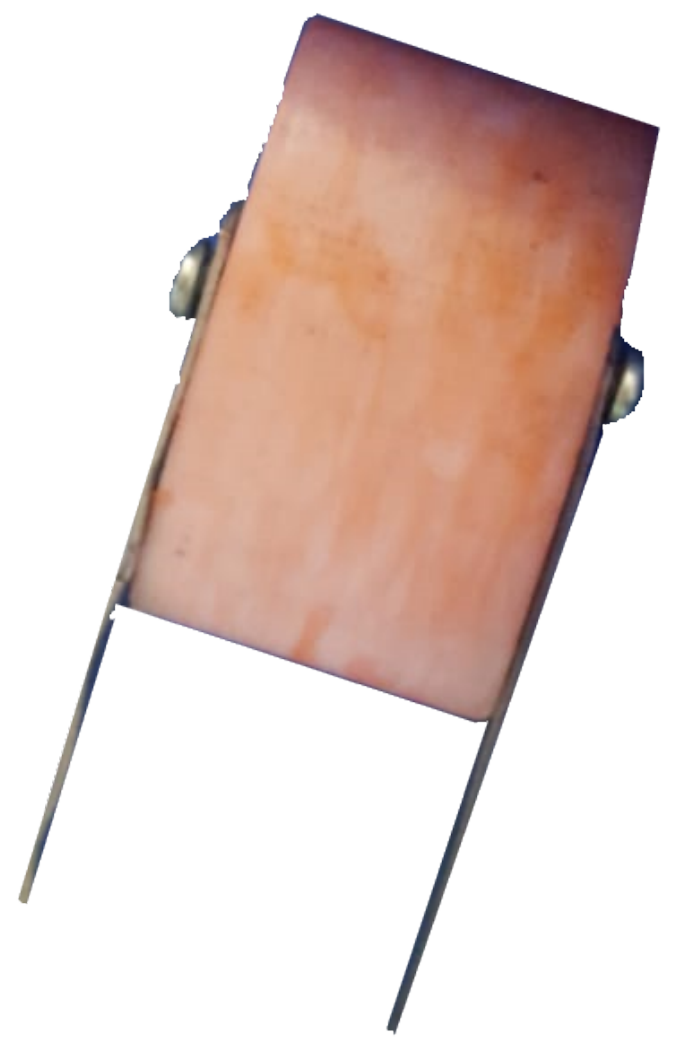

Figura 38 - Modelo com deposição de PtOEP.

\section{Fonte: Autor}

Os testes na amostra foram efetuados no mesmo dia da deposição, pois, as propriedades fotoluminescentes degradam com o tempo e utilização, além do tempo de exposição de luz sofrido pela amostra. Os testes foram efetuados durante a noite, para isolar fontes luminosas indesejadas. A temperatura ambiente no interior da seção de testes estava 17,4 ${ }^{\circ} \mathrm{C}$.

Os testes foram efetuados no intervalo de 1 hora cada, ou seja, foram tiradas fotos nas velocidades descritas na metodologia. Dessa forma, foram montados 3 bancos de imagens no intervalo de 3 horas. O tempo para a repetibilidade da operação foi relativamente longo, para que o motor resfriasse, pois, o motor estava trabalhando acima de seus limites recomendados. 


\subsection{Testes no interior do túnel}

Para os testes as amostras foram dispostas no interior do túnel a uma disposição de 20 (MITSUO; NAKAKITA; KURITA, 2004) com a face de entrada da seção de teste, em sua região central, conforme apresentado na figura 39.

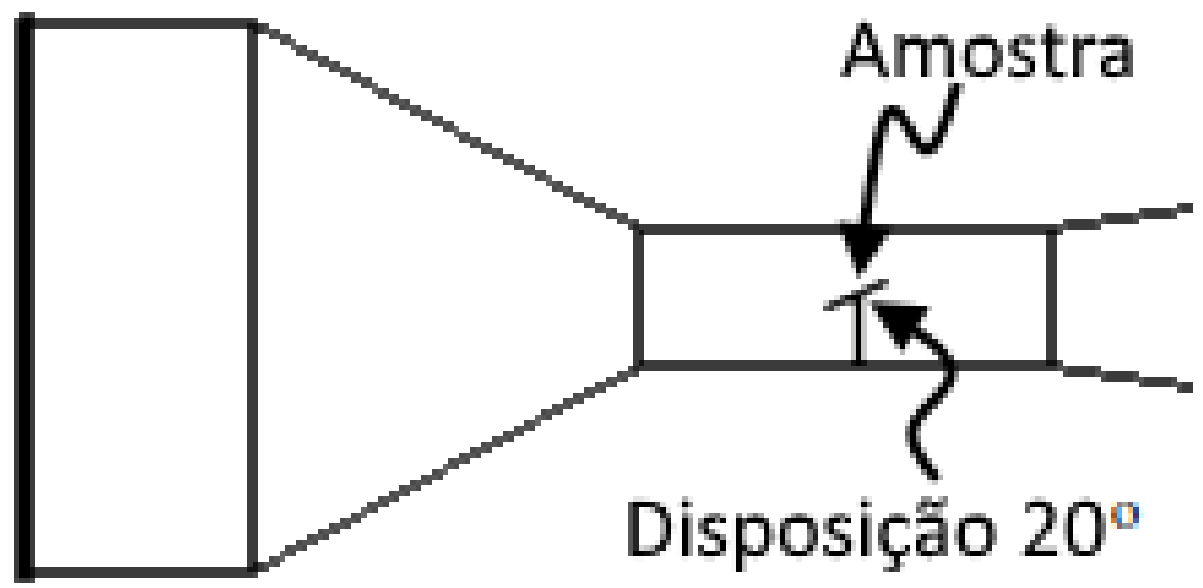

Figura 39 - Disposição da amostra.

Fonte: Autor

A câmera utilizada para tomar as imagens da amostra foi disposta em um lado da seção de teste e o LED utilizado para a excitação da molécula foi disposto no lado oposto da câmera. Janelas de inspeção foram feitas para a excitação e análise da amostra. Para essas janelas foram utilizados lâminas para microscopia. Sua disposição é apresentada na figura 40 . 


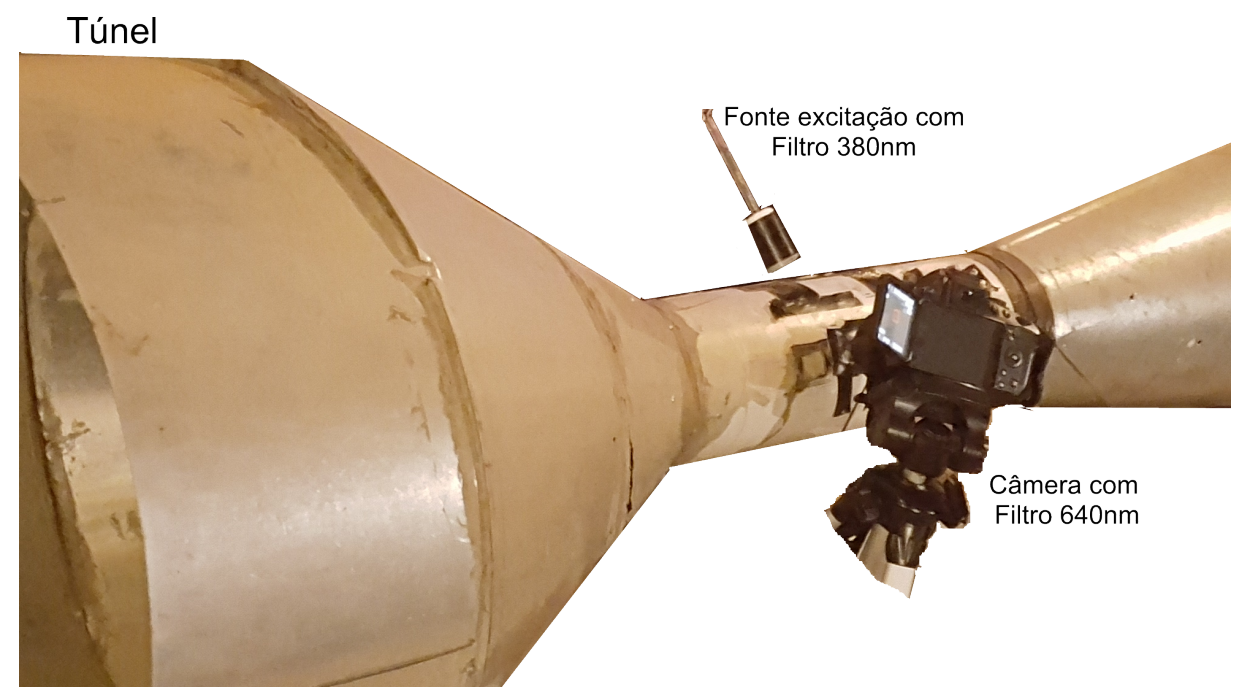

Figura 40 - Disposição da câmera e LED emissor da excitação.

Fonte: Autor

Para a excitação da molécula foi utilizado um UV LED de $5 \mathrm{~mm}$ de $380 \mathrm{~nm}$, conforme descrito na seção 5.5.1.

Como visto nos capítulos anteriores a amostra responde em um comprimento de onda de $640 \mathrm{~nm}$, portanto, um filtro ótico de $640 \mathrm{~nm}$ foi fixado na lente da câmera. O filtro ótico utilizado foi o Carl Zeiss BP640/30 de $640 \mathrm{~nm}$ com transmitância de 70\%. A câmera utilizada foi o modelo NIKON D5100, com sensor CMOS.

\subsubsection{Análise das imagens}

A técnica utilizada para análise das imagens foi a conversão para escala cinza e gerar o histograma da imagem para verificar a alteração de intensidade da emissão fotoluminescente e, gerar a imagem binarizada para verificar a distribuição fotoluminescente sobre a amostra utilizada (BASU; VASANTHARAJAN; RAJU, 2009). As imagens foram obtidas em diferentes velocidades, entre $90 \mathrm{~km} \mathrm{~h}^{-1}$ e $107 \mathrm{~km} \mathrm{~h}^{-1}$.

O eixo horizontal, no histograma, pode apresentar uma variação de 0 a 1, o qual, quanto mais próximo a 1 mais claro é a amostra e quanto mais próximo de 0 , mais escura a amostra. Essa situação apresenta a distribuição da molécula no corpo analisado, assim, quanto mais próximo ao branco indica que a molécula está sendo ativada. No eixo vertical é apresentado a intensidade de emissão da molécula na região do pixel analisado. 


\section{RESULTADOS}

\subsection{Túnel desenvolvido}

Com o túnel montado, os instrumentos de controle e medição instalados e a aplicação desenvolvida, ele foi colocado em operação. Os dados foram coletados e armazenados em uma tabela criada no servidor de banco de dados $S Q L$ Server. No apêndice C é possível verificar os campos utilizados para armazenar os dados.

\subsubsection{Montagem do Túnel}

Após selecionar e parametrizar todos os instrumentos, toda a instrumentação do túnel de vento foi interligada ao CLP; os sensores foram instalados no túnel para que os testes de performance e PSP fossem efetuados, conforme apresentado na figura 41.

$\mathrm{Na}$ figura 41 todos os dispositivos selecionados foram instalados, os sensores de temperatura e de velocidade (Annubar) acoplados no túnel. Somente o tubo de Pitot fica de fora, sendo utilizado apenas para verificação de velocidade pontual na seção de testes. O CLP, o Inversor, a remota IO-Link e o transmissor de temperatura foram alocados em uma mesa ao lado do túnel. 


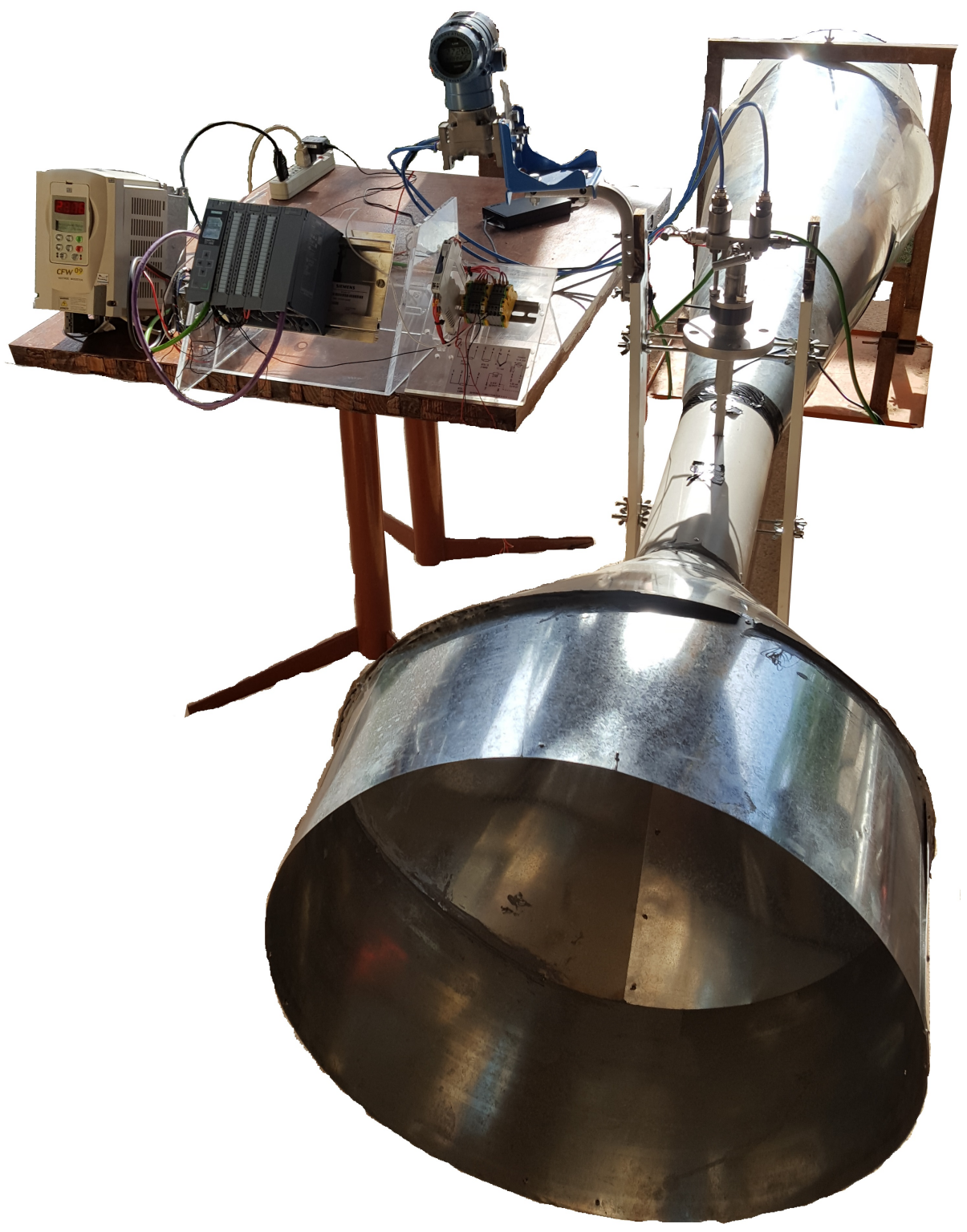

Figura 41 - Montagem completa do Túnel de Vento.

Fonte: Autor

Após a montagem da infraestrutura os testes de velocidade puderam ser efetuados.

\subsubsection{Fator de correção do Annubar}

Assim que as distâncias de medição foram calculadas, as medições das velocidades no interior do túnel fazendo uso do tubo e Pitot foram tomadas e apresentadas na tabela 4. Dessa forma, a velocidade média no interior do túnel pode ser calculada, sendo obtido o valor de $101,05 \mathrm{~km} \mathrm{~h}^{-1}$. 
Tabela 4 - Velocidade média na seção de testes

\begin{tabular}{cc}
\hline Distância $(\mathbf{m m})$ & Velocidade $\left(\mathrm{km} \mathrm{h}^{-1}\right)$ \\
\hline 5,7 & 98,58 \\
21,97 & 103,14 \\
46,3 & 105,11 \\
103,7 & 105,93 \\
128,03 & 104,5 \\
144,29 & 89,05 \\
\hline Média & 101,05 \\
\hline
\end{tabular}

Fonte: Autor

Neste momento foi medida a velocidade obtida pelo Annubar que foi de 152,8 $\mathrm{km} \mathrm{h}^{-1}$. Com isso, fazendo uso da equação 10, podemos calcular o fator $\mathrm{K}$ de correção de velocidade no interior do túnel, cujo valor, é apresentado na equação 12.

$$
k=\frac{V_{P} \text { itot }}{V_{A} \text { nnubar }}=\frac{101,05}{152,8}=>k=0,661364
$$

Esse fator foi acrescentado na programação do CLP, dessa forma, o usuário pode escolher entre utilizar o Annubar ou o tubo de Pitot para calcular a velocidade, sendo que, caso escolha o tubo de Pitot, nenhuma correção é aplicada, e caso escolha o Annubar o fator calculado na equação 12 é utilizado pela aplicação para calcular a velocidade no interior da seção de teste. Essa função é apresentada no apêndice A.

\subsubsection{Dados coletados}

No gráfico 4 é apresentado os resultados da primeira sequência de testes, onde, se apresenta a velocidade do vento no interior do túnel, conforme o aumento da rotação do motor. As rotações do motor aplicadas neste teste estão descritas na tabela 3. Conforme mencionado anteriormente esse teste foi efetuado para verificar o limiar de início da queda da rotação do motor, devido a perda de torque quando a rotação do motor está acima de suas especificações de fábrica (WEG, 2006b). 


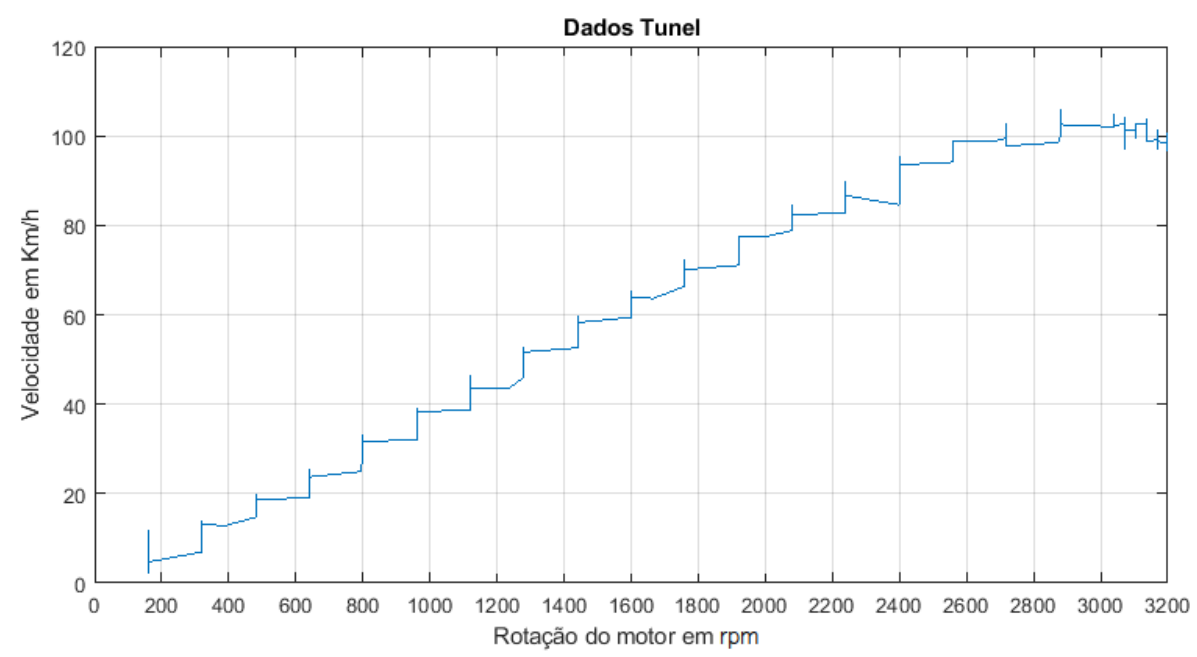

Gráfico 4 - Velocidade do vento no interior do túnel em relação a rotação do motor.

Fonte: Autor

Os picos apresentados no gráfico 4 são as variações de velocidades nas rotações definidas na tabela 3, os pontos de reta (degraus) apresentam o intervalo de alteração entre rotações estabelecidas. Além disso, podemos verificar que a partir de $3000 \mathrm{rpm}$ houve ligeira diminuição da velocidade e para verificar essa situação foi gerado o gráfico 5 com escala definida nesta região de variação.

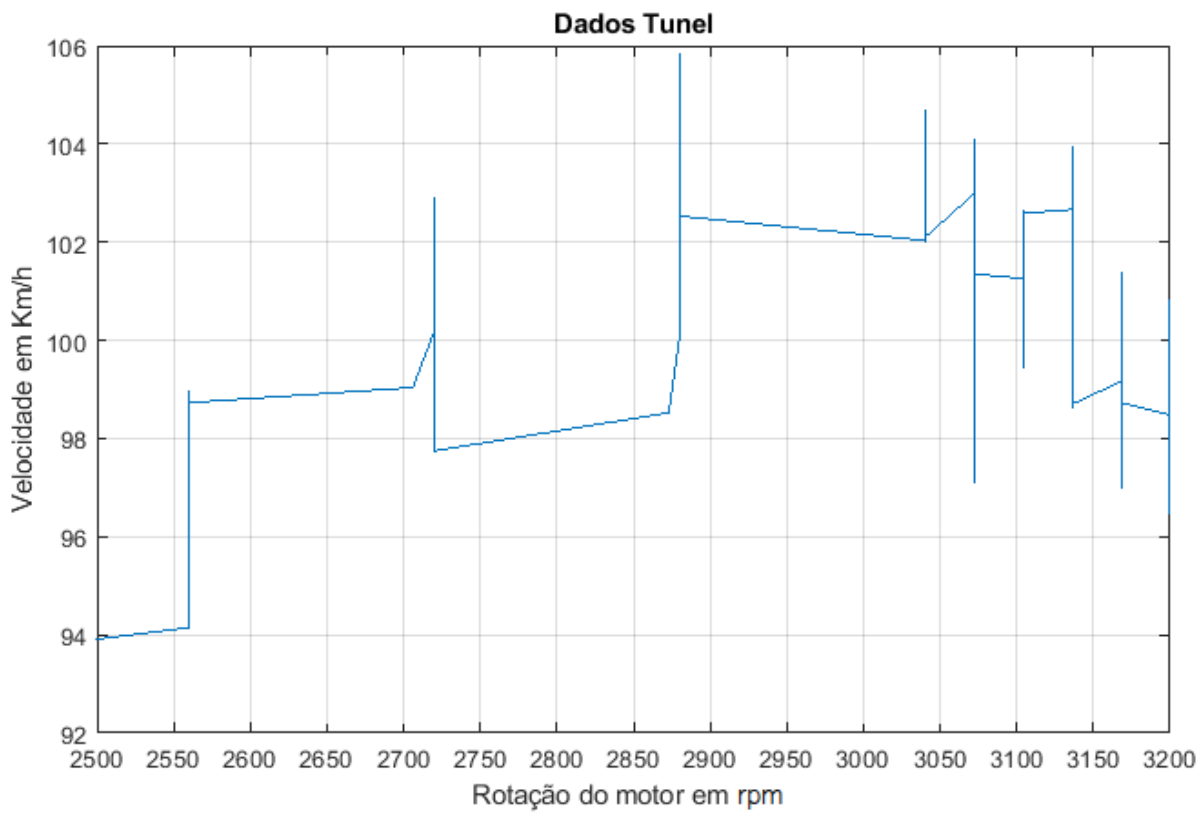

Gráfico 5 - Verificação da limiar com diminuição na velocidade do vento no interior do túnel. 
Conforme mencionado os pontos de pico apresentados no gráfico 5 são a variação de velocidade nas rotações definidas na tabela 3. Além disso, é possível verificar que a partir de 3100 rpm apresentou uma queda na rotação do motor. É constatado também, que até cerca de $3070 \mathrm{rpm}$ as variações de velocidade permanecem em torno dos $100 \mathrm{~km} \mathrm{~h}^{-1}$ e a partir deste ponto, a velocidade começa a diminuir.

Assim que a rotação máxima foi definida outros testes nessa rotação foi efetuada no interior do túnel, conforme apresentado nos gráficos 6 "a", "b", "c" e "d".

Verifique que nos gráficos 6 "a", "b" e "d" a velocidade se mantém ligeiramente acima dos $100 \mathrm{~km} \mathrm{~h}^{-1}$, porém, no gráfico 6 "c" é apresentado uma pequena diminuição da velocidade, agora variando pouco acima e abaixo de $100 \mathrm{~km} \mathrm{~h}^{-1}$.

Os dados coletados e apresentados nos gráficos 6 "a" e "b" foram selecionados da sequência de testes efetuados, com pouco intervalo de descanso para o motor, em torno de 50 minutos. Os dados apresentados no gráfico 6 "c" foram coletados dessa mesma sequência de testes, a partir desse ponto os resultados foram similares. Os dados apresentados no gráfico 6 "d" foram coletados no dia seguinte, após um longo período de descanso para o motor. Porém, com testes em intervalos de descanso de 50 minutos, voltou a apresentar resultados simulares ao que foi apresentado no gráfico "c".

Esse fato passou a ocorrer após o constante uso do motor, dando apenas pequenos intervalos de descanso para o motor, cerca de 50 minutos, como ele passou a aquecer começou a perder suas características físicas e se continuasse a sequência os danos no motor poderiam ser permanentes (FRANCHI, 2008). 

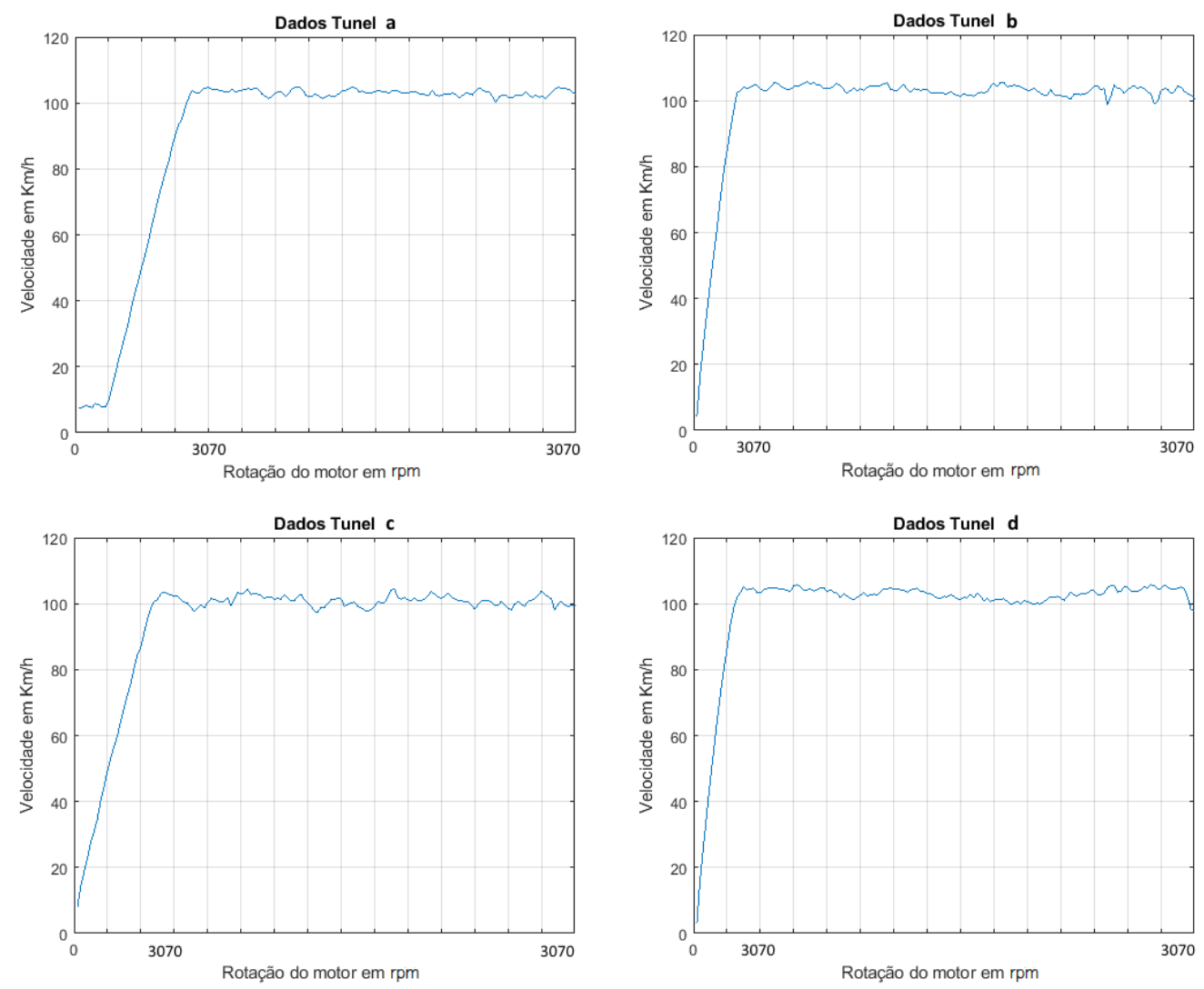

Gráfico 6 - Testes de velocidade no interior do túnel.

\section{Fonte: Autor}

Portanto os testes foram estabelecidos para no máximo 10 minutos em funcionamento e descanso de 50 minutos no intervalo de duas horas. Após transcorrido esse período novos testes seriam executados somente após 5 horas de descanso do motor.

\subsection{Filme PSP}

Os resultados apresentados a seguir foram efetuados nas lâminas de vidro e no modelo de aerofólio impresso em impressora 3D.

\subsubsection{Testes com amostra depositada nas lâminas}

As amostras foram testadas nas mesmas condições apresentadas na figura 39. Porém, todas as amostras depositadas por spin não apresentaram resultados satisfatórios, sendo que, as amostras em $3000 \mathrm{rpm}, 2000 \mathrm{rpm}$ e $1000 \mathrm{rpm}$ não apresentaram variações de intensidade. A amostra de $500 \mathrm{rpm}$ apresentou uma pequena variação de cerca de $2 \%$ 
em relação ao pixel com maior intensidade entre o túnel desligado e ligado na velocidade máxima, uma resposta baixa e dentro da faixa de erro.

Um dos motivos possíveis na falta de resultados com as amostras depositadas por spin, é devido a baixa velocidade do túnel, que é inferior aos levantados na literatura (MITSUO; NAKAKITA; KURITA, 2004), além da câmera utilizada estar fora dos padrões utilizados em pesquisas PSP. A velocidade máxima obtida no interior do túnel foi cerca de $107 \mathrm{~km} \mathrm{~h}^{-1}$.

As amostras que foram depositadas por gotejamento apresentaram variações em relação túnel desligado e túnel ligado. Para verificar a resposta da amostra, foi feita uma relação entre o pixel mais intenso do túnel ligado a velocidade máxima com o túnel desligado, cujo resultado variou entre $9 \%$ e $13 \%$.

Na figura 42 temos um exemplo do teste de uma das amostras, cuja intensidade foi cerca de $13 \%$ em relação a imagem do túnel ligado em $107 \mathrm{~km} \mathrm{~h}^{-1}$ e desligado. Porém, todas as tentativas para variação de velocidade no interior do túnel não foram satisfatórias, pois, quando a velocidade foi diminuída de $107 \mathrm{~km} \mathrm{~h}^{-1}$ para $100 \mathrm{~km} \mathrm{~h}^{-1}$ a variação foi cerca de $1 \%$.

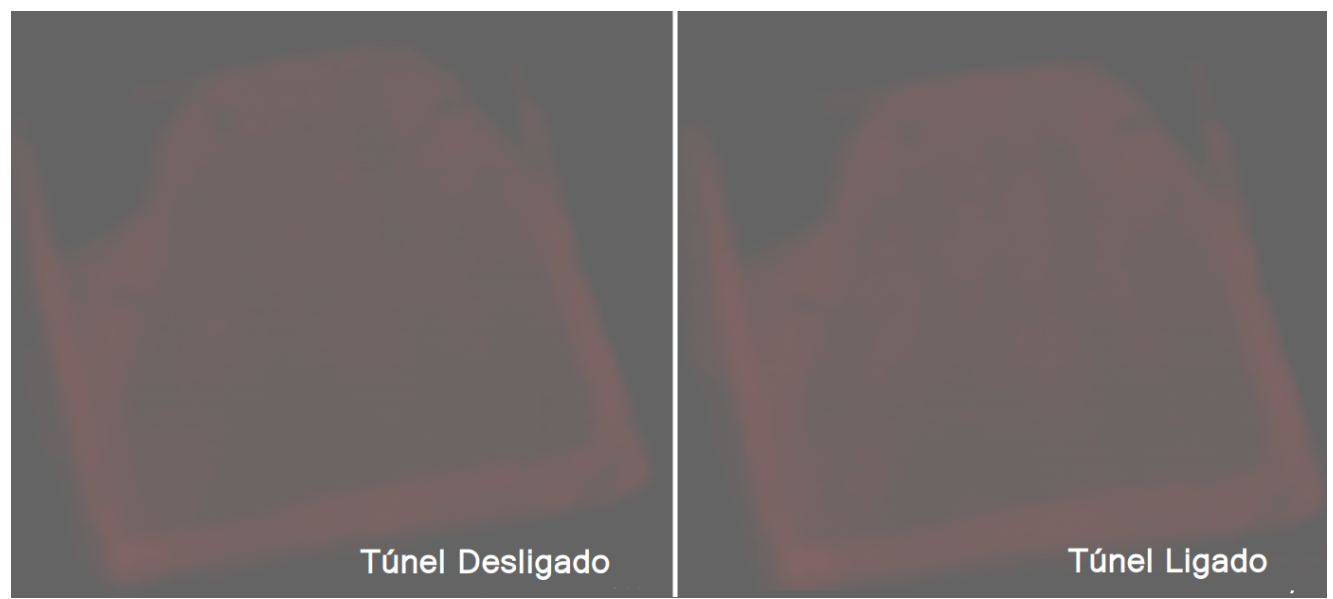

Figura 42 - Imagem com o túnel desligado e ligado a $107 \mathrm{~km} \mathrm{~h}^{-1}$ da Amostra 1.

Fonte: Autor

Conforme mencionado anteriormente, as imagens foram convertidas para escala cinza e gerado um histograma, para verificar a variação da intensidade fotoluminescente na amostra e assim, efetuar a binarização com o limiar apresentado no histograma. Os algoritmos utilizados constam nos apêndices D e E. 
Nos gráficos 7 (a) e 7 (b) são apresentados os histogramas das imagens tiradas com o túnel desligado e ligado a $107 \mathrm{~km} \mathrm{~h}^{-1}$, respectivamente. Nos histogramas podemos verificar que a variação de intensidade ficou em torno de 0 à 0,035 do nível de escala cinza, próximo a zero. Lembrando que, com os valores de nível de escala cinza mais próximo de "1" a superfície da amostra está mais clara, ou seja, as moléculas estão sendo ativadas. Quanto mais próximo de "0" a superfície da amostra está mais escura, ou seja, representa regiões que a molécula não foi ativada. Além disso, podemos verificar que as variações de intensidade permaneceu na região próxima a zero, significa que houveram pouca variação de intensidade, quase que imperceptível.

No gráfico 7 (b) podemos verificar um aumento na concentração de pixeis por escala cinza em comparação com o gráfico 7 (a), a partir do limiar 0,02 da escala cinza. Além disso, verificamos que não houve aumento da região ativada, pois, o nível de escala cinza permaneceu abaixo de 0,035, houve apenas o aumento da intensidade. Dessa forma, verificamos que houve ligeira diminuição de pressão em algumas regiões da amostra.

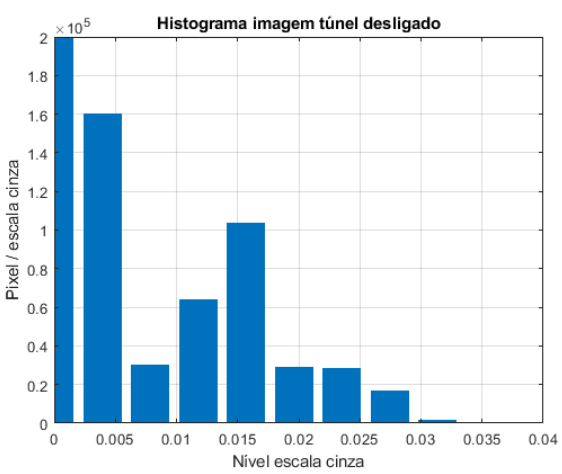

(a) túnel desligado.

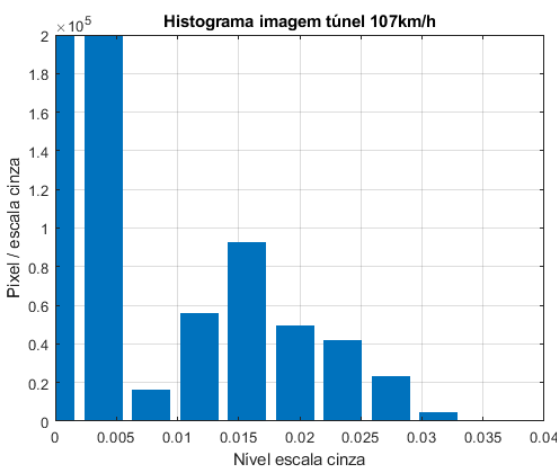

(b) velocidade de $107 \mathrm{~km} \mathrm{~h}^{-1}$.

Gráfico 7 - Histograma gerado das imagens tiradas com o túnel desligado e ligado a $107 \mathrm{~km} \mathrm{~h}^{-1}$.

\section{Fonte: Autor}

Com o levantamento efetuado a partir da análise dos histogramas foi gerado uma imagem binarizada, para uma análise visual da alteração na intensidade da supressão do oxigênio durante o teste na amostra. A figura 43 apresenta as imagens binarizadas com variação de intensidade entre o túnel desligado e ligado, o ponto de "Threshold" foi de 0,025, pois, foi o ponto de variação identificado de acordo com os histogramas gerados. Nesta imagem é possível verificar pontos de diminuição de pressão devido ao fluxo de ar passar pela lâmina a um ângulo de $20^{\circ}$. 


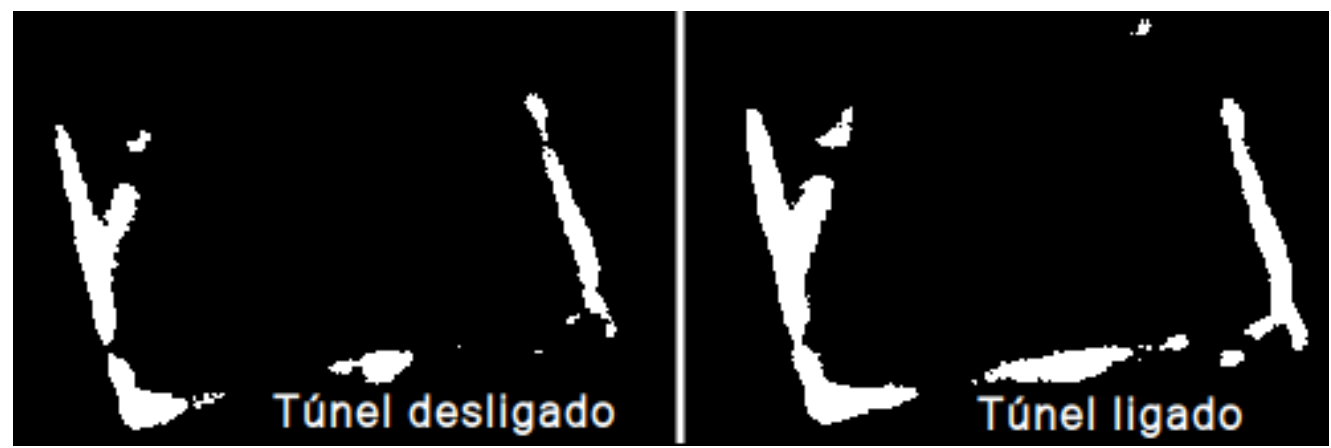

Figura 43 - Imagens binarizadas da amostra 1.

\section{Fonte: Autor}

Na figura 44 temos as imagens tiradas nas velocidades com o túnel desligado, velocidade de $95 \mathrm{~km} \mathrm{~h}^{-1}$, velocidade de $100 \mathrm{~km} \mathrm{~h}^{-1}$ e velocidade de $107 \mathrm{~km} \mathrm{~h}^{-1}$, respectivamente. Com esta amostra houveram variações na intensidade fotoluminescente de acordo com a variação de velocidade e que são discutidas a seguir, ou seja, a pressão foi diminuída em alguns pontos da amostra.

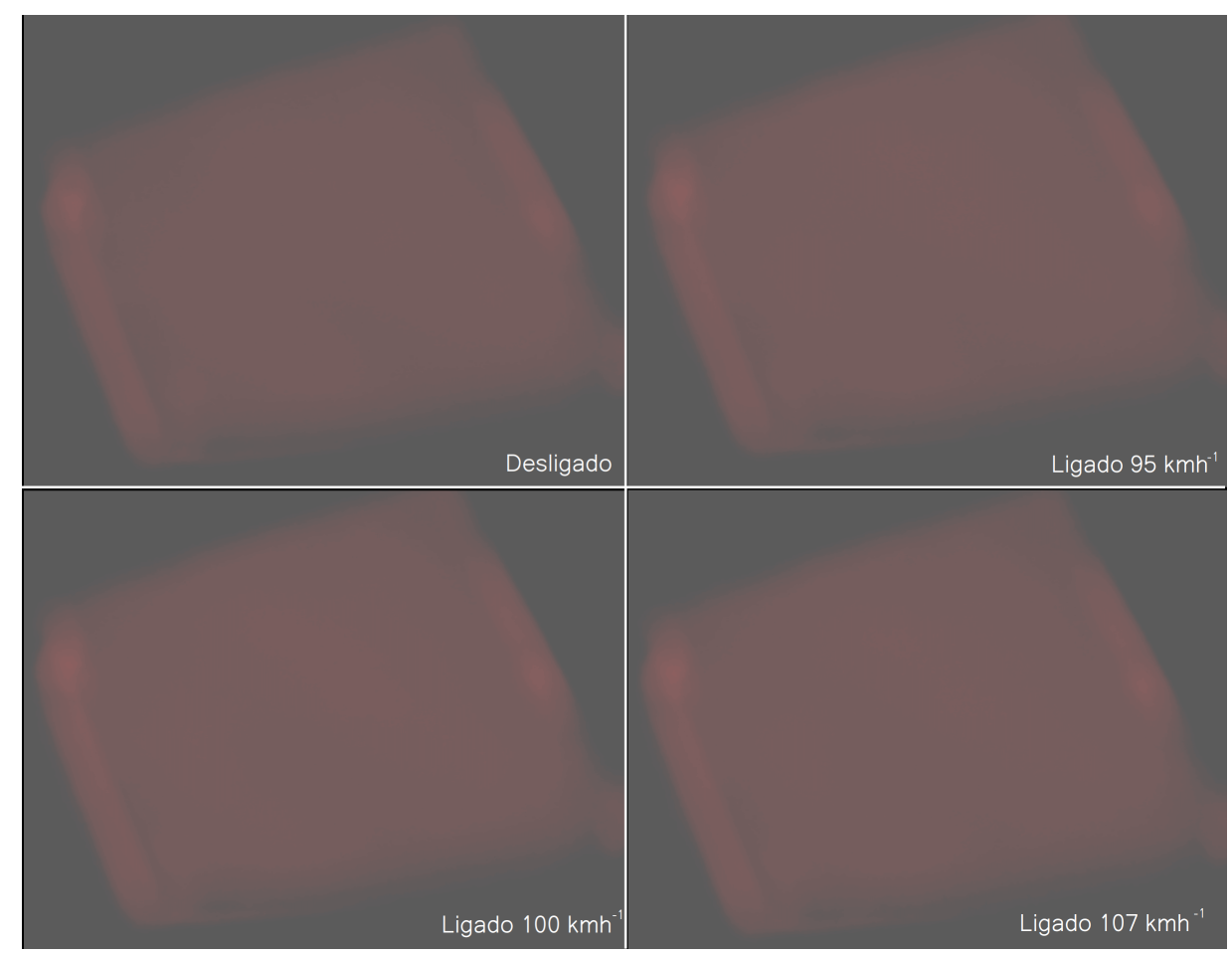

Figura 44 - Imagens com o túnel desligado e ligado da amostra 2. 
Seguindo o método de análise apresentado anteriormente, as imagens foram convertidas para escala cinza e depois gerados os histogramas das imagens para analise do limiar da variação fotoluminescente de acordo com a variação de velocidade.

No gráfico 8 (a) temos o histograma da imagem com o túnel desligado e podemos verificar que o limiar de variação do nível da escala cinza permanece entre entre 0 e 0,05.

No gráfico 8 (b) temos o histograma da imagem com a intensidade fotoluminescente a uma velocidade de $95 \mathrm{~km} \mathrm{~h}^{-1}$, a qual, verificamos variações na quantidade de pixeis ativados a partir de 0,03. Dessa forma, 0,03 se torna o limiar para geração do arquivo binarizado.

O gráfico 8 (c) apresenta o histograma da imagem com a intensidade fotoluminescente na velocidade de $100 \mathrm{~km} \mathrm{~h}^{-1}$ e pode-se verificar que as variações aumentam entre as escalas de 0,03 até 0,045. Portanto, com o aumento da velocidade a amostra apresenta variações de emissão fotoluminescente.

Já no gráfico 8 (d) é apresentado o histograma da imagem da amostra com velocidade de $107 \mathrm{~km} \mathrm{~h}^{-1}$, onde verifica-se que houve um aumento na intensidade fotoluminescente, próximo ao limiar de 0,045 .

Conforme destacado a partir do histograma do gráfico 8 (b) uma nova região da amostra, entre 0,04 e 0,045, foi ativada e sua intensidade variou entre $95 \mathrm{~km} \mathrm{~h}^{-1} \mathrm{e}$ $107 \mathrm{~km} \mathrm{~h}^{-1}$. Isso indica, que a pressão nessa região começou a diminuir com o aumento da velocidade. 


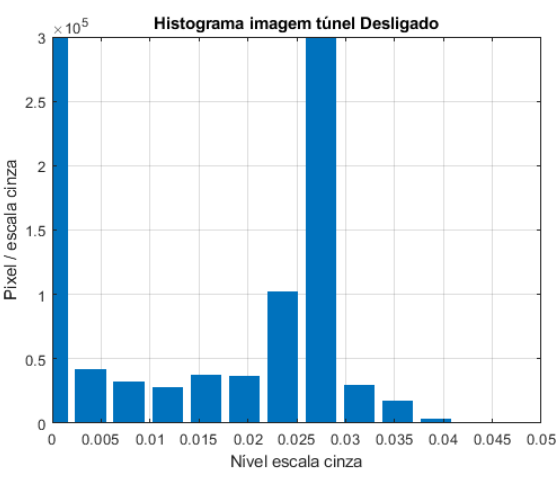

(a) Histograma da imagem com o túnel desligado

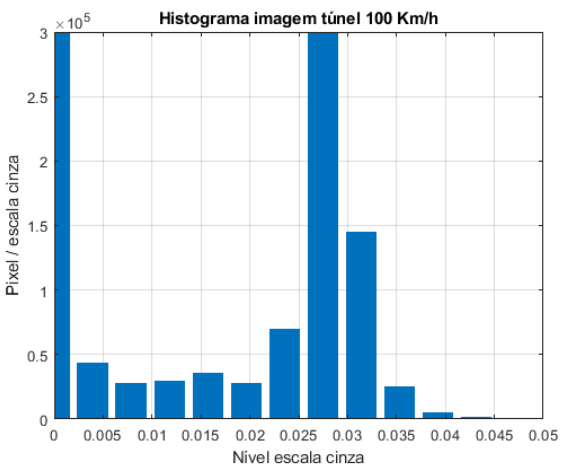

(c) Histograma da imagem a $100 \mathrm{~km} \mathrm{~h}^{-1}$.

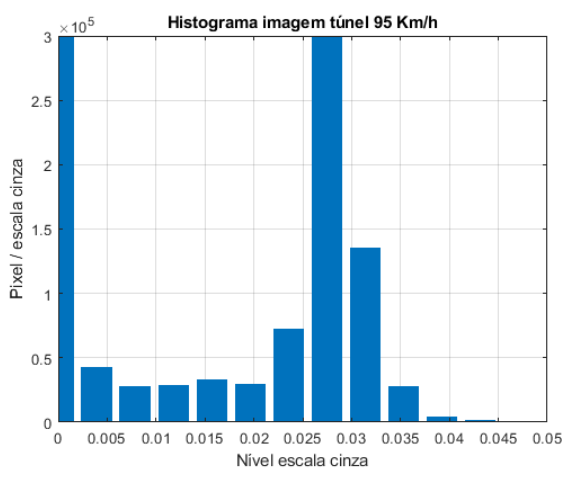

(b) Histograma da imagem a $95 \mathrm{~km} \mathrm{~h}^{-1}$

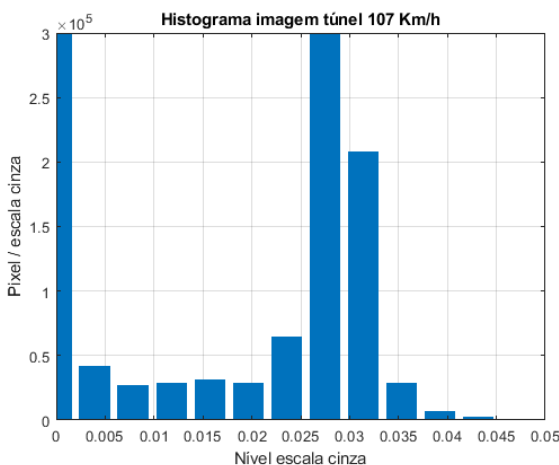

(d) Histograma da imagem a $107 \mathrm{~km} \mathrm{~h}^{-1}$

Gráfico 8 - Histograma gerado das imagens tiradas com o túnel desligado e ligado a $95 \mathrm{~km} \mathrm{~h}^{-1}, 100 \mathrm{~km} \mathrm{~h}^{-1}$ e $107 \mathrm{~km} \mathrm{~h}^{-1}$.

\section{Fonte: Autor}

Portanto, para gerar a imagem binarizada utilizamos o limiar de 0,03. Dessa forma, é possível análise visual das variações de intensidade de acordo com as velocidades que a amostra foi submetida.

Na figura 45 temos a imagem binarizada das amostras nas velocidades analisadas. Como pode-se verificar, de acordo com o aumento da velocidade a emissão fotoluminescente foi se alterando. 

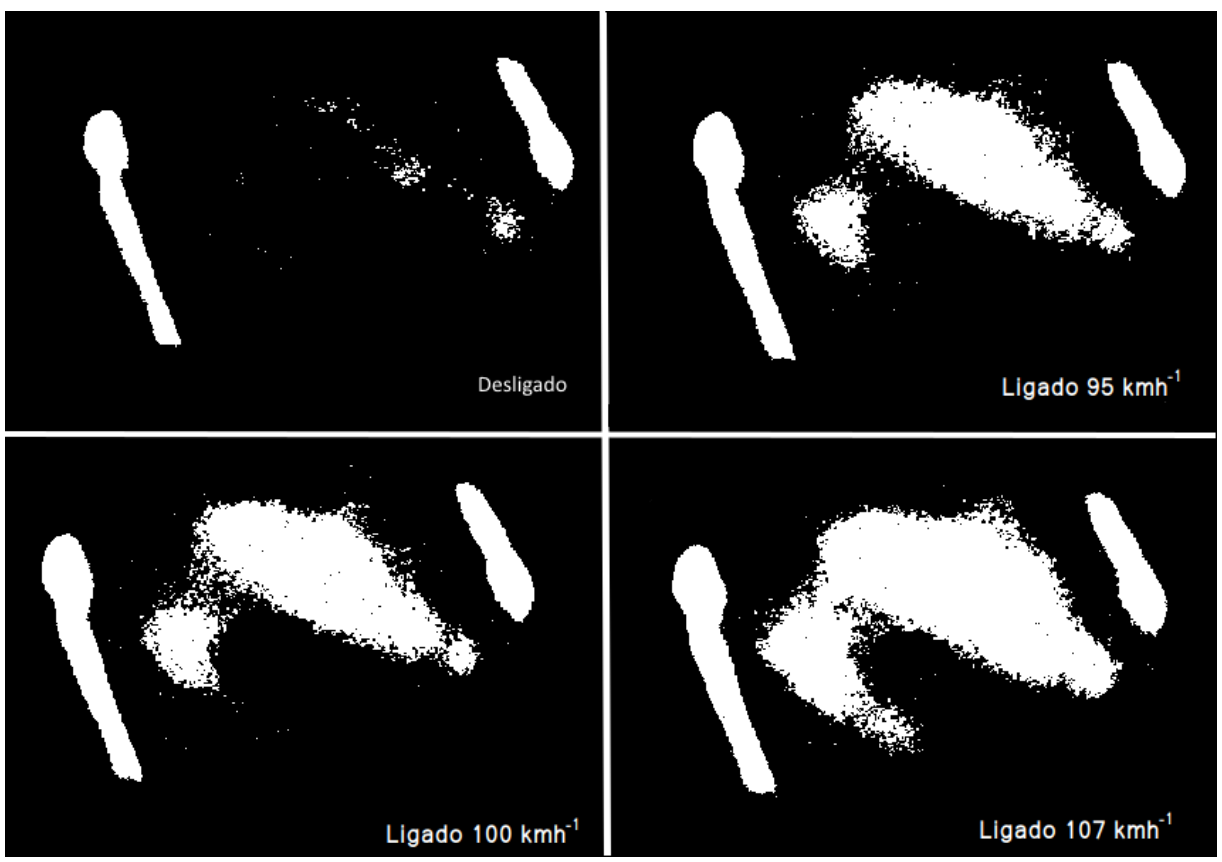

Figura 45 - Imagens binarizadas com limiar de 0,03.

Fonte: Autor

De acordo com a figura 45 não ocorreram variações significativas na intensidade fotoluminescente das imagens com as velocidades de $95 \mathrm{~km} \mathrm{~h}^{-1}$ e $100 \mathrm{~km} \mathrm{~h}^{-1}$, porém, na velocidade de $107 \mathrm{~km} \mathrm{~h}^{-1}$ houve um aumento acentuado na intensidade fotoluminescente, que indica regiões com diminuição de pressão sobre sua superfície, devido ao fluxo de ar que passa pela lâmina (GREGORY. et al., 2014).

Dessa forma, podemos comprovar as variações da intensidade fotoluminescente em diferentes velocidades nas duas amostras analisadas. Devido as limitações físicas do túnel a velocidade foi limitada, não sendo possível analisar em velocidades superiores.

\subsubsection{Teste no modelo}

Conforme descrito anteriormente, os testes foram efetuados em velocidades que variavam de $90 \mathrm{~km} \mathrm{~h}^{-1}$ a $107 \mathrm{~km} \mathrm{~h}^{-1}$ (velocidade máxima) atingida pelo túnel. Porém, somente as velocidades $95 \mathrm{~km} \mathrm{~h}^{-1}$ e $107 \mathrm{~km} \mathrm{~h}^{-1}$ apresentaram resultados relevantes para o processo. O procedimento para testes efetuados foram, uma foto com o túnel desligado e com ele ligado (KOSE, 2005) nas velocidades: $90 \mathrm{~km} \mathrm{~h}^{-1}, 95 \mathrm{~km} \mathrm{~h}^{-1}, 100 \mathrm{~km} \mathrm{~h}^{-1}$ e $107 \mathrm{~km} \mathrm{~h}^{-1}$.

Um total de 3 bancos de imagens foram gerados durante o período de 3 horas, com o intervalo de testes a cada hora. 


\subsubsection{Primeira sequência de testes}

Na figura 46 temos as imagens em escala cinza que foram obtidas durante as medições. A primeira imagem apresenta o corpo no momento em que o túnel está desligado, a segunda imagem apresenta uma pequena variação em relação a primeira quando o corpo é submetido a uma velocidade de $95 \mathrm{~km} \mathrm{~h}^{-1}$ e a última imagem, com uma maior relevância de resultado quando o corpo é submetido a uma velocidade de $107 \mathrm{~km} \mathrm{~h}^{-1}$. Com base nas imagens apresentadas na figura 46 é possível notar pequenas variações de pressão no modelo. 


\section{Desligado}
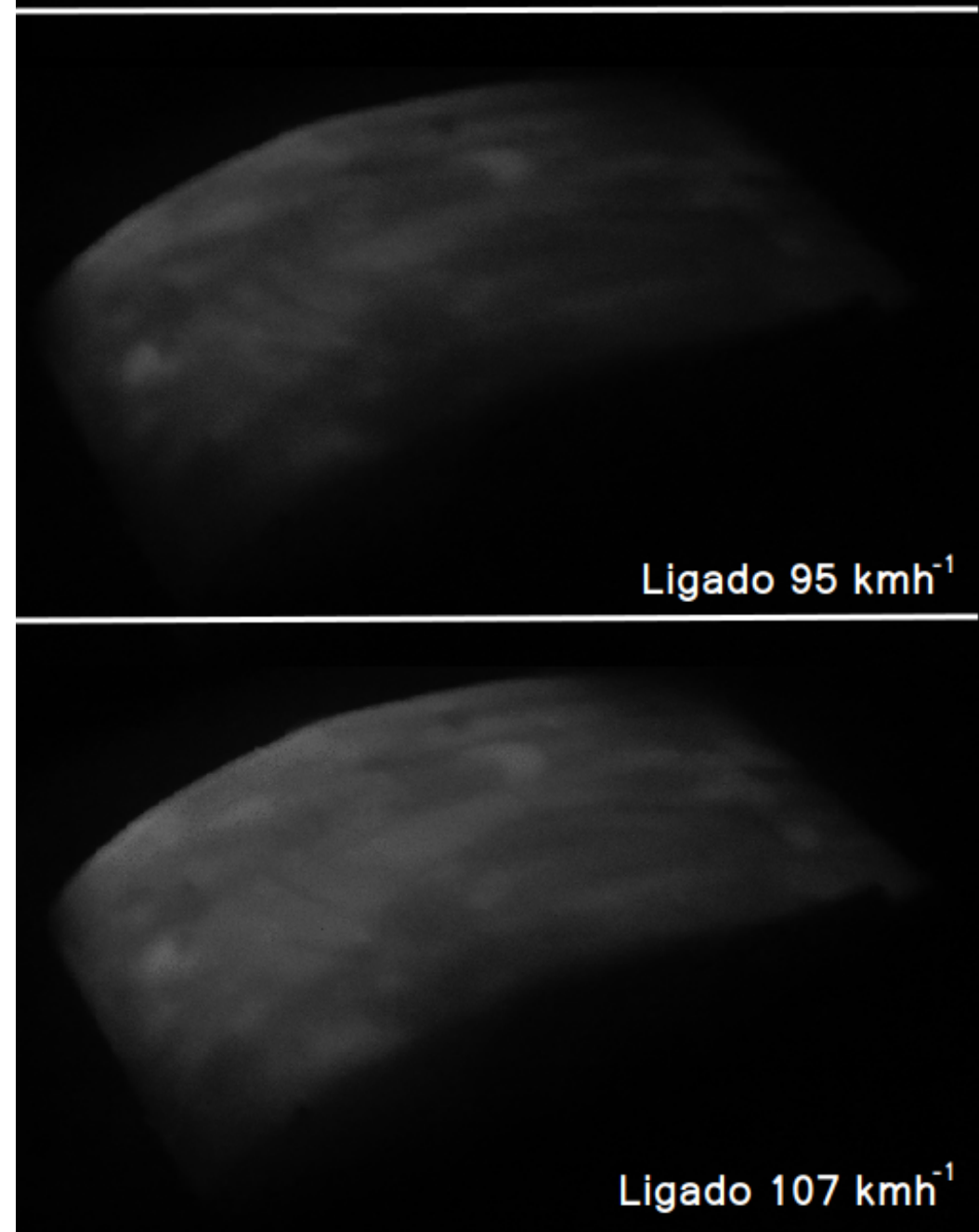

Figura 46 - Amostras em escala cinza no interior do túnel, com o sistema desligado, a $95 \mathrm{~km} \mathrm{~h}^{-1}$ e a $107 \mathrm{~km} \mathrm{~h}^{-1}$ da primeira sequência de testes.

\section{Fonte: Autor}

Para verificar a intensidade da resposta de emissão fotoluminescente da amostra foram gerados os histogramas de cada imagem (KOSE, 2005) (NAVARRA, 1997), utilizando o mesmo método efetuado com as lâminas. Lembrando que, quanto mais próximo a "1" 
maior será a intensidade fotoluminescente; e quanto mais próximo a "0", menor será a intensidade fotoluminescente.

No gráfico 9 (a) temos o histograma representando a amostra com o túnel desligado para comparar com as imagens do túnel em diferentes velocidades. Verificamos que a intensidade não ultrapassa o 0,3, porém, é superior a intensidade, com o túnel desligado, se comparados com as amostras depositadas na lâmina de vidro. No gráfico 9 (b) é apresentado o histograma da intensidade fotoluminescente com o túnel a $95 \mathrm{~km} \mathrm{~h}^{-1}$, a qual, pode-se verificar variações de intensidade entre 0,2 e 0,3, não ocorreu um aumento significativo da região mais clara, porém, houve aumento da intensidade fotoluminescente nas regiões ativadas durante os testes.

Já no gráfico 9 (c) temos o terceiro resultado com a maior significância com os dados obtidos entre o túnel desligado e ligado à velocidade máxima, de $107 \mathrm{~km} \mathrm{~h}^{-1}$. O nível da escala cinza da imagem se aproximou de 0,4 , mostrando uma região maior de emissão fotoluminescente, além de um aumento significativo da intensidade entre 0,2 e 0,4. Esse foi o resultado com maior significância obtido durante os testes, o que, causou a maior percepção de emissão fotoluminescente, pois, as alterações na superfície das amostras anteriores eram praticamente imperceptíveis sem uso de instrumentos específicos. Outro fator relevante, foi que, em determinadas regiões a intensidade dos pixeis diminuiu; isso ocorre, devido a diminuição da pressão nessa região em comparação com a situação anterior; a maior alteração ocorreu na região com escala cinza entre 0,05 e 0,15.

Portanto, o limiar para análise desta amostra com as demais foi 0,2 da escala cinza e a intensidade dos pixeis nas demais amostras. 


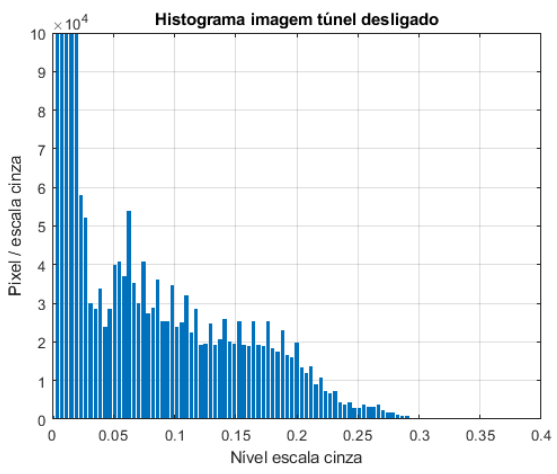

(a) Intensidade fotoluminescente com o túnel desligado.

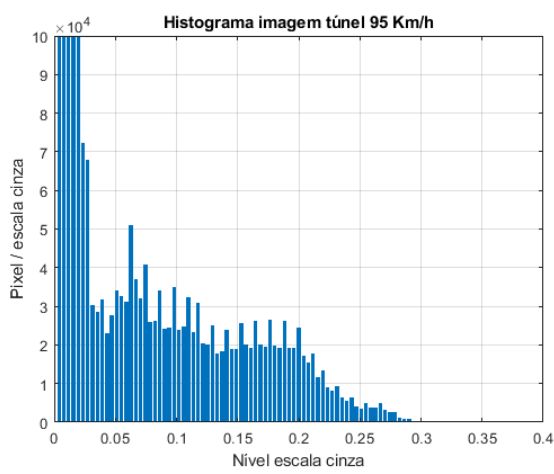

(b) Intensidade fotoluminescente com velocidade de $95 \mathrm{~km} \mathrm{~h}^{-1}$

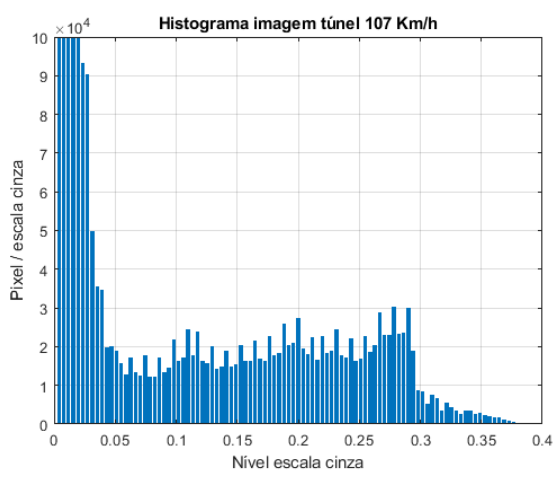

(c) Intensidade fotoluminescente com velocidade de $107 \mathrm{~km} \mathrm{~h}^{-1}$

Gráfico 9 - Histograma gerado das imagens tiradas com o túnel desligado, ligado a $95 \mathrm{~km} \mathrm{~h}^{-1}$ e $107 \mathrm{~km} \mathrm{~h}^{-1}$ da primeira sequência de testes.

\section{Fonte: Autor}

Após análises dos histogramas gerados, a imagem foi binarizada para destacar a relevância das alterações fotoluminescentes durante o processo. O limiar selecionado para binarizar a imagem foi de 0,2 , pois, foi o ponto que apresentou maior relevância nas alterações da resposta fotoluminescente da amostra. Na figura 47 podemos verificar que houve alterações em relação ao túnel ligado e desligado a partir de $95 \mathrm{~km} \mathrm{~h}^{-1}$, com o resultado de maior relação ligado/desligado a $107 \mathrm{~km} \mathrm{~h}^{-1}$. 

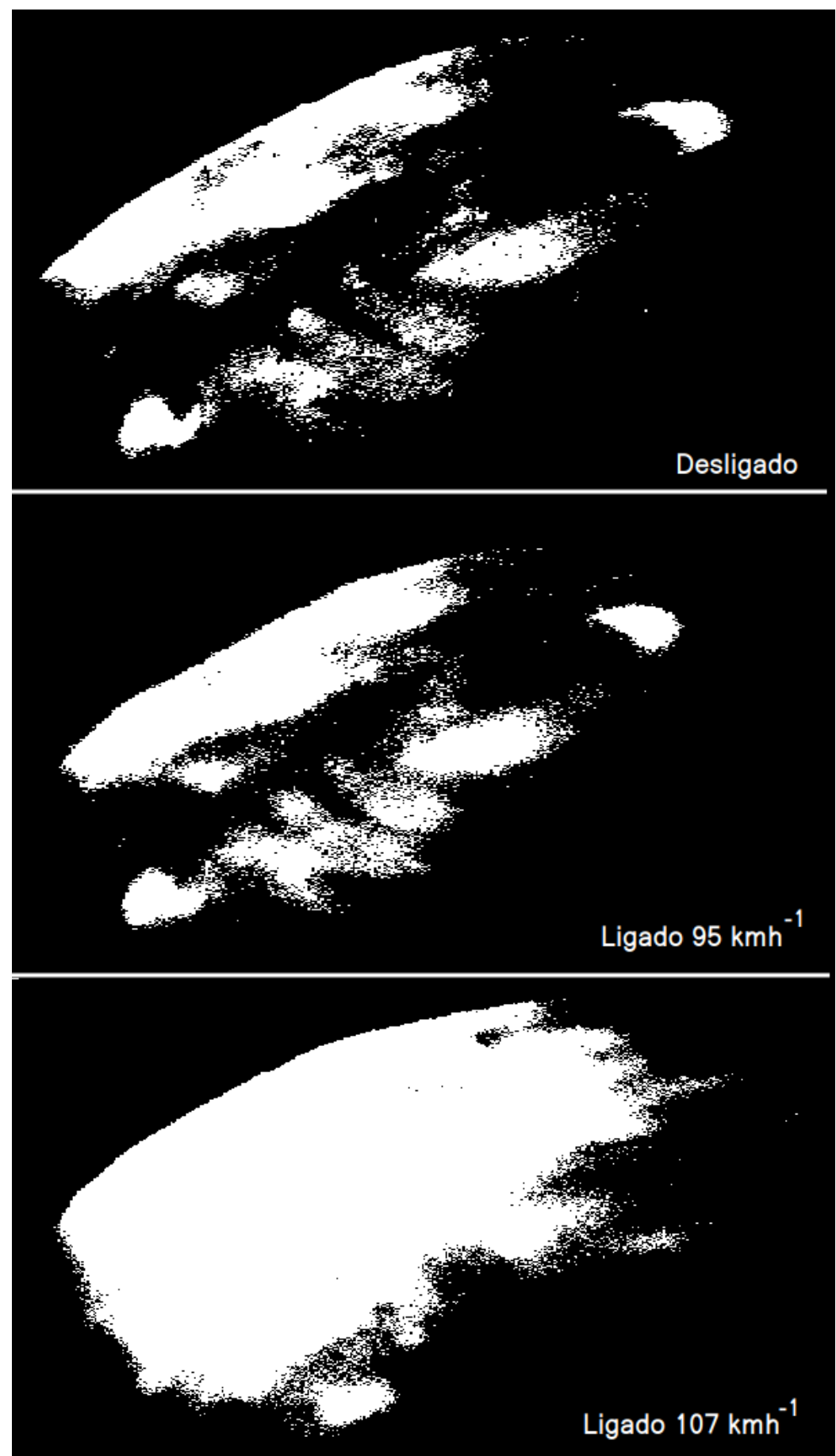

Figura 47 - Imagem binarizada do modelo na primeira sequência de testes.

\section{Fonte: Autor}

\subsubsection{Segunda sequência de testes}

Após uma hora da primeira sequência de testes foi efetuada uma nova sequência nas mesmas condições da primeira. 
Na figura 48 temos a imagem em escala cinza, sendo a primeira, com o túnel desligado, a segunda com o túnel ligado a $95 \mathrm{~km} \mathrm{~h}^{-1}$ e a terceira com o túnel a $107 \mathrm{~km} \mathrm{~h}^{-1}$. As variações entre a primeira imagem e a segunda é pouco perceptível, porém, entre a primeira e a última a diferença se torna mais nítida. 


\section{Desligado}

\section{Ligado $95 \mathrm{kmh}^{-1}$}

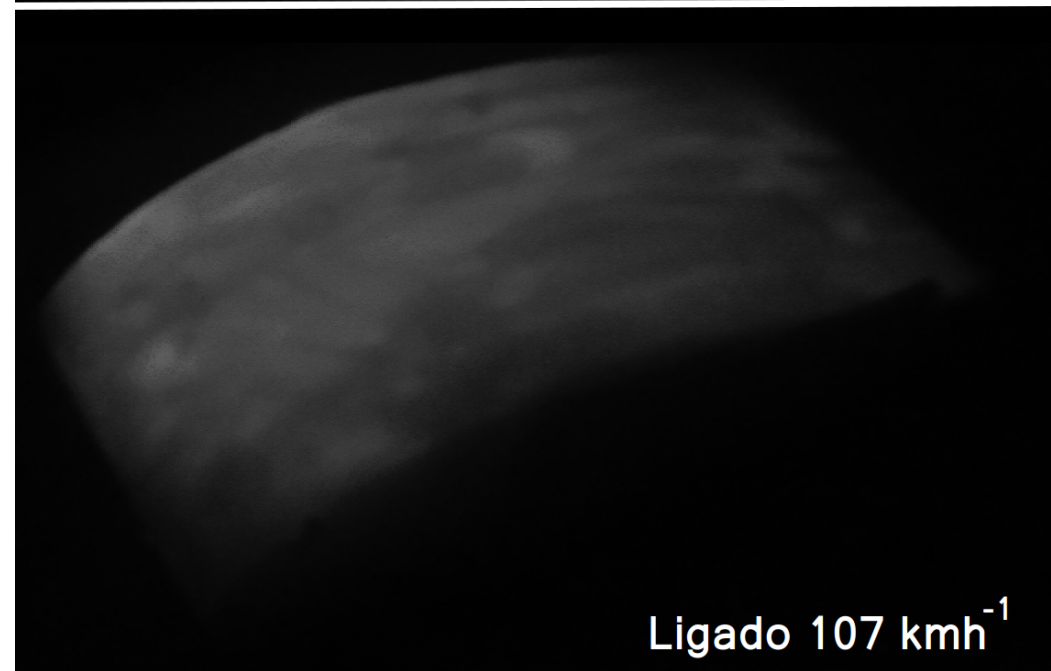

Figura 48 - Amostras em escala cinza no interior do túnel, com o sistema desligado, a $95 \mathrm{~km} \mathrm{~h}^{-1}$ e a $107 \mathrm{~km} \mathrm{~h}^{-1}$ da segunda sequência de testes.

\section{Fonte: Autor}

Conforme o procedimento anterior foram gerados os histogramas das imagens de cada uma das velocidades submetidas. No gráfico 10 (a) temos o histograma da imagem tirada com o túnel desligado, o qual, podemos verificar que os valores são similares à 
primeira sequência de testes. No gráfico 10 (b) temos o histograma do túnel com velocidade de $95 \mathrm{~km} \mathrm{~h}^{-1}$. Neste caso houve uma pequena variação para baixo na escala cinza em relação ao túnel desligado (gráfico 10 (a)), ocorrendo um aumento na intensidade fotoluminescente em algumas regiões. Neste caso a variação foi inferior à apresentada na primeira sequência de testes.

Já na velocidade máxima de $107 \mathrm{~km} \mathrm{~h}^{-1}$ a variação entre o túnel ligado e desligado foi considerável, conforme apresentado no gráfico 10 (c). Além disso, a relação intensidade fotoluminescente x escala cinza é similar a primeira sequência de testes.

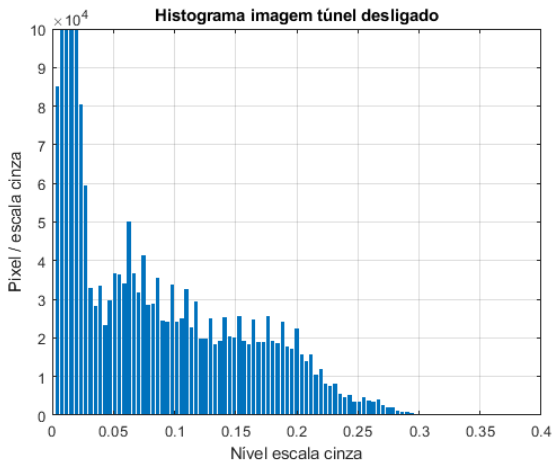

(a) Intensidade fotoluminescente com o túnel desligado.

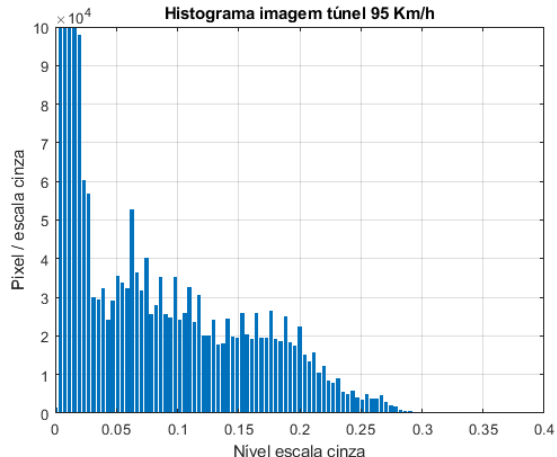

(b) Intensidade fotoluminescente com velocidade de $95 \mathrm{~km} \mathrm{~h}^{-1}$

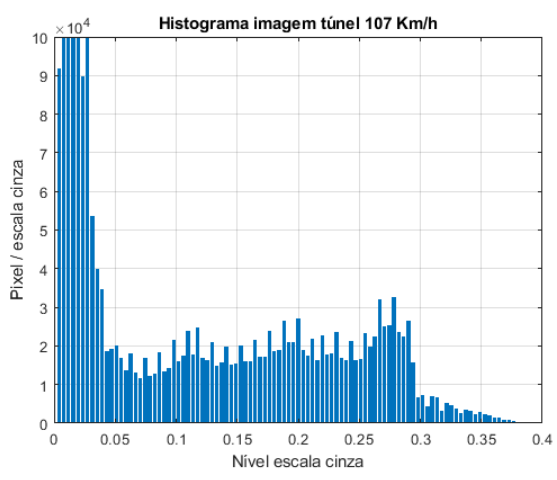

(c) Intensidade fotoluminescente com velocidade de $107 \mathrm{~km} \mathrm{~h}^{-1}$

Gráfico 10 - Histograma gerado das imagens tiradas com o túnel desligado, ligado a $95 \mathrm{~km} \mathrm{~h}^{-1}$ e $107 \mathrm{~km} \mathrm{~h}^{-1}$ da segunda sequência de testes.

Fonte: Autor

O ponto de limiar da variação de intensidade permaneceu em torno de 0,2 , apesar de ter diminuído na amostra a $95 \mathrm{~km} \mathrm{~h}^{-1}$. Para manter o padrão em relação às primeiras análises, o limiar para gerar a imagem binarizada permaneceu em 0,2.

Na figura 49 temos a imagem binarizada da segunda sequência de testes. Dessa vez, a diferença entre a imagem do túnel desligado e a uma velocidade de $95 \mathrm{~km} \mathrm{~h}^{-1}$ é 
pequena, com alguns pontos em branco a mais que a do túnel desligado. Já a imagem com velocidade a $107 \mathrm{~km} \mathrm{~h}^{-1}$ se destaca como podemos verificar.
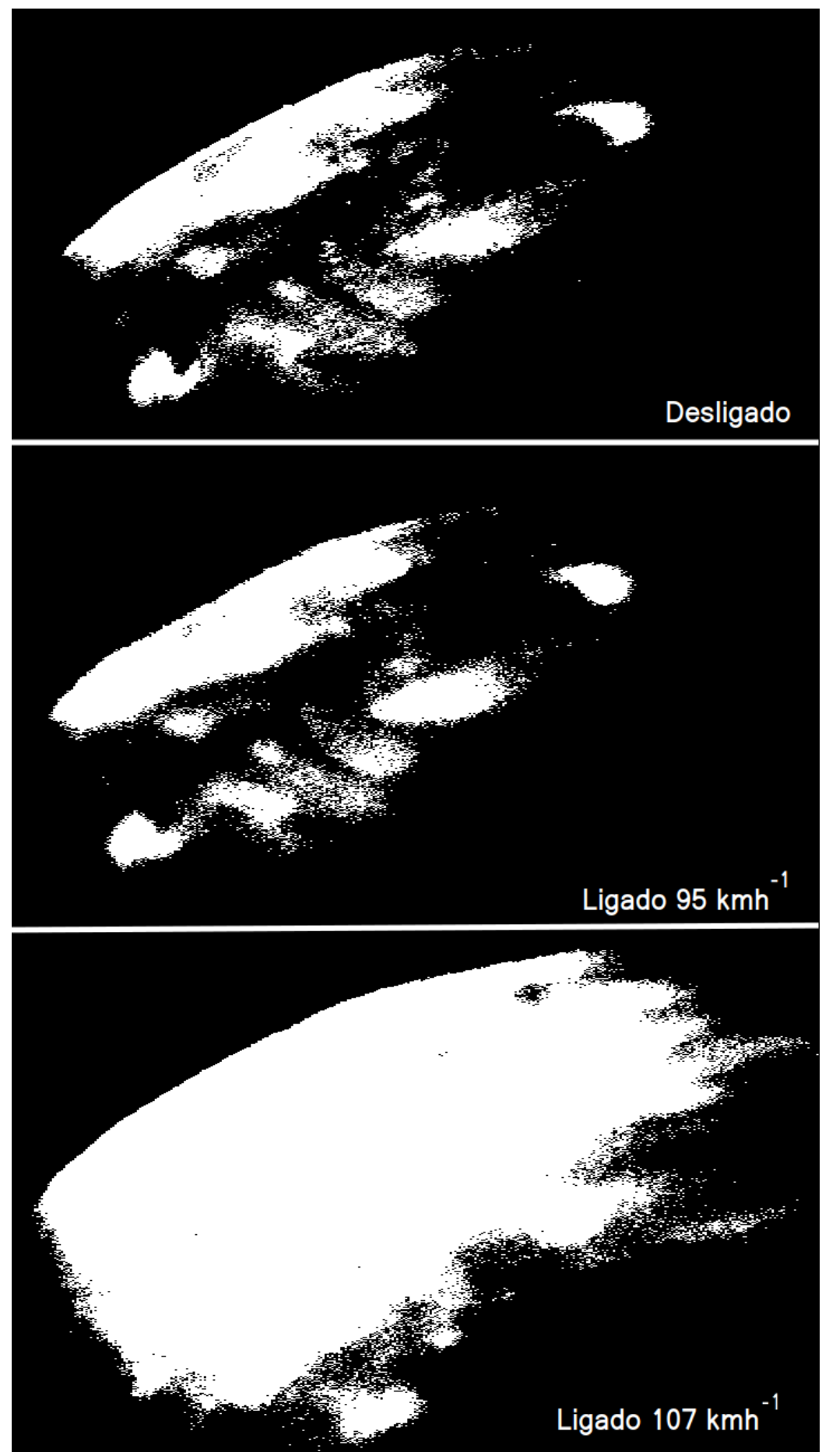

Figura 49 - Imagem binarizada do modelo na segunda sequência de testes.

Fonte: Autor 


\subsubsection{Terceira sequência de testes}

A terceira e última sequência de testes está sendo apresentada na figura 50. Novamente as mesmas condições dos testes anteriores foram mantidas.

Na figura 50 temos as três imagens tiradas com o túnel desligado, com velocidade de $95 \mathrm{~km} \mathrm{~h}^{-1}$ e a $107 \mathrm{~km} \mathrm{~h}^{-1}$, respectivamente. 


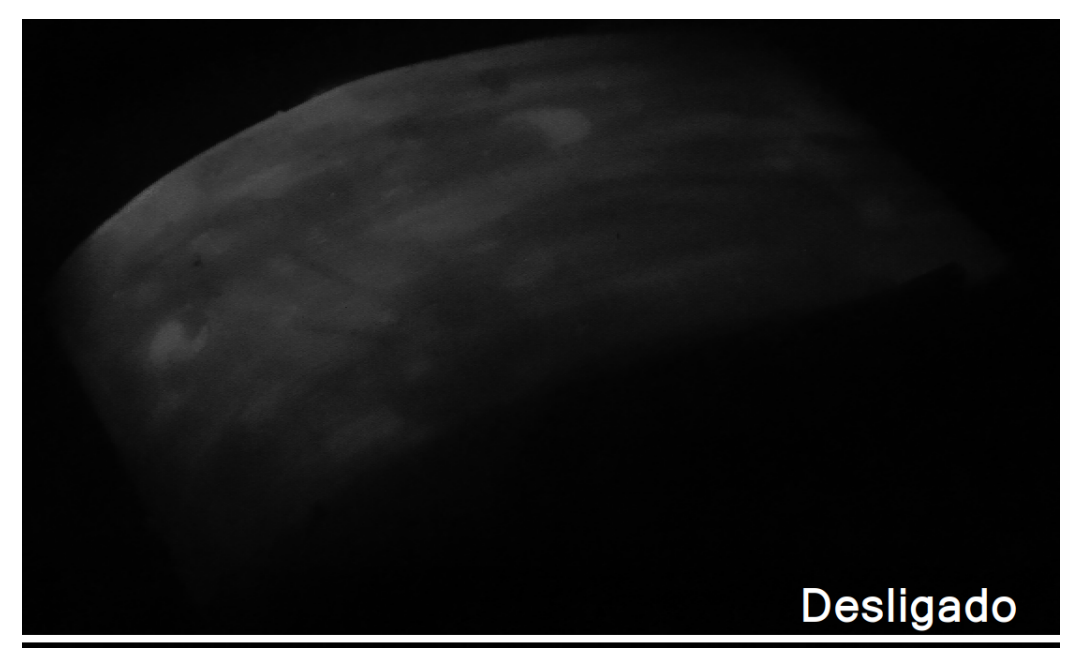

Ligado $95 \mathrm{kmh}^{-1}$

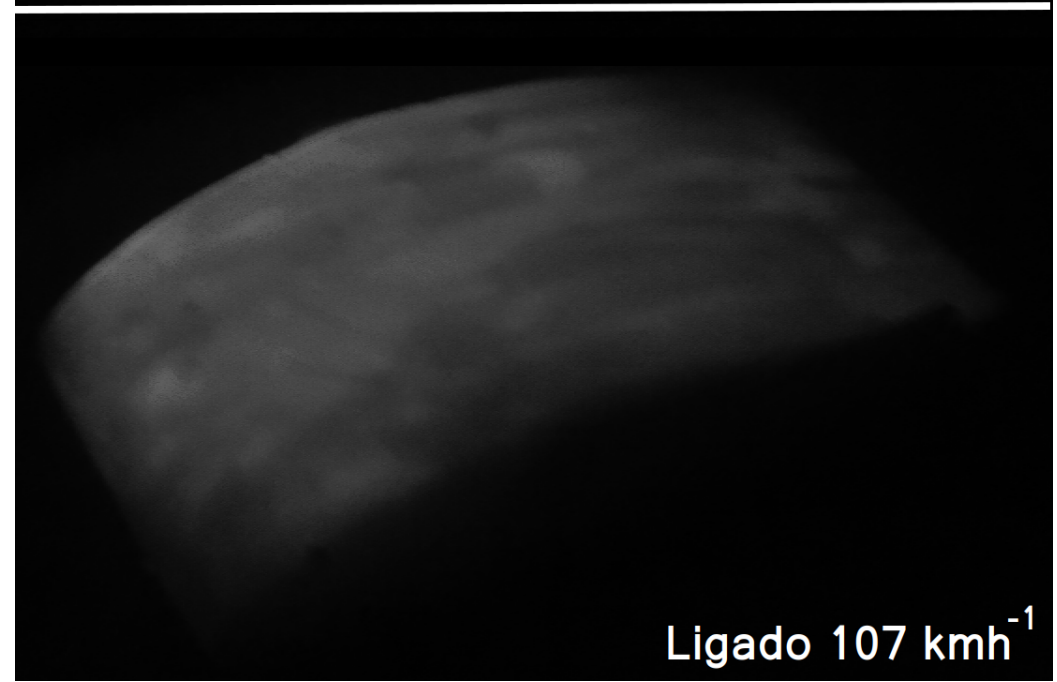

Figura 50 - Amostras em escala cinza no interior do túnel, com o sistema desligado, a $95 \mathrm{~km} \mathrm{~h}^{-1}$ e a $107 \mathrm{~km} \mathrm{~h}^{-1}$ da terceira sequência de testes.

Fonte: Autor

No gráfico 11 (a) temos o histograma da imagem com o túnel desligado, a relação intensidade x escala cinza permanece como as demais analisadas anteriormente. No gráfico 
11 (b) temos o histograma da imagem tirada a uma velocidade de $95 \mathrm{~km} \mathrm{~h}^{-1}$. Nela podemos ver um pequeno aumento na intensidade a partir de 0,25 da escala cinza.

Na velocidade de $107 \mathrm{~km} \mathrm{~h}^{-1}$ houve um considerável aumento na intensidade fotoluminescente da amostra, conforme apresentado no gráfico 11 (c), chegando próximo a 0,4, como visto nas sequências de testes anteriores.

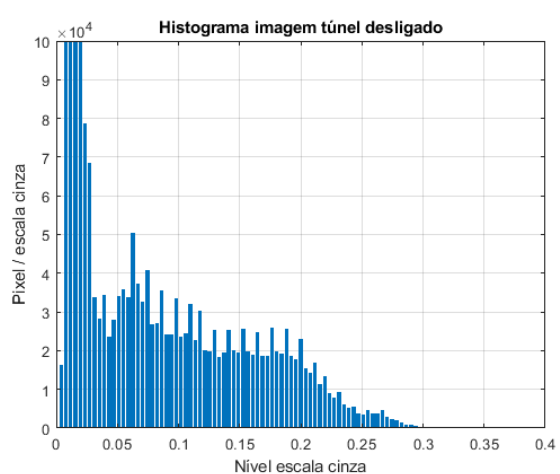

(a) Intensidade fotoluminescente com o túnel desligado.

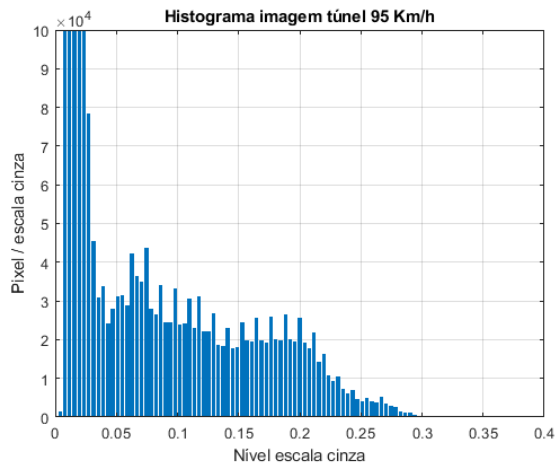

(b) Intensidade fotoluminescente com velocidade de $95 \mathrm{~km} \mathrm{~h}^{-1}$

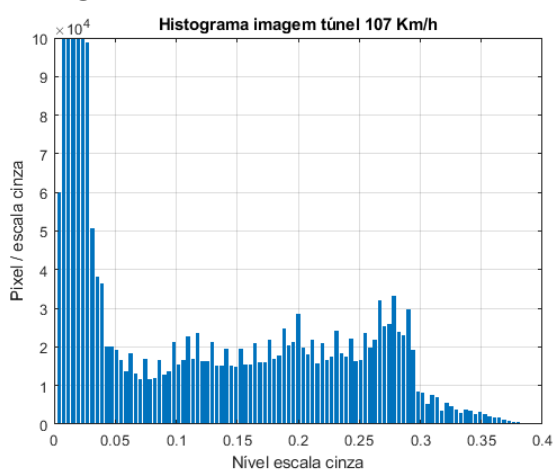

(c) Intensidade fotoluminescente com velocidade de $107 \mathrm{~km} \mathrm{~h}^{-1}$

Gráfico 11 - Histograma gerado das imagens tiradas com o túnel desligado, ligado a $95 \mathrm{~km} \mathrm{~h}^{-1}$ e $107 \mathrm{~km} \mathrm{~h}^{-1}$ da terceira sequência de testes.

\section{Fonte: Autor}

A imagem binarizada apresentada na figura 51 dos testes foi gerado com o mesmo valor de limiar de 0,2 utilizado nos testes anteriores.

Vale ressaltar que neste caso a imagem tirada a $95 \mathrm{~km} \mathrm{~h}^{-1}$ houve um pequeno aumento da intensidade em relação ao segundo teste. Já na terceira imagem a intensidade na velocidade de $107 \mathrm{~km} \mathrm{~h}^{-1}$ permaneceu a mesma dos testes anteriores. 

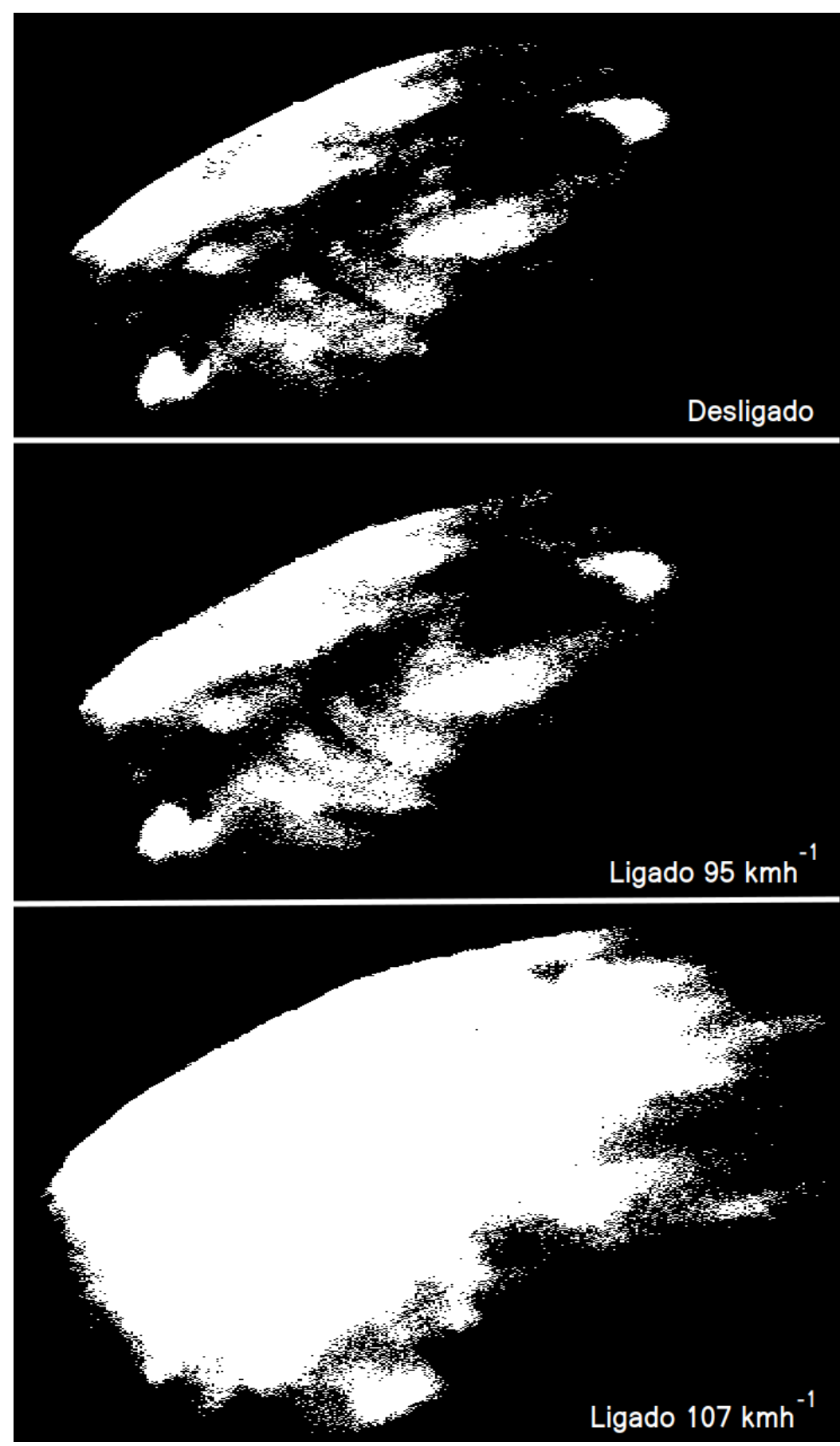

Figura 51 - Imagem binarizada do modelo na terceira sequência de testes.

\section{Fonte: Autor}

Os diferentes pontos apresentados com relevância na alteração ocorreram devido a não uniformidade da pintura da amostra no corpo, sendo influenciado pela composição química da amostra com tempo de secagem e evaporação curtos, causando não uniformidades à pintura. 


\section{CONCLUSÕES}

No presente trabalho foi projetado e fabricado um sistema de túnel de vento com controles automatizados para a leitura da velocidade do vento e temperatura que permitiram controlar a velocidade do vento desejada na área de ensaios dinâmicos do túnel. O túnel de vento assim projetado foi aplicado no monitoramento da pressão dinâmica de um sistema aerodinâmico utilizando-se o principio de emissão fluorescente de uma tinta baseada em uma solução de PVC dopada com moléculas de Octaetilporfirina de platina $(\mathrm{PtOEP})$.

As dimensões geométricas do túnel de vento utilizadas no processo de fabricação foram projetadas para obter velocidades de vento na faixa de 0 a $200 \mathrm{~km} \mathrm{~h}^{-1}$, estes resultados foram obtidos utilizando-se o programa computacional COMSOL Multiphysics. Os resultados, da simulação, mostraram que formatos com seções transversais circulares são mais eficientes no dimensionamento da potência do motor e velocidade máxima do vento no túnel de vento, desta forma fabricamos um túnel de vento com secções transversais circulares.

A monitoração da velocidade do vento foi obtida utilizando-se dispositivos utilizados em processos industriais, o Annubar, permitiu a obtenção da velocidade média do vento na região ativa do túnel já que este dispositivo é aplicado para medir a velocidade media no interior de tubulações. O Annubar foi calibrado utilizando-se um tubo de Pitot que em general apresenta uma excelente resolução espacial.

O sistema de controle foi implementado a partir de um CLP S7-1500, que é um dispositivo de controle, de uma nova linha de CLPs da SIEMENS utilizado em processos industriais de médio e grande porte. Adicionalmente foi introduzido um sistema de sensoreamento inteligente IO-Link, que possui inteligência embarcada no elemento sensor e envia informações de diagnóstico aos níveis superiores de controle, diminuindo necessidades de processamento por parte do controlador.

Os dados obtidos como resultado dos processos de medição dos diferentes parâmetros do túnel de vento junto com os parâmetros de controle foram armazenados no banco de dados $S Q L$ Server para posteriores análises, como por exemplo, o intervalo de uso do sistema, devido as limitações do motor. Assim o sistema automatizado do túnel de vento projetado e fabricado nos forneceu uma faixa de velocidades entre 0 e $107 \mathrm{~km} \mathrm{~h}^{-1}$, resultado 
menor ao projetado teoricamente. Esta diferença é atribuído às limitações impostas pela máxima potência do motor utilizado.

A monitoração de pressão dinâmica foi obtida através do uso de um sistema ótico constituída de um diodo laser de comprimento de onda de $380 \mathrm{~nm}$ como fonte excitadora e uma câmera com sensor CMOS como sistema detector, este sistema permitiu a obtenção de imagens da pressão dinâmica na superfície do objeto aerodinâmico em analises previamente pintada com a tinta sensível. Os resultados das imagens de pressão dinâmica obtidos no presente trabalho correspondem a pontos extremos da velocidade do vento no túnel (0 e $107 \mathrm{~km} \mathrm{~h}^{-1}$ ), isto foi devido às limitações de sensibilidade da câmara utilizada no presente projeto. No entanto, o sistema projetado e o método proposto para a medição da pressão dinâmica mostrou-se adequado para se obter uma imagem de pressão dinâmica de superfícies aerodinâmicas, deve se considerar também que outra limitação imposta no sistema esta relacionado com a máxima velocidade do vento $\left(107 \mathrm{~km} \mathrm{~h}^{-1}\right)$.

Os resultados obtidos no presente trabalho podem ser melhorados, se for utilizado um sistema de túnel de vento com circuito fechado, já que neste sistema o consumo de potência do motor é otimizado dando margem para atingir velocidades acima dos obtidos no presente trabalho. O sistema ótico de medição pode ser otimizado utilizando câmaras CCD de elevada sensibilidade, por exemplo, nos espectrômetros Raman. 


\section{REFERÊNCIAS}

ARIFUZZAMAN, M. M. M. Design construction and performance test of a low cost subsonic wind tunnel. IOSR Journal of Engineering (IOSRJEN), www.iosrjen.org, v. 2, p. 83-92, 2012.

BASU, B. J.; VASANTHARAJAN, N.; RAJU, C. A novel pyrene-based binary pressure sensitive paint with low temperaturecoefficient and improved stability. Sensors and Actuators B: Chemical, ELSEVIER, p. 283-288, 2009.

BENSON, T. The Wandering Wind Tunnel. 2014. Disponível em: <http: //www.grc.nasa.gov/WWW/K-12/WindTunnel/wandering_windtunnel.html>. Acesso em: 19 dez. 2016.

BOLTON, W. Programmable Logic Controllers. 4. ed. [S.l.]: ELSEVIER, 2006.

BRAGA, M.; SALCEDO, W. Sensores ópticos multiespectrais e espectrofotômetro portátil para detecção de gases e íons metálicos. [S.l.]: CRV, 2018. 166 p.

BRAGA, M. S. Sistemas optoeletrônicos portáteis para detecção de gases, oxigênio dissolvido e de metais pesados aplicados no controle ambiental. Tese (Doutorado em Microeletrônica). Escola Politécnica, Universidade de São Paulo. 2016.

CARE, I.; BONTHOUX, F.; FONTAINE, J. R. Measurement of air flow in duct by velocity measurements. IntechOpen, EDP Sciences, 2014.

CARL ZEISS. Filter Assistant. 2018. Disponível em: <https://www.micro-shop.zeiss.com/ en/us/shop/filterAssistant/filtersets/488050-9901-000>. Acesso em: 10 mar. 2018.

CHR., K. et al. Application of pressure sensitive paint (psp) for determination of the pressure field and calculation of forces and moments of models in a wind tunnel. Institute of Aerodynamics and Flow Tecnology, 2005.

COMMUNITY, I.-L. C. IO-Link System Description - Technology and Application. [S.1.], 2013.

DATE, C. Relational Theory for Computer Professionals. [S.l.]: O'Reilly Media, Inc., 2013. ISBN 9781449365431.

DELMEE, G. J. Manual de medição de vazão. 3. ed. [S.l.]: Editora Edgard Blücher Ltda, 2003.

DOMMELEN, R. v. Design of an Atmospheric Boundary Layer Wind Tunnel. Thesis (Master).Department of built environment, the Eindhoven University of Technology. 2013.

EBAY. 2pcs 380nm Bandpass Filter Blue Optical Filter Dia.

25mm. 2018. Disponível em: <https://www.ebay.com/itm/

2pcs-380nm-Bandpass-Filter-Blue-Optical-Filter-350NM-450NM-Pass-Dia-25mm-/

262718581490>. Acesso em: 10 mar. 2018.

ENGLER, R. H.; CHR, K. Pressure sensitive paint systems for pressure distribution measurements in wind tunnels and turbomachines. Meas. Sci. Technol., v. 11, p. 1770-1085, 2000. 
FRANCHI, C. Acionamentos Elétricos. 4. ed. [S.l.]: Ed. Erica, 2008.

GARCIA, C. Modelagem e simulação de processos industriais e de sistemas eletromecânicos. 2. ed. São Paulo: EDUSP, 2005.

GREGORY, J. W. et al. A review of pressure-sensitive paint for high-speed and unsteady aerodynamics. Proc. IMechE, Division of Fluid Dynamics, p. 243-290, 2008.

GREGORY., J. W. et al. Fast pressure-sensitive paint for flow and acoustic diagnostics. The Annual Review of Fluid Mechanics, AR - Reviews in Advance, p. 303-303, 2014.

HALL, N. Closed return wind tunnel. 2015. Disponível em: <https://www.grc.nasa.gov/ www/k-12/airplane/tuncret.html>. Acesso em: 28 jul. 2017.

HALL, N. Conservation of Mass. 2015. Disponível em: <https://www.grc.nasa.gov/www/ k-12/airplane/mass.html>. Acesso em: 18 out. 2016.

HALL, N. Open return wind tunnel. 2015. Disponível em: <https://www.grc.nasa.gov/ www/k-12/airplane/tunoret.html>. Acesso em: 28 jul. 2017.

HALL, N. Wind tunnel design. 2015. Disponível em: <https://www.grc.nasa.gov/www/ k-12/airplane/tunnozd.html>. Acesso em: 10 jun. 2017.

HALL, N. Wind Tunnel Theory. 2015. Disponível em: <https://www.grc.nasa.gov/ WWW/K-12/airplane/tunnozt.html>. Acesso em: 10 jun. 2017.

HALL, N. Wind tunnels. 2015. Disponível em: <https://www.grc.nasa.gov/www/k-12/ airplane/bgt.html>. Acesso em: 25 jul. 2017.

HERNANDEZ, M. A. G. et al. Design methodology for a quick and low-cost wind tunnel. IntechOpen, Wind Tunnel Designs and Their Diverse Engineering Applications, p. 3-28, 2013.

HITT, D. What Are Wind Tunnels. [S.l.]: Nasa Educational Tecnology Services, 2008.

HOFFPAUIR, D. Pressure Sensitive Paint for Measuring Unsteady Launch Vehicle Aerodynamic Buffet. 2017. Disponível em: <https://www.nasa.gov/feature/ pressure-sensitive-paint-for-measuring-unsteady-launch-vehicle-aerodynamic-buffet $>$. Acesso em: 10 jul. 2019.

IFM. Manual de instruções Unidade de avaliação para sensores de temperatura. [S.l.], 2011.

IFM. TR2432 - Control monitor for temperature measurement, $-40^{\circ} \mathrm{C}$ to $300^{\circ} \mathrm{C}$. [S.l.], 2012 .

ISA. ANSI/ISA-5.1-2009 - Instrumentation Symbols and Identification. [S.1.], 2009.

JAHANMIRI, M. Pressure sensitive paints: The basics and applications. Division of Fluid Dynamics, 2011.

KIRK, F. W.; WEEDON, T. A.; KIRK, P. Instrumentation. 5. ed. [S.l.]: American Technical Publishers, 2006. 
KOSE, M. E. Multi-Luminophore Coatings for Pressure Sensitive Paint Applications. Thesis (PhD). 2005.

LIPTAK, B. G. Process Measurement and Analysis. 4. ed. [S.l.]: CRC PRESS, 2003.

MAGRYTA, P. Wind tunnel research on the influence of active airflow on the lift force generated by the airfoil. Advances in Science and Technology Research Journal, v. 7, n. 19, p. $60-65,2013$.

MATOS, K. R. M. Filmes Sensiveis a Pressão pela Técnica de Fotoluminescência. Dissertação (Mestrado) — Escola Politécnica, Universidade de São Paulo, 2011.

MERBARKI, Y. Pressure sesitive paint: From laboratory to wind tunnel. Icas 2000 Congress, Intitute for Aerospace Research, 2000.

MITSUO, K.; NAKAKITA, K.; KURITA, M. Investigation of image-based lifetime psp measurements with sinusoidal excitation light. International Congress of the Aeronautical Sciences, ICAS, 2004.

NAVARRA, K. R. Development of the Pressure-Sensitive-Paint Technique for advanced turbomachinery applications. Dissertação (Mestrado) - Virginia Polytechnic Institute and State University, 1997.

NIKON. Câmera digital D5100 - Manual do usuário. [S.l.], 2011.

PERFECT PRIME. PT6300 304 Stainless Steel Pitot-Static Tube 300mm x 110mm. 2018. Disponível em: <https://perfectprime.com/products/pt6300>. Acesso em: 08 jan. 2018.

ROSEMOUNT. Rosemount Annubar Primary Flow Element Flow Test Data Book. [S.l.], 2009. Disponível em: <https://www.emerson.com/documents/automation/ manual-rosemount-annubar-primary-flow-element-flow-test-data-book-en-74372.pdf $>$. Acesso em: 14 mar. 2018.

SCALEGRID. 2019 Database Trends - SQL vs. NoSQL, Top Databases, Single vs. Multiple Database Use. 2019. Disponível em: <https://scalegrid.io/blog/ 2019-database-trends-sql-vs-nosql-top-databases-single-vs-multiple-database-use $/>$. Acesso em: 04 abr. 2019.

SIEMENS. The intelligent choice for your automation tasks - SIMATIC Controllers. [S.l.], 2016.

SIEMENS. ET 200SP - Communication module IO-Link Master CM 4xIO-Link (6ES7137-6BD00-0BA0). [S.1.], 2017.

SIEMENS. ET 200SP IM 155-6 PN ST interface module (6ES7155-6AU01-0BN0). [S.1.], 2017.

SIEMENS. Acyclic Reading and Writing using the "IO-Link Library". [S.1.], 2018.

SILBERSCHATZ, A.; KORTH, H. F.; SUDARSHAN, S. DATABASE SYSTEM

CONCEPTS. 6. ed. [S.1.]: McGraw-Hill, 2011. ISBN 978-0-07-352332-3.

SPAHN, J.; STEELMAN, R. How to build and use a subsonic wind tunne. 2015.

Disponível em: <http://www.sciencebuddies.org/science-fair-projects/wind-tunnel-toc. shtml\#introductionl>. Acesso em: 13 ago. 2017. 
WEG. CFW09 - Manual do usuário. [S.1.], 2006.

WEG. Guia Técnico - Motores de indução alimentados por conversores de freqüência PWM. 2006. Disponível em: <http://www.coe.ufrj.br/ richard/Acionamentos/motores de_inducao_alimentados_por_conversores_de_frequencia_PWM.pdf $>$. Acesso em: 04 fev. 2018 .

WEG. Guia de aplicação de inversores de frequência. WEG Automação, WEG, 2014.

YORITA, D. et al. Investigation of image-based lifetime psp measurements with sinusoidal excitation light. American Institute of Aeronautics and Astronautics, DLR, 2019. 
Apêndices 


\section{Apêndice A - Lógica de Controle}

Desenvolvimento lógico do sistema de controle do túnel de vento. Todo o desenvolvimento foi elaborado em blocos, a iniciar pelo bloco Organization Block 100 (OB100), que é uma $\mathrm{OB}$ de inicialização, esse bloco executa somente uma vez, no primeiro ciclo de clock da CPU, sendo utilizado para limpar as memórias na inicialização do programa.

O segundo bloco é a Main(OB1), que é o programa principal, o qual, chama todos os blocos de funções que executam conversões, leitura de dados e ações de controle.

As Functions (FC) e as Functions Block (FB) são Funções e Blocos de Funções, respectivamente, que executam conversões matemáticas e ações no sistema, além disso, são utilizadas para organizar a estrutura do programa, assim, facilita a organização lógica de controle do processo.

O bloco chamado IO_LINK_DEVICE (FB50001) é um bloco utilizado para estabelecer comunicação via dispositivos IO-Link e foi baixado diretamente do suporte da Siemens, ou seja, foi desenvolvido pela equipe da Siemens e liberado para Download. 
Totally Integrated
Automation Portal

\section{Startup [OB100]}

Startup Properties

General

Name Startup

\begin{tabular}{l} 
Startup \\
Automatic \\
\hline
\end{tabular}

Number

Type

OB

Language

LAD

Numbering

Information "Complete Restart"

Author

Comment

Family

Version

0.1

User-defined ID

$\nabla$ Input

Data type

Default value

Supervision Comment

\begin{tabular}{|l|l|l}
\hline LostRetentive & Bool & True if retentive data are lost
\end{tabular}

\begin{tabular}{|l|l|l}
\hline LostRTC & Bool & True if date and time are lost
\end{tabular}

Constant

Network 1:

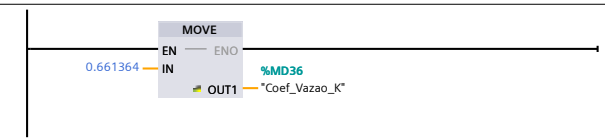

Network 2:

\begin{tabular}{|c|c|} 
MOVE & \\
\hline EN & \\
\hline $1.019-$ IN & - OUT1 - "PressaoAtm" \\
&
\end{tabular}


Totally Integrated

Automation Portal

\section{Main [OB1]}

Main Properties

General

Numbering Automatic

\begin{tabular}{|l|l|}
\hline Information & "Main Program Sweep (Cy- \\
cle)"
\end{tabular}

$\begin{array}{ll} & \\ \text { Version } & 0.1\end{array}$

Number

Type

LAD

Name

User-defined ID

$\checkmark$ Input

Data type Default value

Comment

Family

Initial_Call

Remanence

Temp

Constant

Network 1

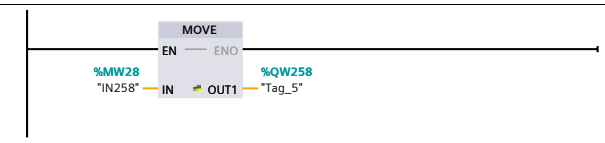

Network 2:

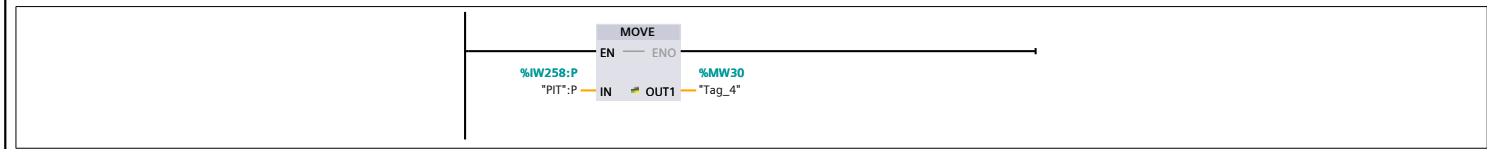

Network 3:

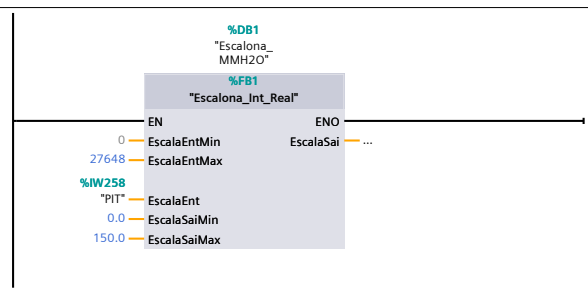

Network 4

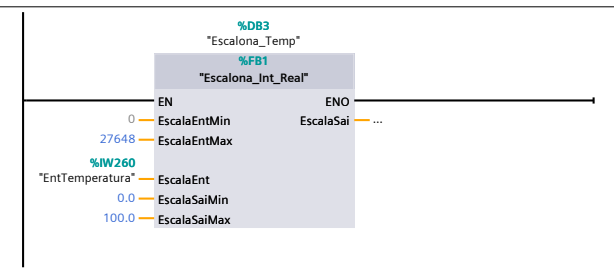

Network 5: 
Totally Integrated

Automation Portal

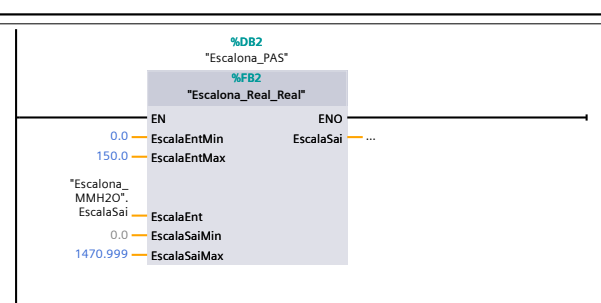

Network 6 :

Correção valor Corrente

0001 "corrente" := INT_TO_REAL ("Tag_3") / 10;

Network 7:

0001 "tKelvin" := "Escalona_Temp".Escalasai + 273.15;

0002 "fatorConvVel" := SQRT_REAL ("tKelvin") * 0.0754;

Network 8:

0001 "VelKM" : = (SQRT_REAL ("Escalona_PAS".EscalaSai) * "fatorConvVel") * 3.6;

Network 9:

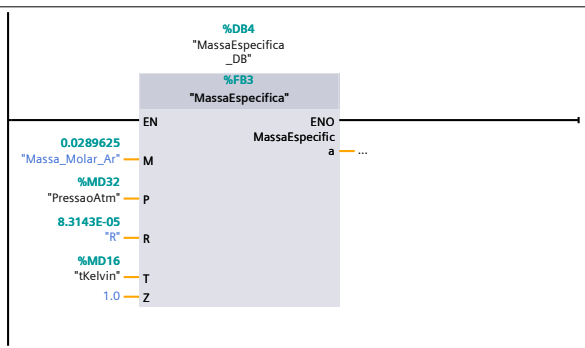

Network 10:

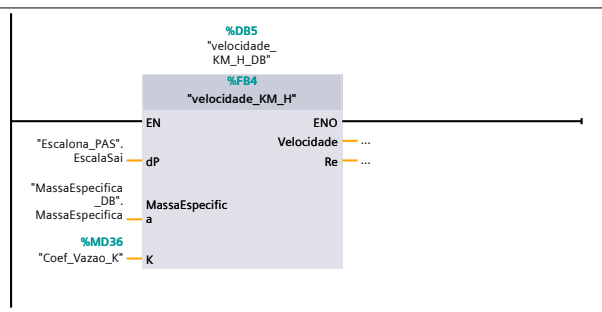

Network 11:

"IO-

EN 


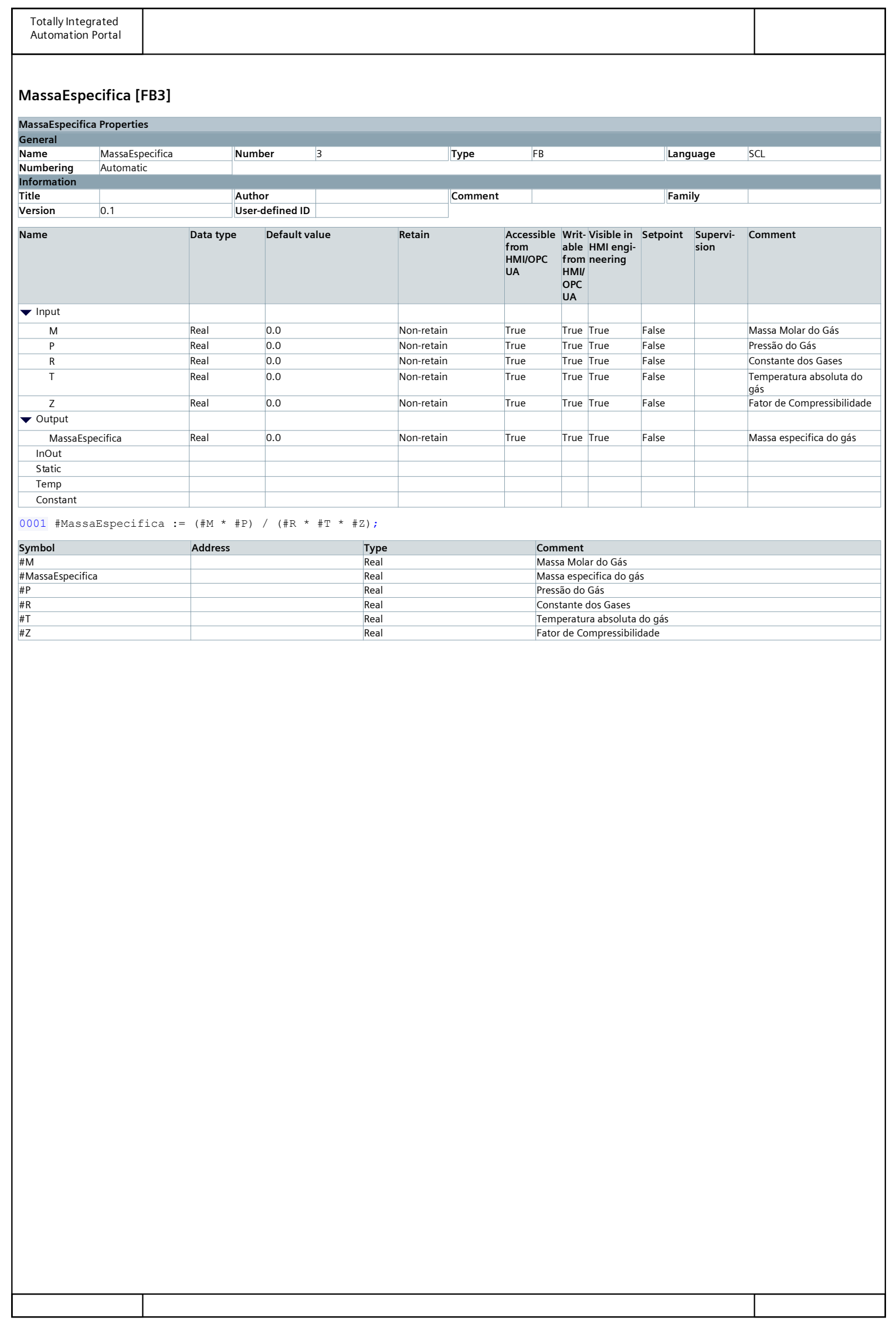




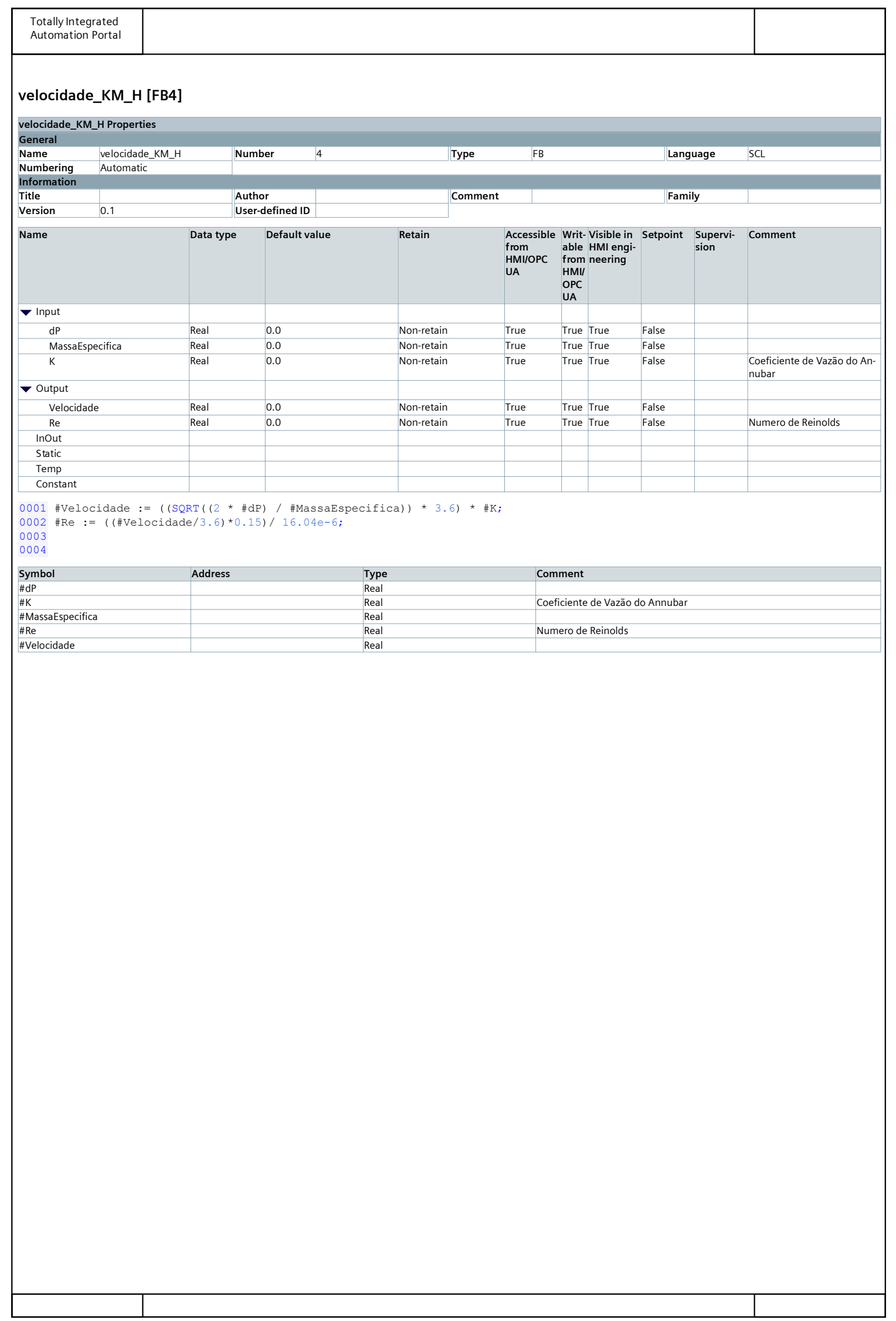




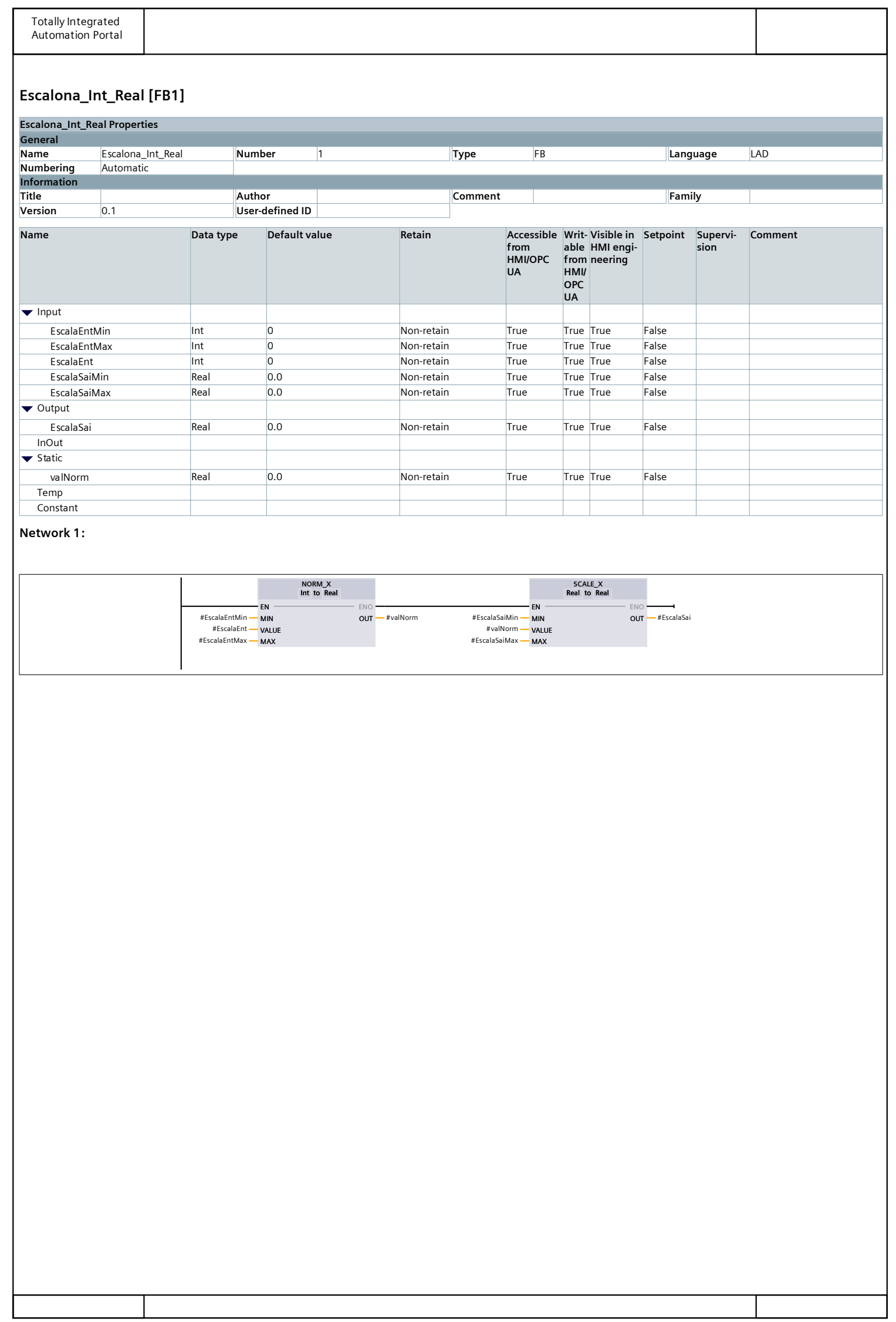




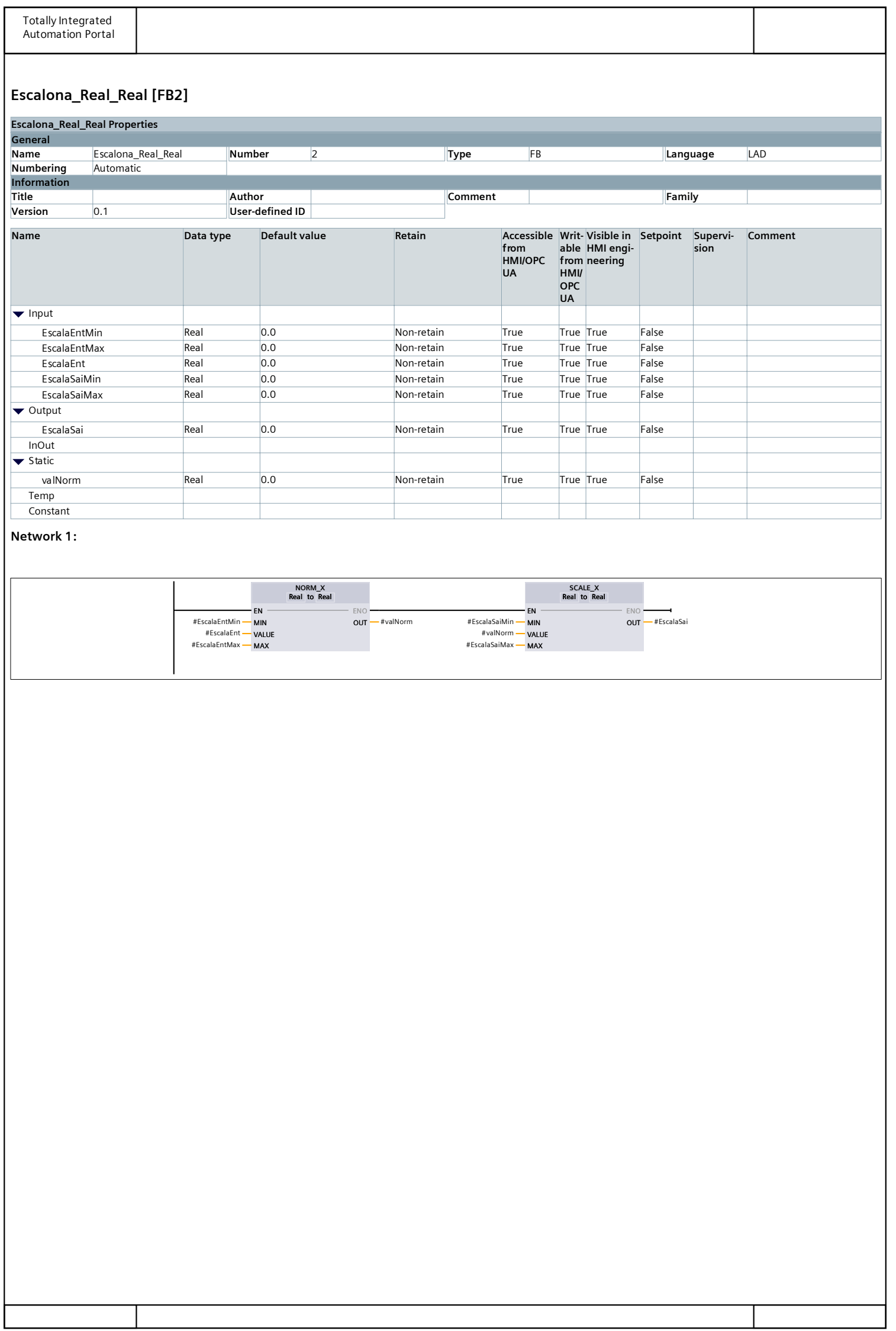




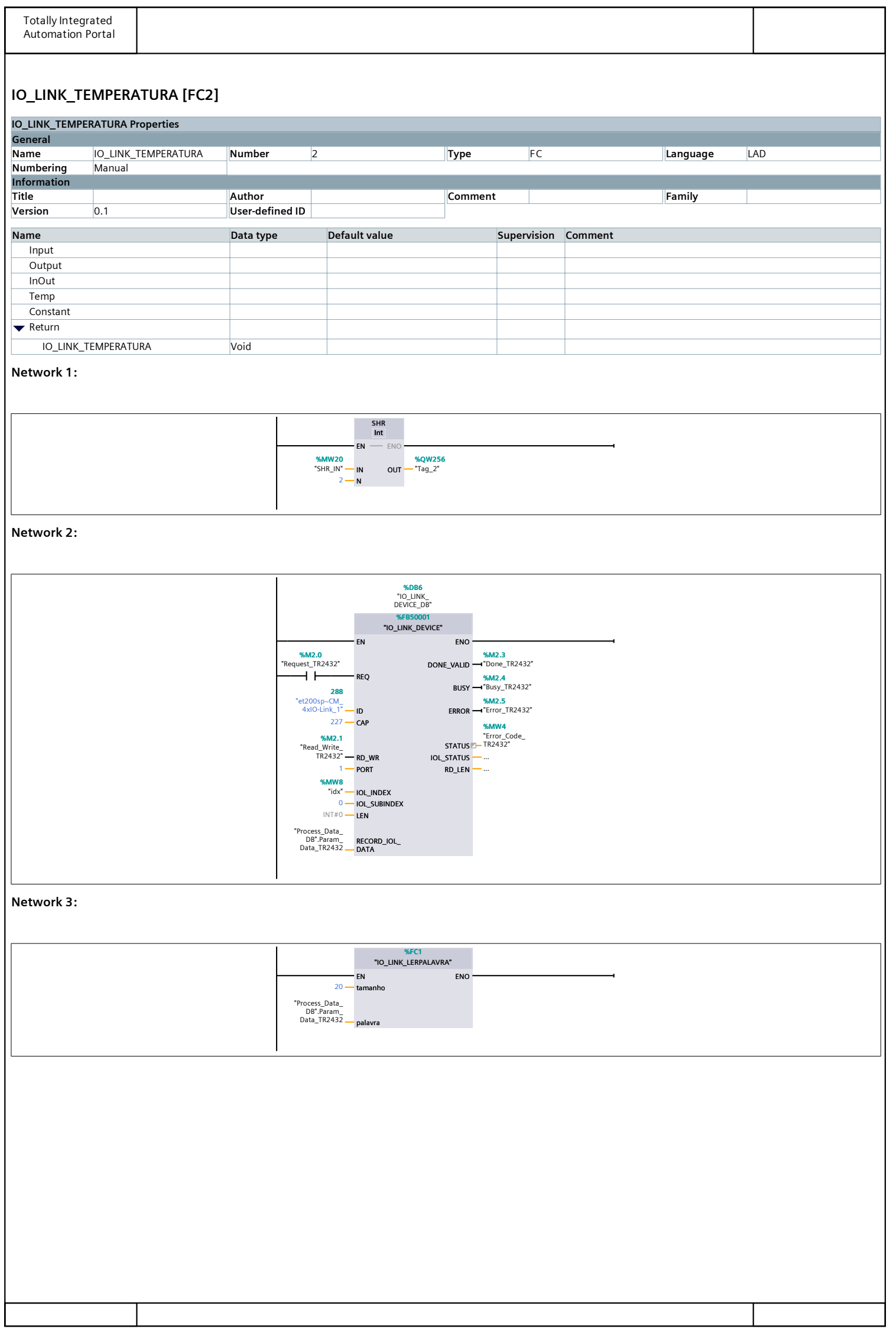




\section{Apêndice B - Script de integração no SQL Server}

Abaixo segue a rotina de integração dos dados de medição do túnel que foi desenvolvida em VB-Script e integrada no WINCC RT Advanced. 


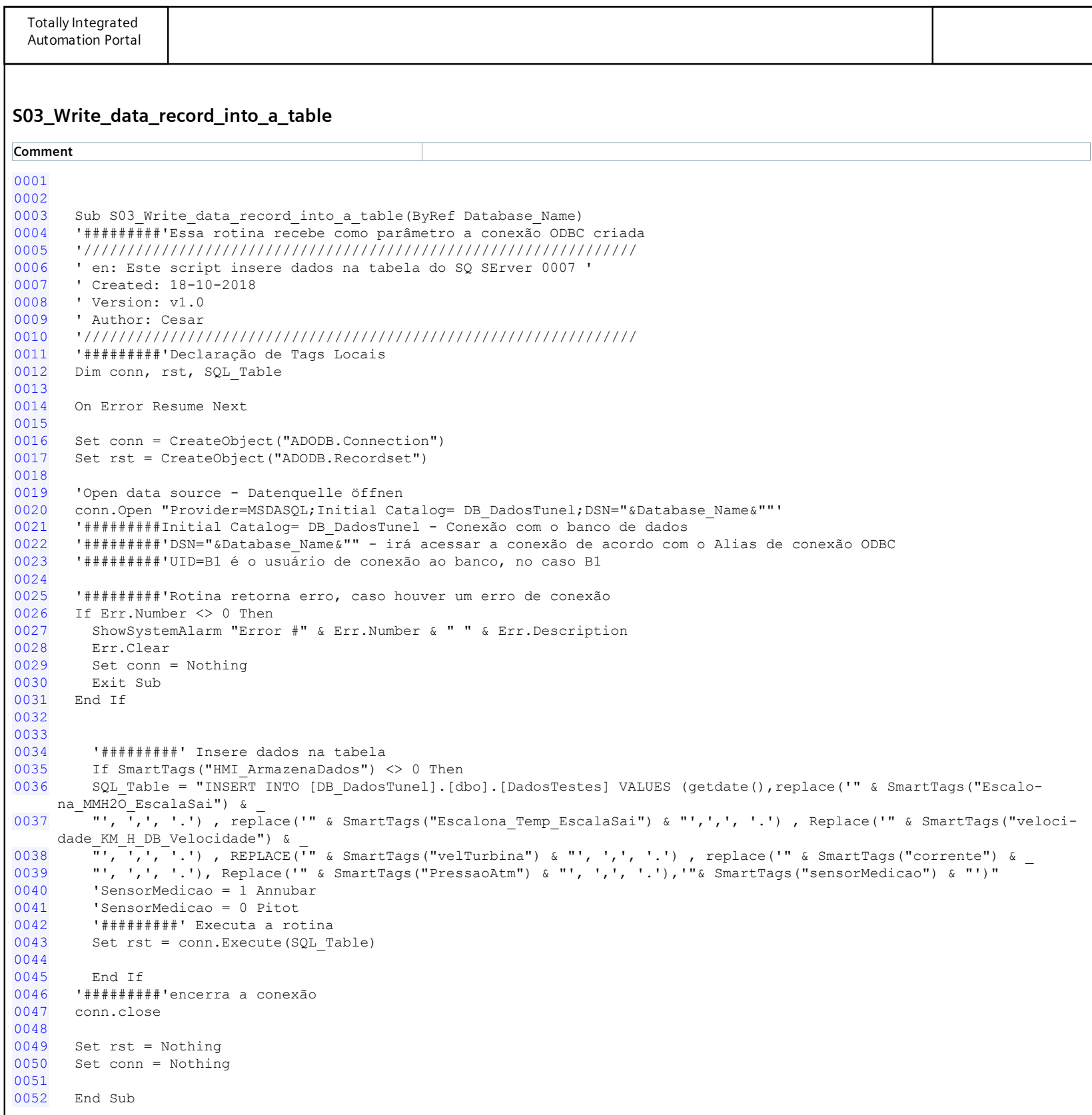




\section{Apêndice C - Estrutura da tabela criada no SQL}

A tabela criada no banco de dados SQL Server foi criada conforme script abaixo. 

USE [DB_DadosTunel]

GO

SET ANSI_NULLS ON

$\mathrm{GO}$

SET QUOTED_IDENTIFIER ON

GO

CREATE TABLE [dbo].[DadosTestes](

[id] [decimal] $(18,0) \operatorname{IDENTITY}(1,1)$ NOT NULL, [datahora] [datetime] NULL, [pressaoMMH20] [real] NULL, [temperatura] [real] NULL, [vel_KMH] [real] NULL,

[vel_RPM] [real] NULL,

[CorrenteMotor] [real] NULL, [PressaoAtm] [real] NULL,

[ElementoSensor] [bit] NULL ) ON [PRIMARY]

GO 


\section{Apêndice D - Algoritmo que gera histograma no MATLAB}

Este algoritmo primeiramente efetua a leitura no local onde a imagem se encontra, depois, converte a imagem em precisão dupla. Após isso, seleciona apenas a região que se encontra a imagem, ou seja, o imcrop enquadra apenas a região que se encontra a imagem desejada.

Após converter a imagem para escala cinza ela, o histograma da imagem é gerado. 
$\underline{\underline{27 / 10 / 19} 20: 05 \quad C: \backslash U \text { sers } \backslash \text { Besitzer \Desktop } \backslash \ldots \backslash \text { imgHstNew.m } 1 \text { of } 1}$

impsp = imread('C: \Users \Besitzer\Desktop \ANALISE29092019\DSC 0019.jpg);

impsp $=$ im2double (impsp);

impsp_cr $=$ imcrop (impsp, $\left.\left[\begin{array}{lllll}2000 & 400 & 2300 & 1400\end{array}\right]\right)$;

oConverte a imagem a uma escala Cinza

impsp_gray $=$ rgb2gray (impsp_cr);

figure;

[pixelcount, grayLevels] = imhist(impsp_gray);

bar(graylevels, pixelcount); $\frac{\circ}{\circ}$ Plot it as a bar chart.

grid on;

$x \lim ([0, \max (0.4)])$;

$y \lim ([0, \max (100000)])$;

title('Histograma imagem túnel $107 \mathrm{Km} / \mathrm{h}$ ') ;

xlabel ('Nível escala cinza');

ylabel('Pixel / escala cinza'); 


\section{Apêndice E - Algoritmo de binarização de imagem no MATLAB}

Neste algoritmo primeiramente a imagem é selecionada, depois recortada na região exata da imagem. Após isso, ela é convertida em escala cinza e depois binarizada a partir do limiar encontrado no histograma gerado. 
$\underline{\underline{27 / 10 / 19} 20: 05 \quad C: \backslash U \text { sers } \backslash \text { Besitzer } \backslash \text { Deskto...\EscalaCinza.m } 1 \text { of } 1}$

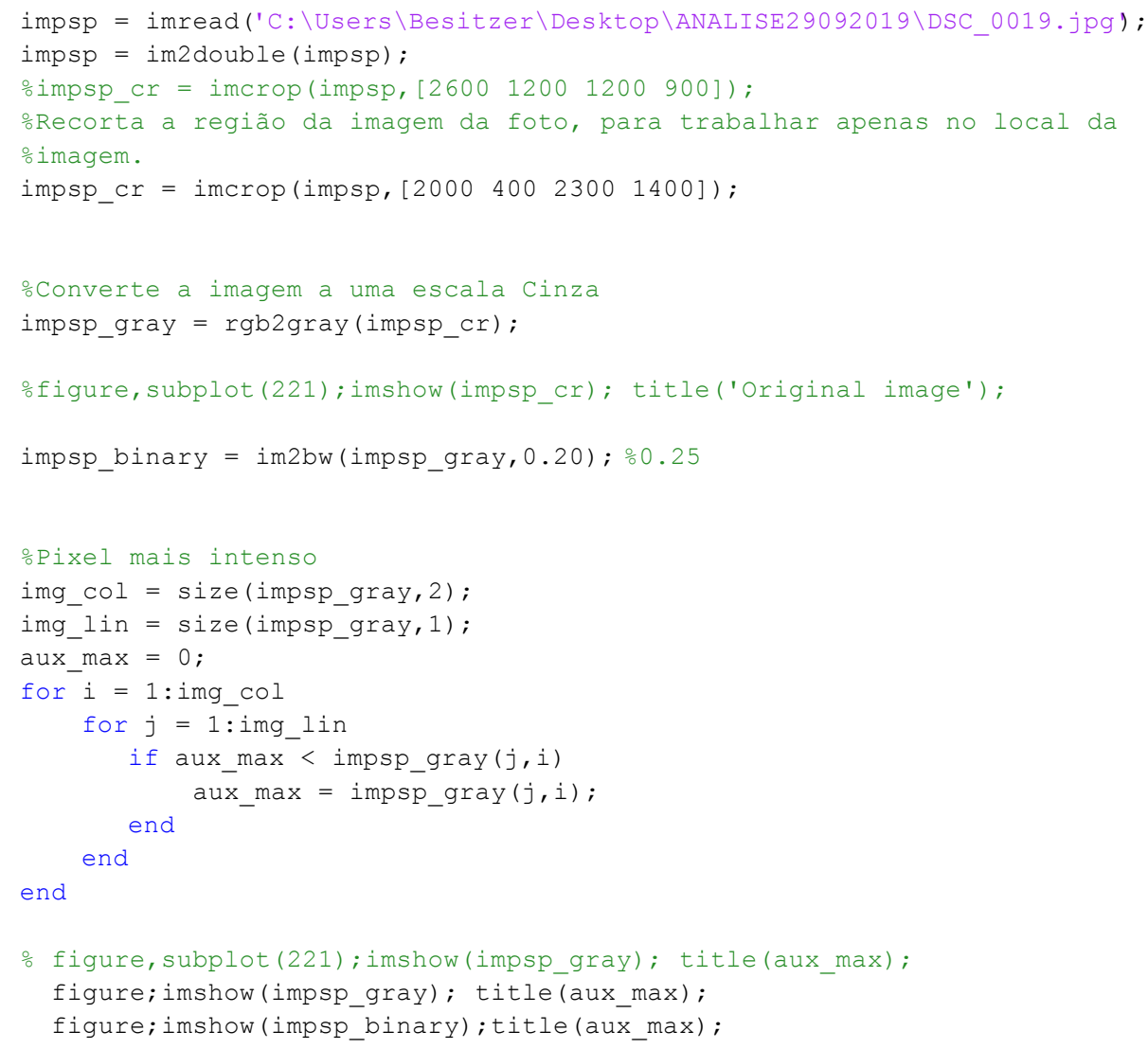


Anexos 
Anexo A - Especificações Técnicas da câmera NIKON D5100

Abaixo segue as especificações técnicas da câmera NIKON D5100. 


\section{Especificações técnicas}

\begin{tabular}{|c|c|}
\hline \multicolumn{2}{|l|}{ Tipo } \\
\hline Tipo & Câmera digital reflex de lente única \\
\hline Montagem da lente & Montagem F da Nikon (com contatos AF) \\
\hline Ângulo de visão efetivo & Aprox. $1,5 \times$ distância focal da lente (formato Nikon DX) \\
\hline \multicolumn{2}{|l|}{ Pixels efetivos } \\
\hline Pixels efetivos & 16,2 milhões \\
\hline \multicolumn{2}{|l|}{ Sensor de imagem } \\
\hline Sensor de imagem & Sensor CMOS de 23,6× 15,6 mm \\
\hline Pixels totais & 16,9 milhões \\
\hline $\begin{array}{l}\text { Sistema para Redução de } \\
\text { Poeira }\end{array}$ & $\begin{array}{l}\text { Limpeza do sensor de imagem, dados de referência para a Remoção de Poeira da } \\
\text { Imagem (software Capture NX } 2 \text { opcional requerido) }\end{array}$ \\
\hline \multicolumn{2}{|l|}{ Armazenamento } \\
\hline $\begin{array}{l}\text { Tamanho da imagem } \\
\text { (pixels) }\end{array}$ & $\begin{array}{l}\text { - } 4928 \times 3264(\mathrm{~L}) \\
\text { - } 2464 \times 1632(\mathrm{~S})\end{array}$ \\
\hline Formato do arquivo & $\begin{array}{l}\text { - NEF (RAW): } 14 \text { bits, comprimido } \\
\text { - JPEG: JPEG-Baseline compatível com a compressão fine (aprox. } 1: 4 \text { ), normal } \\
\text { (aprox. } 1: 8 \text { ) ou basic (aprox. } 1: 16 \text { ) } \\
\text { - NEF (RAW)+JPEG: Uma fotografia gravada nos formatos NEF (RAW) e JPEG }\end{array}$ \\
\hline Sistema Picture Control & $\begin{array}{l}\text { Padrão, Neutro, Vivo (Vívido), Monocromático, Retrato, Paisagem; o Picture } \\
\text { Control selecionado pode ser modificado; armazenamento para os Picture } \\
\text { Controls personalizados }\end{array}$ \\
\hline Mídia & Cartões de memória SD (Secure Digital), SDHC e SDXC \\
\hline Sistema de arquivos & $\begin{array}{l}\text { DCF (Design Rule for Camera File System) 2.0, DPOF (Digital Print Order Format), } \\
\text { Exif 2.3 (Exchangeable Image File Format for Digital Still Cameras), PictBridge }\end{array}$ \\
\hline \multicolumn{2}{|l|}{ Visor } \\
\hline Visor & Visor reflex de lente única com pentaespelho no nível dos olhos \\
\hline $\begin{array}{l}\text { Cobertura do } \\
\text { enquadramento }\end{array}$ & Aprox. $95 \%$ na horizontal e $95 \%$ na vertical \\
\hline Ampliação & Aprox. $0,78 \times\left(\right.$ lente de $50 \mathrm{~mm}$ f/1.4 no infinito, $-1,0 \mathrm{~m}^{-1}$ ) \\
\hline Distância do olho & $17,9 \mathrm{~mm}\left(-1,0 \mathrm{~m}^{-1}\right)$ \\
\hline Ajuste de dioptria & $-1,7-+0,7 \mathrm{~m}^{-1}$ \\
\hline Tela de foco & Tela BriteView Clear Matte Mark VII Tipo B \\
\hline Espelho reflex & Retorno rápido \\
\hline Abertura da lente & Retorno instantâneo, controlado eletronicamente \\
\hline
\end{tabular}

